\title{
NASA's Future HyspIRI Mission and the EO-1 Hyperion Collections
}

\author{
Elizabeth (Betsy) M. Middleton \\ NASA/Goddard Space flight Center \\ Robert Green and Simon Hook \\ (NASA/JPL) \\ Woody Turner \\ (NASA HQ)
}

Hyperspectral Imaging and Sounding of the Environment (HISE) July 10-14 2011, The Westin Harbour Hotel, Toronto, Ontario, Canada Session Title: Spectral Analyses, Presider Martin Mlynczak March 2009 



\section{EO-1 Beginnings}

Original Mission Goals (2000):

- Enable entirely new measurements and science missions from space.

- Fly three revolutionary Land Imaging instruments to collect multispectral and hyperspectral scenes over the course of the mission in coordination with the Landsat-7 Enhanced Thematic Mapper (ETM+).

- Detailed comparisons with ETM+ images were carried out to validate these instruments for future missions.

- Reduce costs of future space and Earth

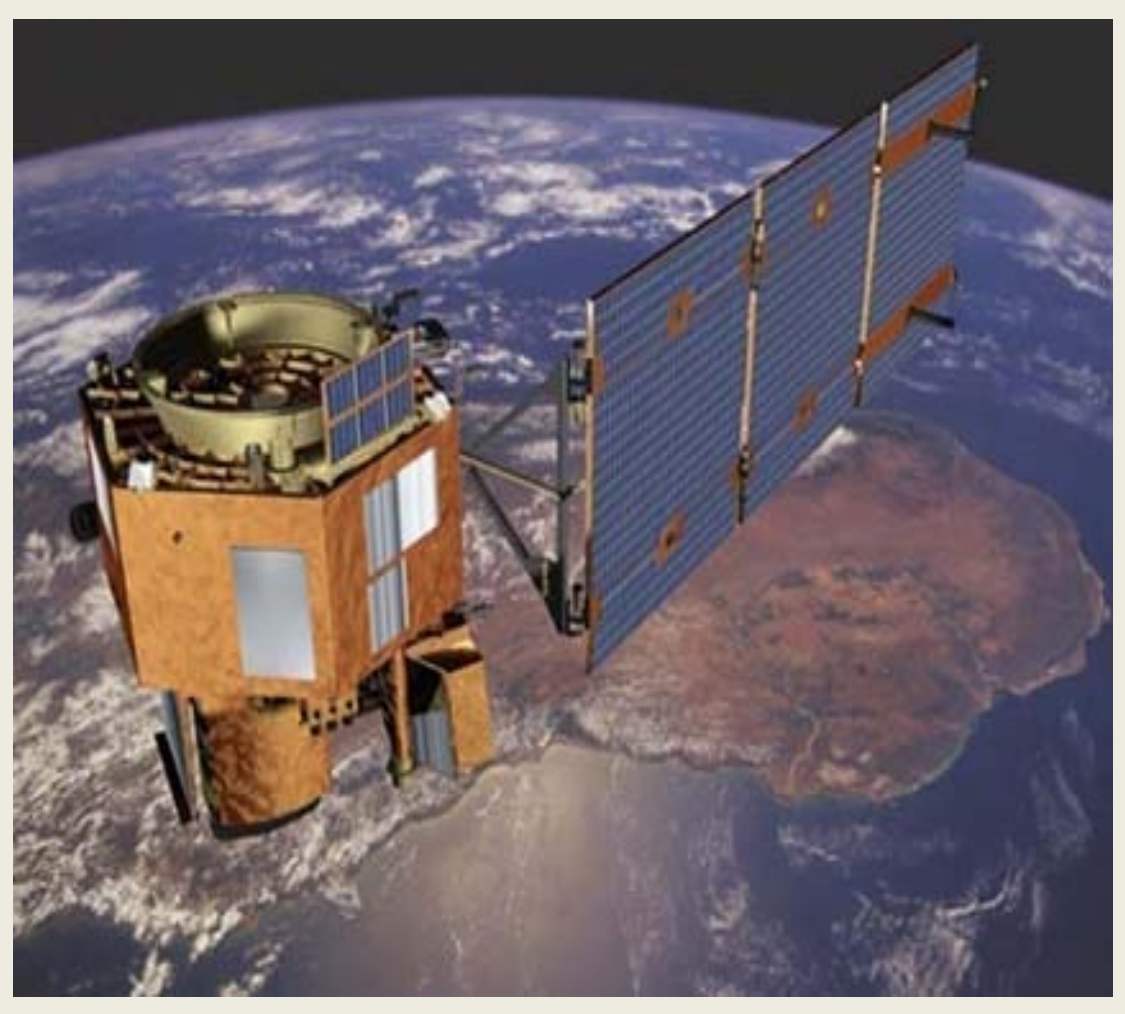
science missions with:

- Breakthrough technologies in lightweight materials,

- High performance integrated detector arrays, and

- Precision spectrometers. 


\section{Earth Observing-1 (EO-1) Mission}

Mission Scientist, Dr. Elizabeth Middleton (NASA/GSFC, 614.4)

Mission Manager, Mr. Daniel Mandl (NASA/GSFC, 581)

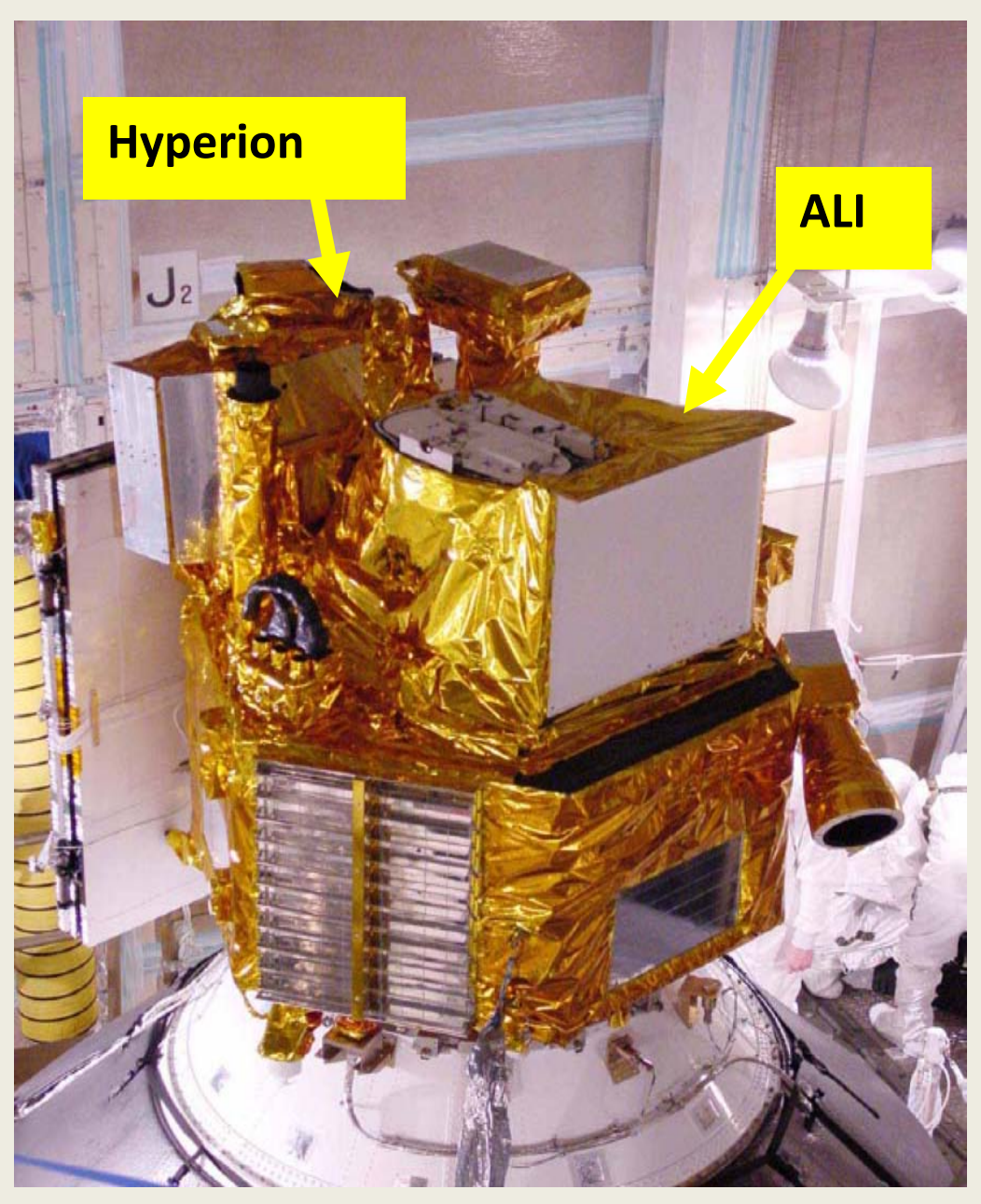

http://eo1.gsfc.nasa.gov/

\begin{tabular}{|c|c|c|}
\hline \multicolumn{2}{|r|}{ ALI } & \multirow[b]{2}{*}{ Hyperion } \\
\hline $\begin{array}{c}\text { Band } \\
\text { designations }\end{array}$ & $\begin{array}{c}\text { Band Names } \\
\text { (wavelength, } \mu \mathrm{m} \text { ) }\end{array}$ & \\
\hline Pan & Pan $\quad(0.48-0.69)$ & \multirow{10}{*}{$\begin{array}{c}\text { Continuous } \\
\text { Spectra } \\
0.4-2.4 \mu \mathrm{m} \\
242 \text { Bands } \\
\text { Bandwidth: } \\
\text { 10nm }\end{array}$} \\
\hline \multirow{2}{*}{ Blue } & MS-1p $(0.433-0.453)$ & \\
\hline & MS-1 $(0.450-0.515)$ & \\
\hline Green & MS-2 $(0.525-0.605)$ & \\
\hline Red & MS-3 $(0.633-0.690)$ & \\
\hline \multirow{2}{*}{ NIR } & MS-4 $(0.775-0.805)$ & \\
\hline & MS-4p $(0.845-0.890)$ & \\
\hline \multirow{3}{*}{ SWIR } & MS-5p $(1.20-1.30)$ & \\
\hline & MS-5 (1.55 - 1.75) & \\
\hline & MS-7 (2.08 - 2.35) & \\
\hline $\begin{array}{c}\text { Spatial } \\
\text { Resolution }\end{array}$ & Pan: 10m, MS: 30m & $30 \mathrm{~m}$ \\
\hline Swath width & $\sim 35 \mathrm{~km}$ & $\sim 7.5 \mathrm{~km}$ \\
\hline
\end{tabular}


Vegetation and Bare Soil Spectra for Hyperion and ALI

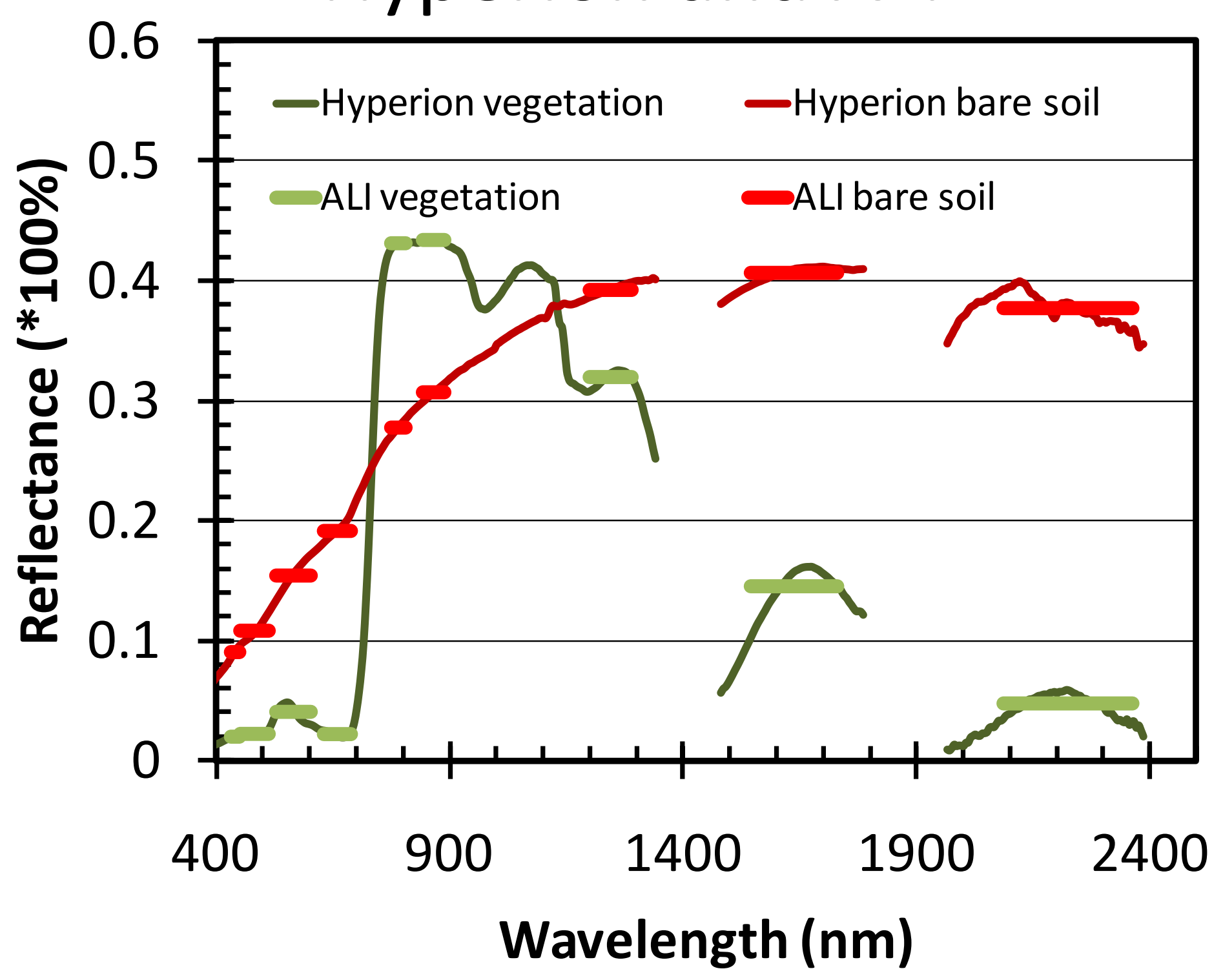




\section{EO-1 Supporting Technologies}
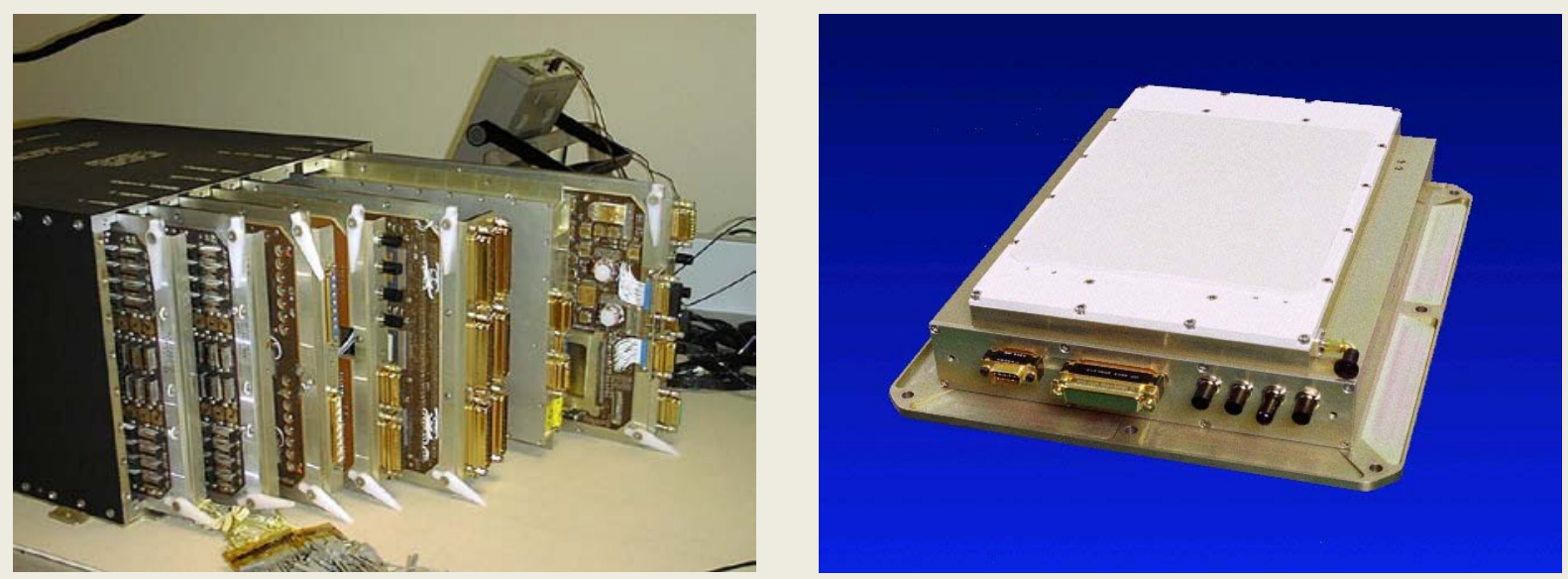

Advanced Recorder Processor

X-Band Phased Array Ant Wideband enna

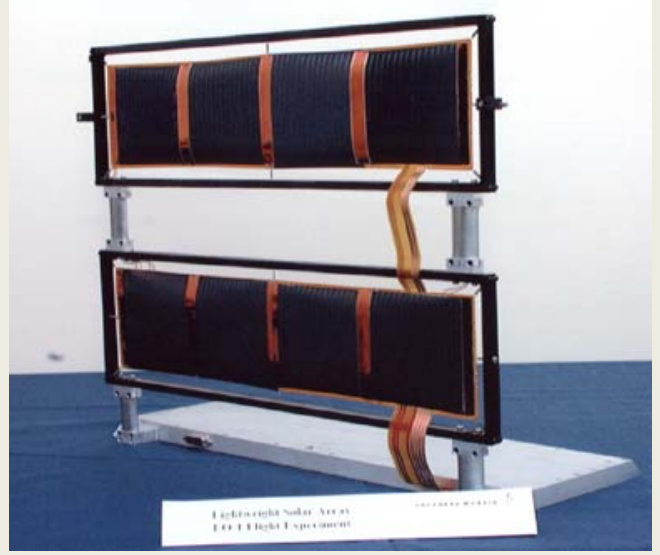

Lightweight Flexible Solar Array

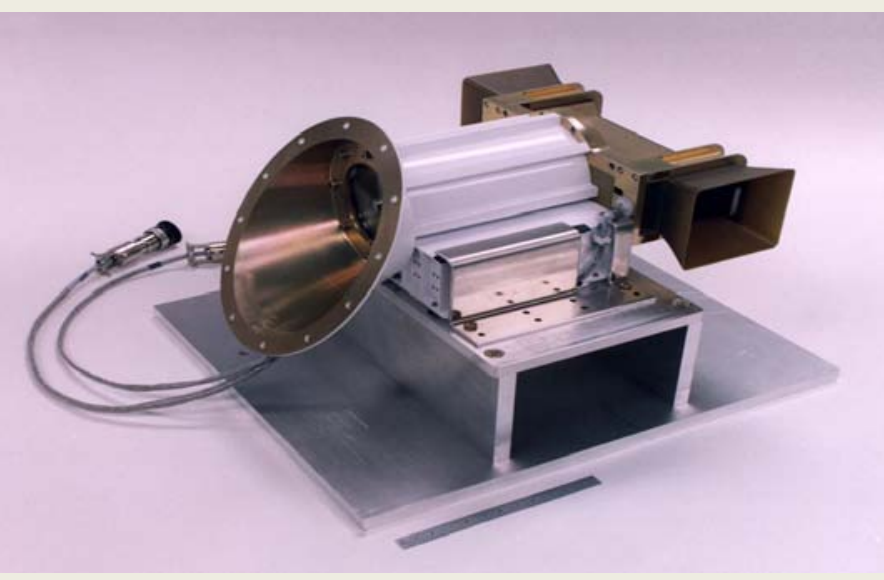

Pulse Plasma Thruster

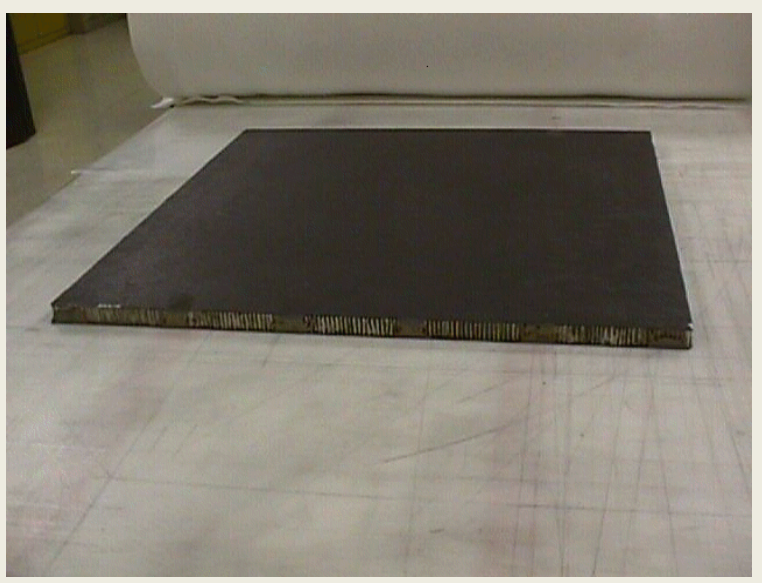

Carbon-Carbon Radiator

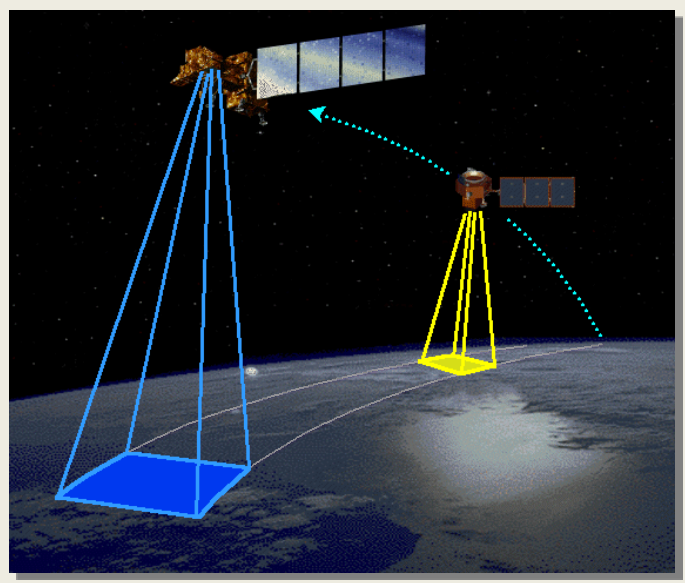

Formation Flying 


\section{EO-1 and Landsat 7 \\ Descending Orbit Ground Tracks}

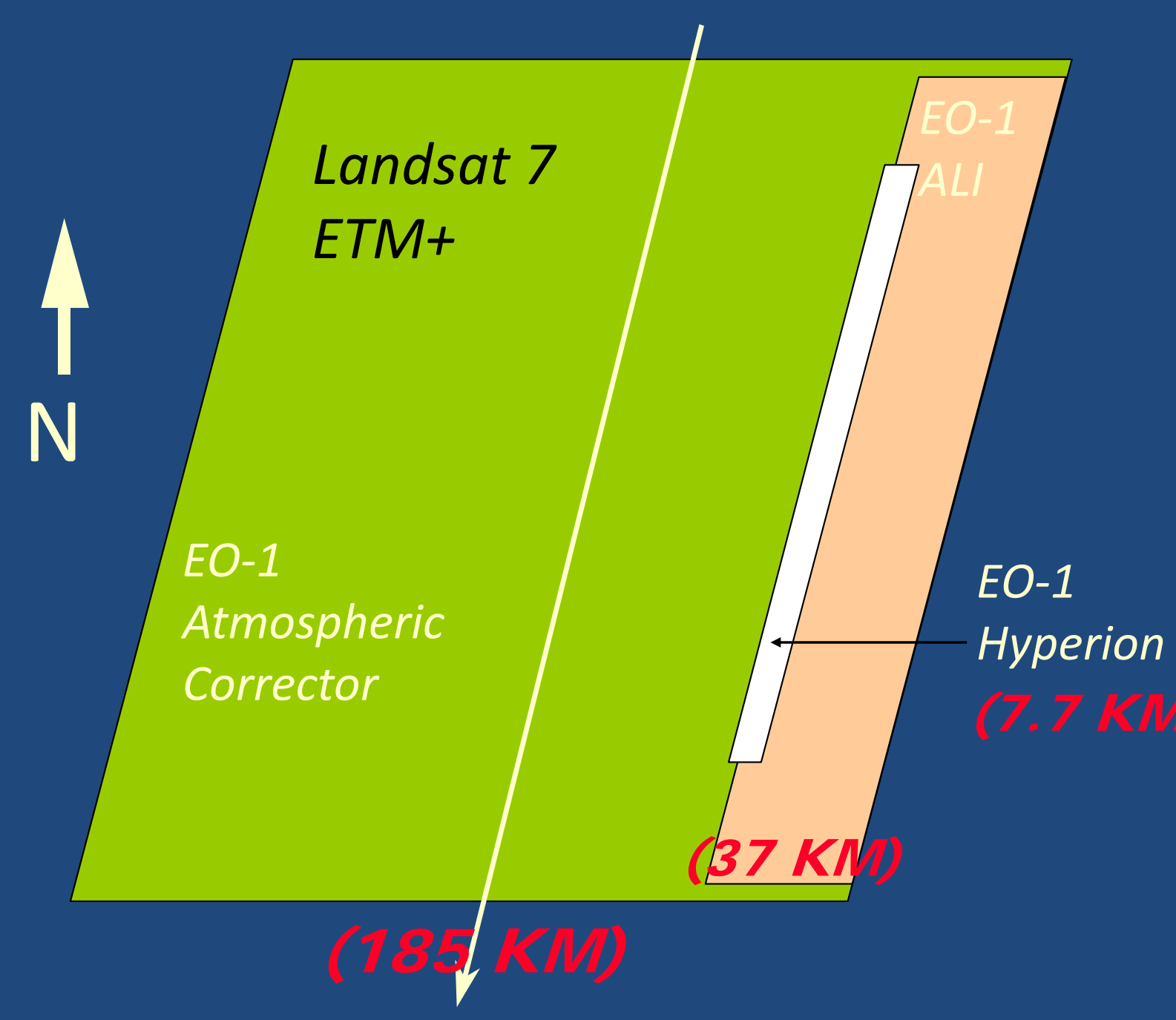




\section{EO-1 Off-Nadir and Landsat 7}

\section{Descending Orbit Ground Tracks}

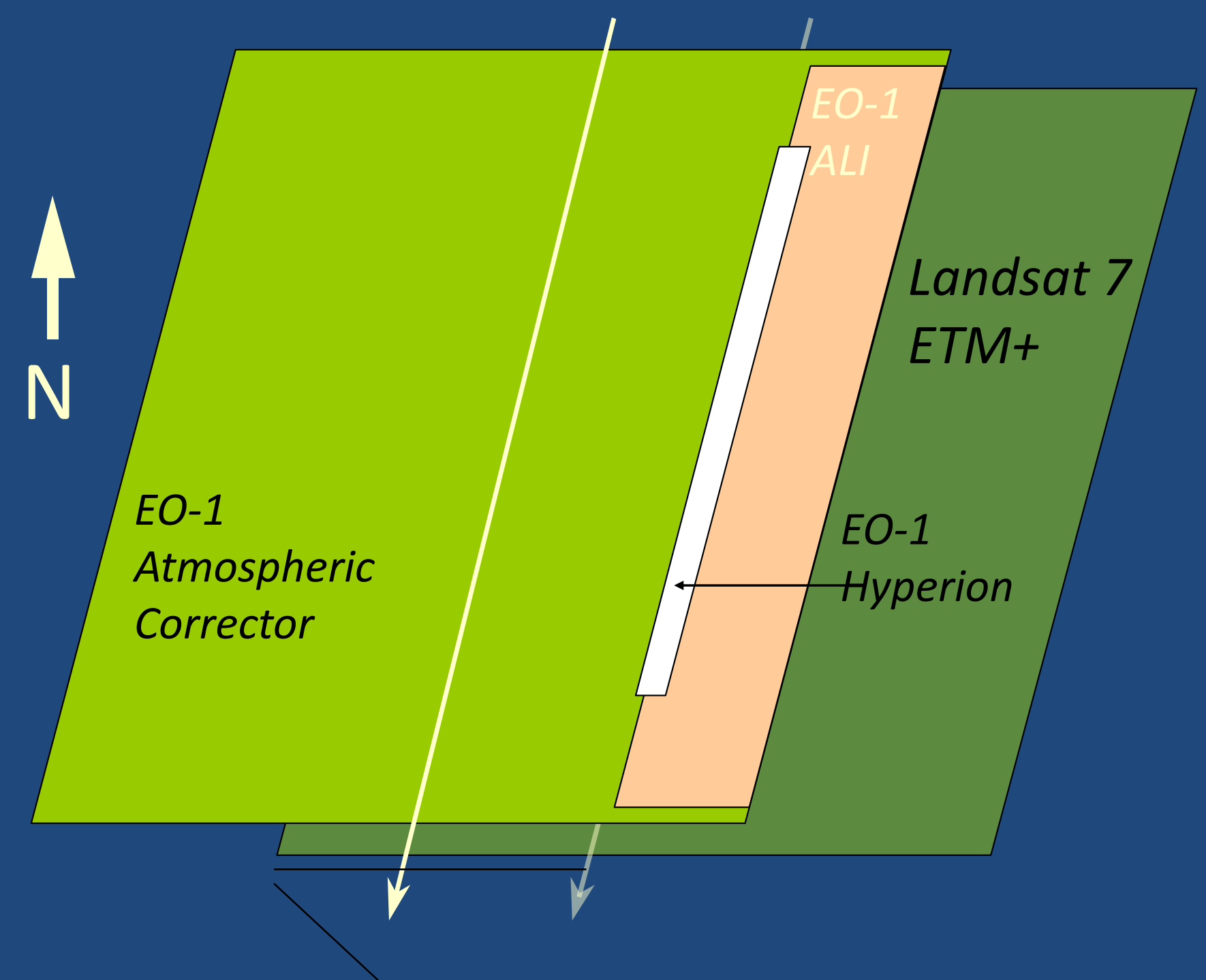


March 2010
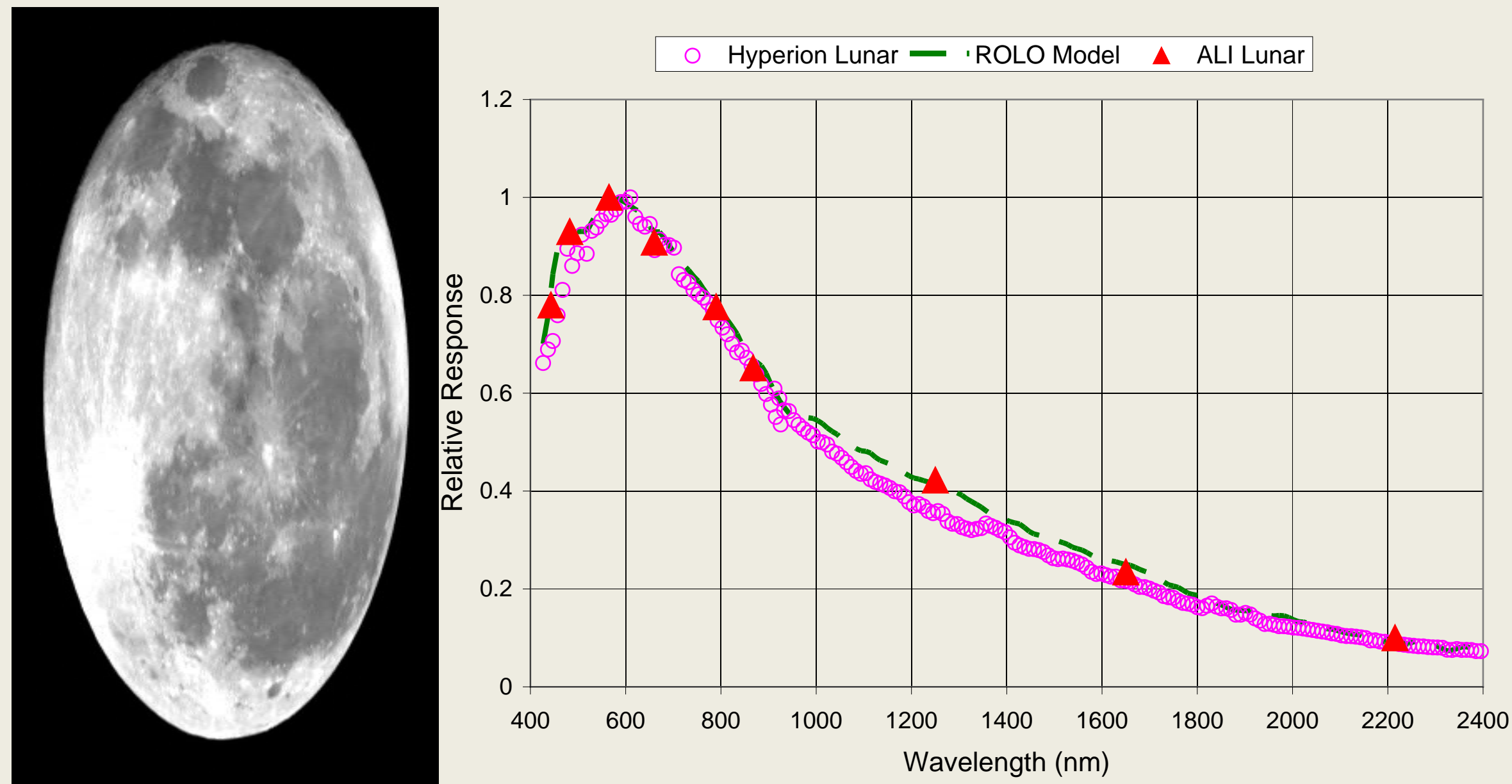

The pitch rate across the moon is the same as that used for earth imaging. This results in a $8 \mathrm{X}$ oversampling of the moon. 
NASA Hyperion Data Example

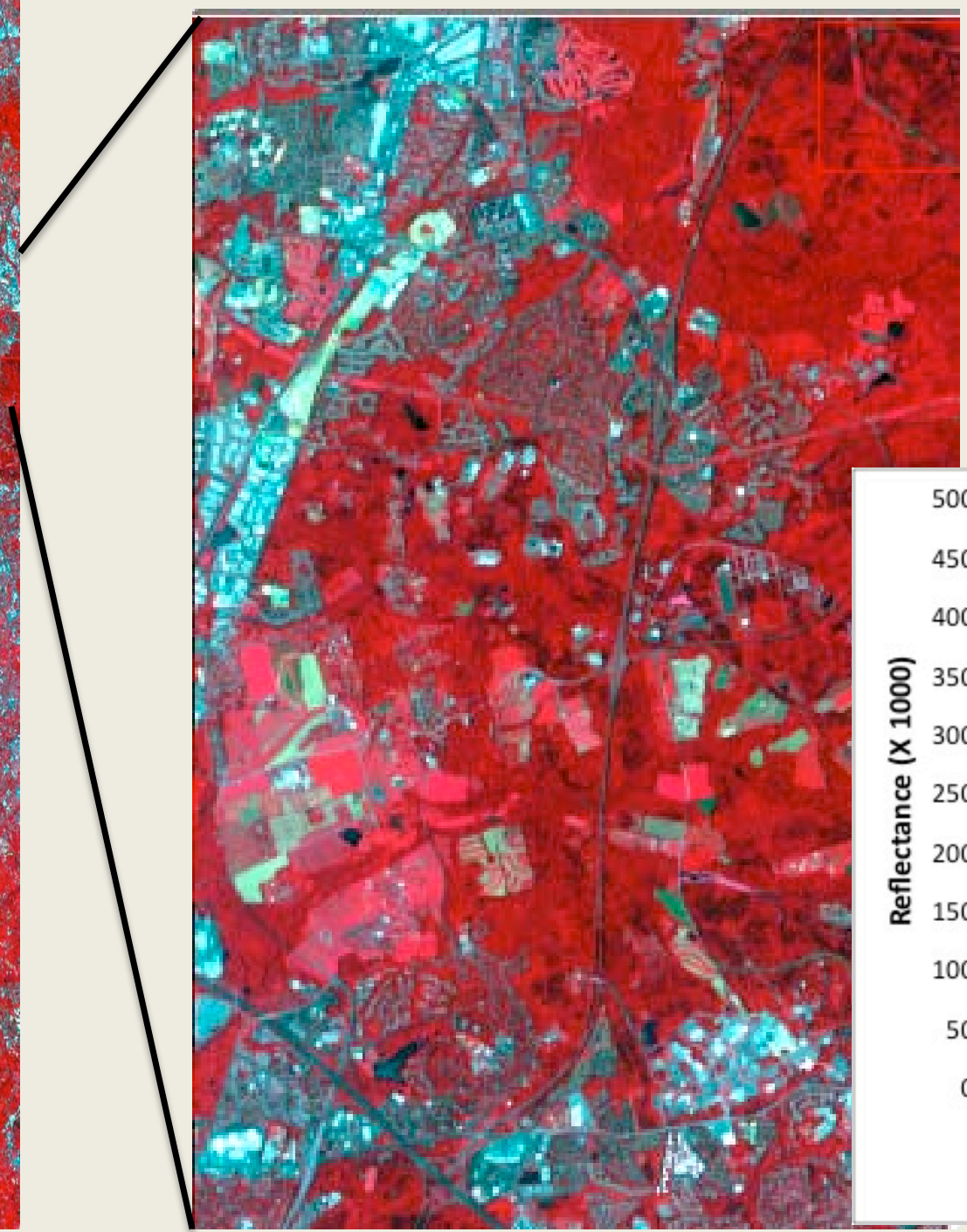

- $30 \mathrm{~m}$ pixels

- $7 \mathrm{~km}$ swath width

- Hyperspectral

- 10 $\mathrm{nm}$ bands

- $350-2500 \mathrm{~nm}$

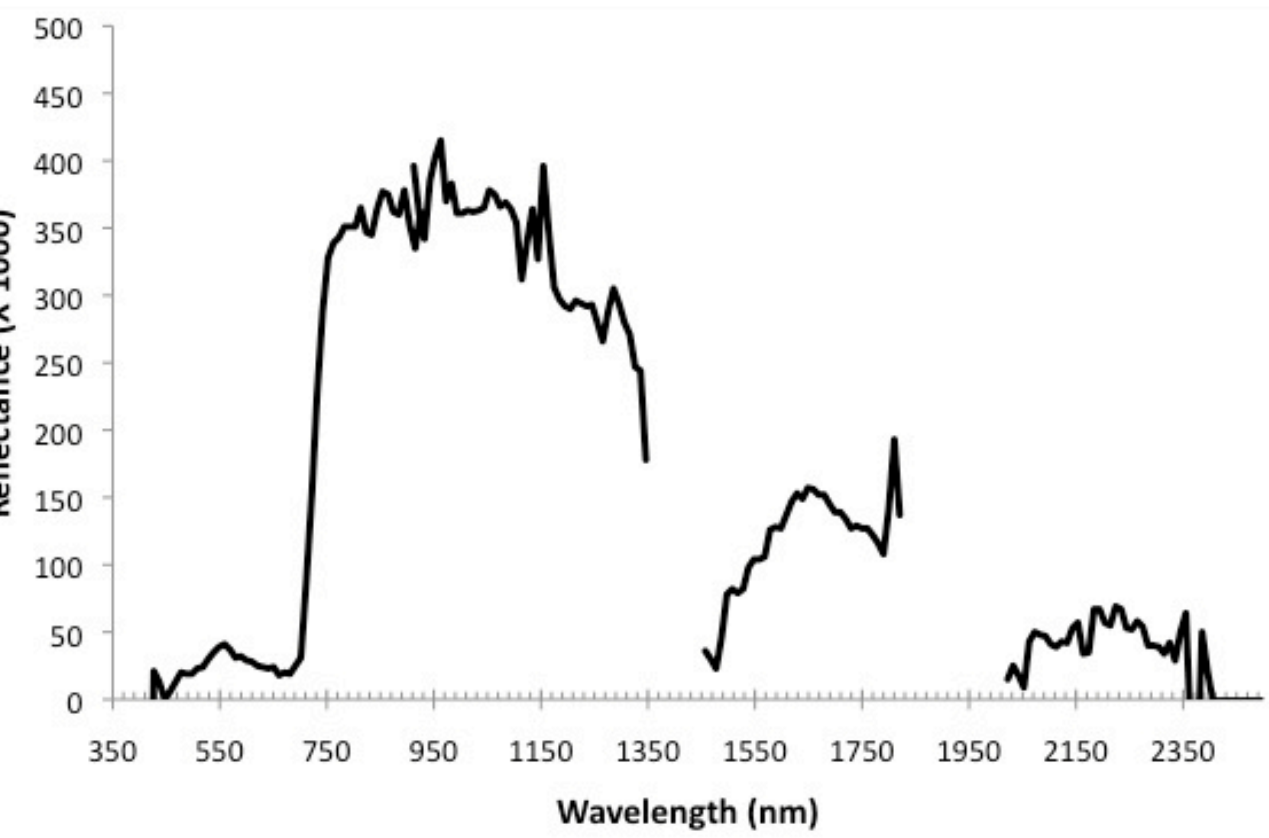




\section{Hyperion Spectral Characteristi}

- Radiometric performance model based on a standard mid-latitude summer scene with a $60^{\circ}$ Solar zenith angle and $30 \%$ surface reflectance

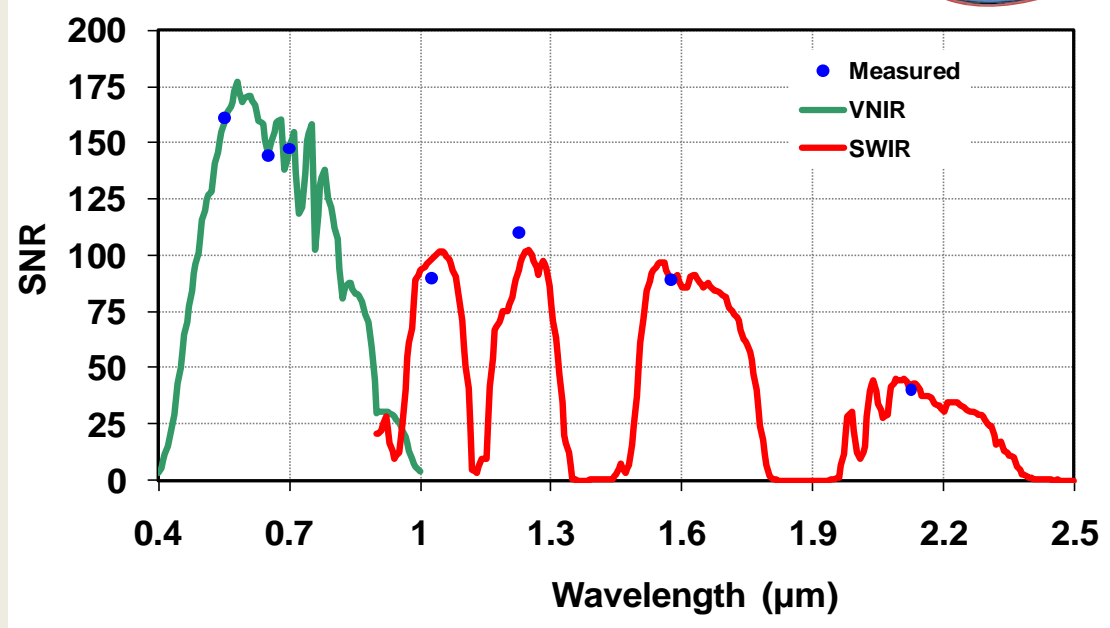

AVIRIS (State of the Art 2002-2004)

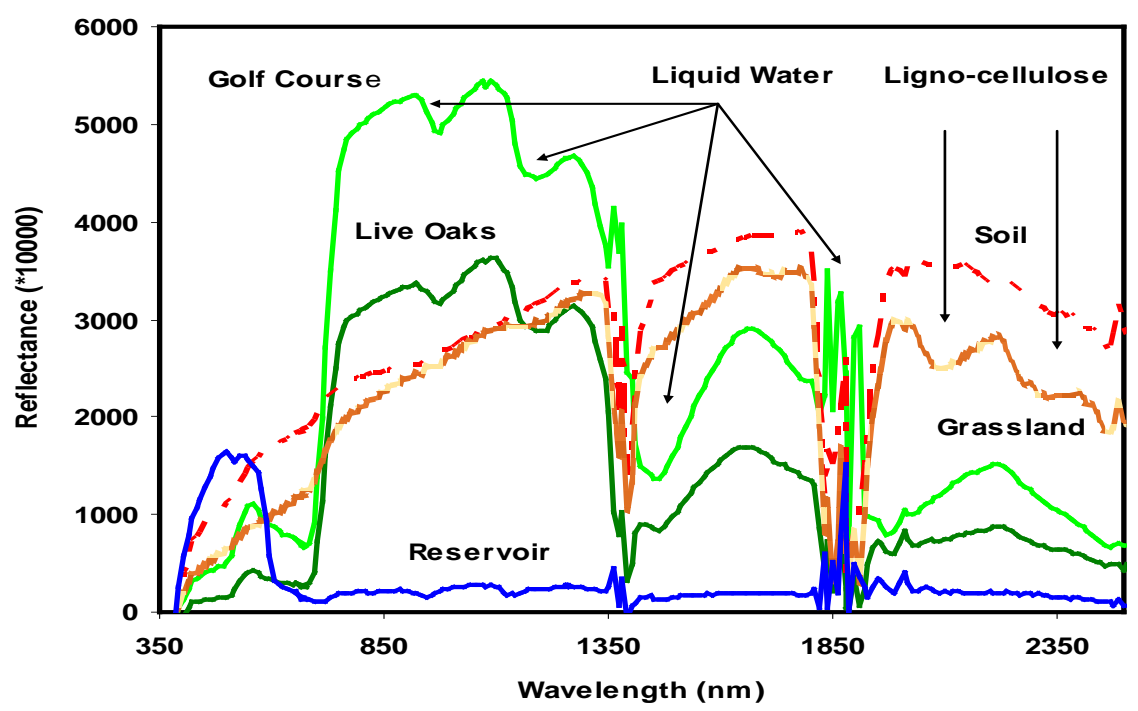

Hyperion Performance ( AVIRIS 1992)

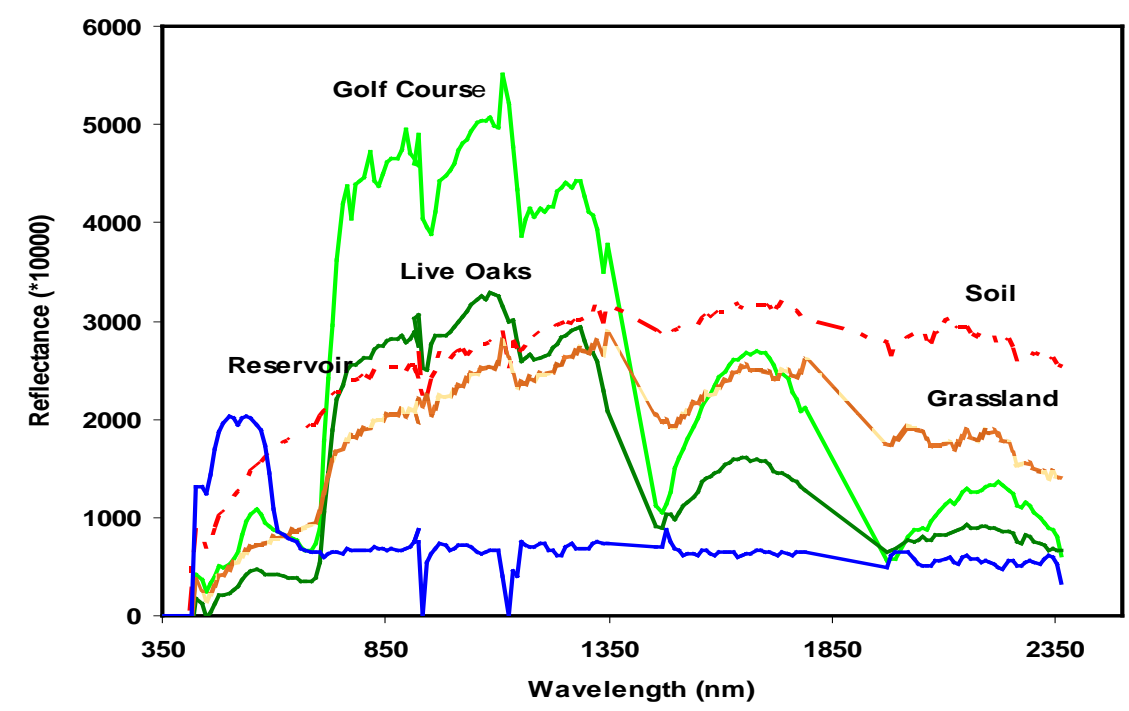

March 2010 

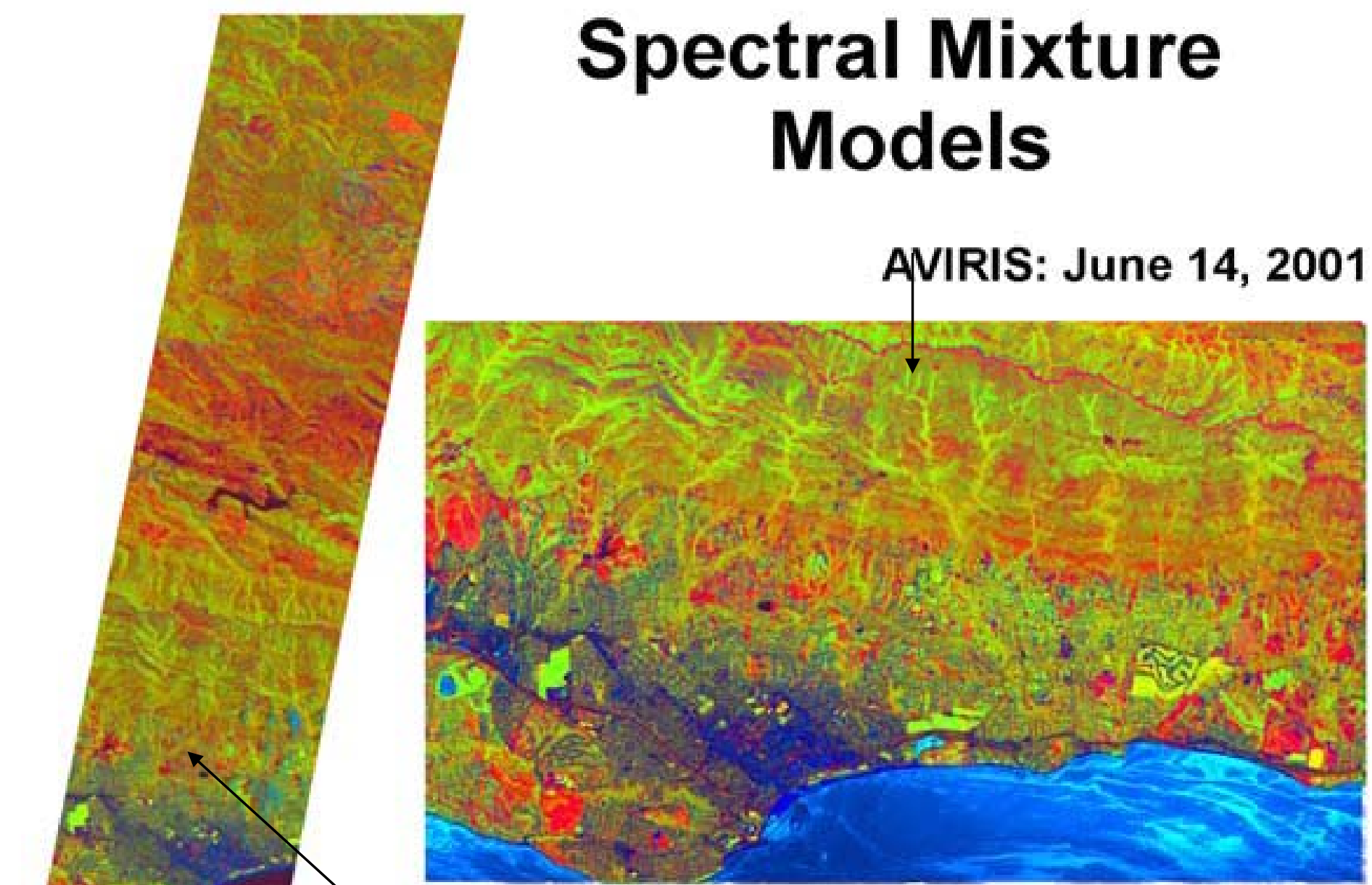

HYPERION: June 12, 2001

NPV, GV, Soil: RGB 


\section{Hyperion Science and Technology Applications}

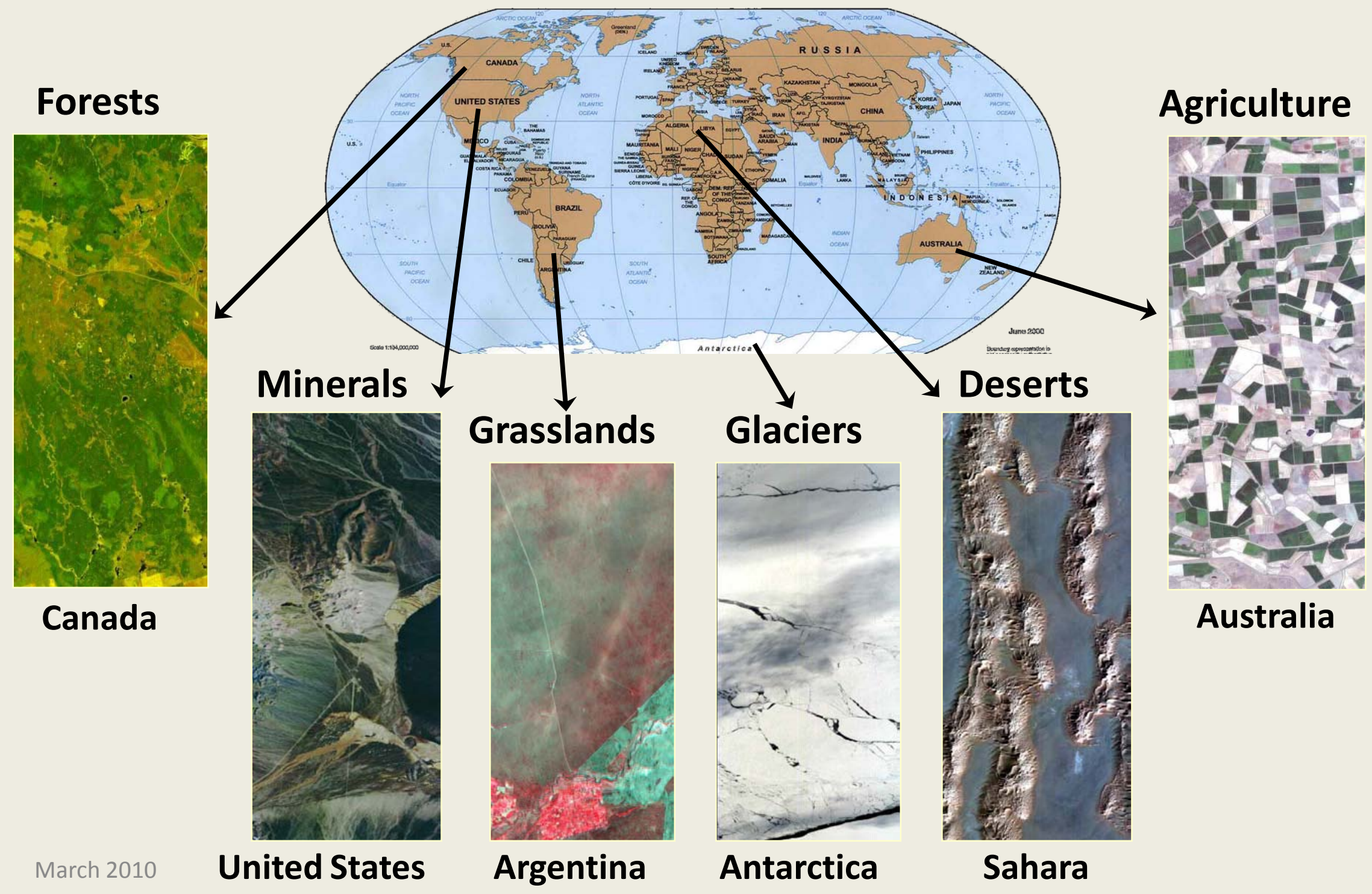




\section{EO-1 Acquisitions, Dec 2000 - Mar 2011}

\section{To date, 52,500+ scenes have been collected}

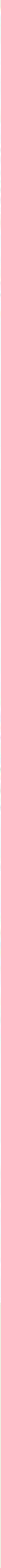


ALI Pan Enhanced

Bands 3 -2-1

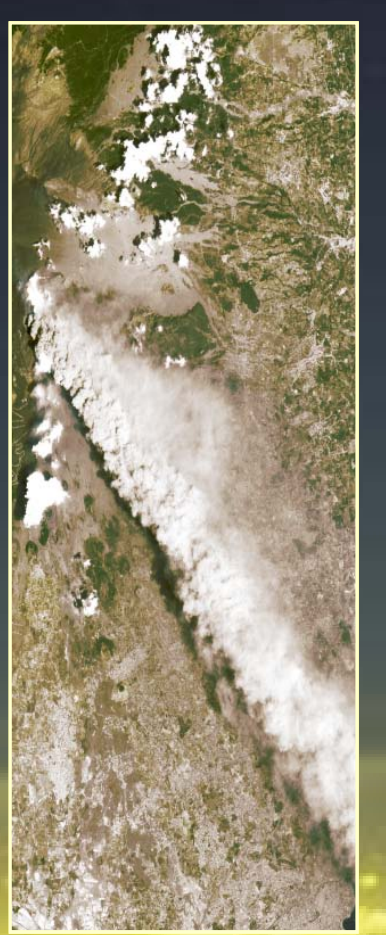

Hyperion

7-5- 4 Equiv

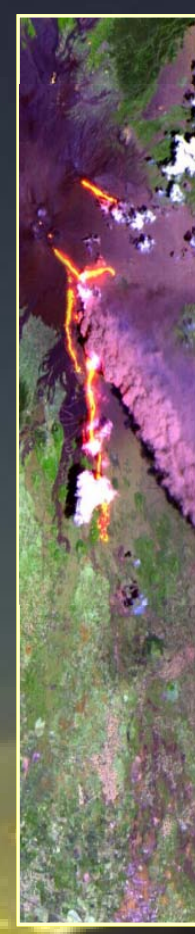

Eruption of Mt. Etna, Sicily

July 22, 2001

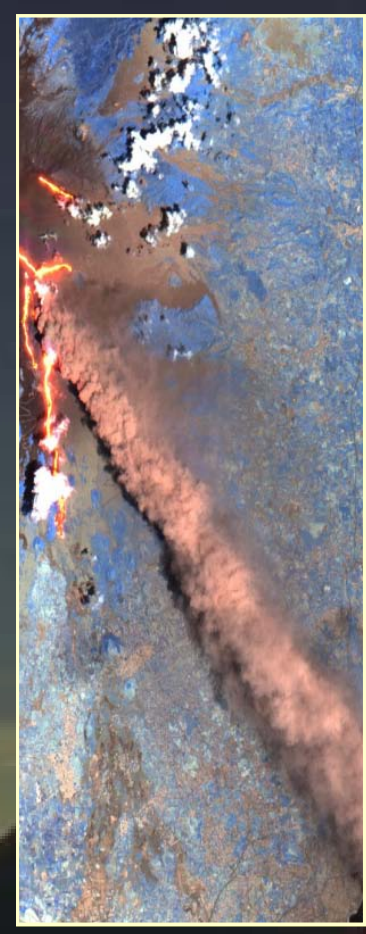

\section{Aiviperion Temperatures for Etna}

Spectrum Crust T ${ }^{\circ} \mathrm{C}$ Hot ToC Area Hot

$\begin{array}{llrl}\text { J 13-CTB } & 346 \mathrm{C} & 994 \mathrm{C} & 0.0025 \\ \text { J 13-MM } & 874 \mathrm{C} & 876 \mathrm{C} & 0.45 \\ \text { J 13-CTS } & 976 \mathrm{C} & 978 \mathrm{C} & 0.47 \\ \text { J 13-TipX } & 210 \mathrm{C} & 900 \mathrm{C} & 0.00034 \\ \text { J 22-MS } & 726 \mathrm{C} & 1075 \mathrm{C} & 0.090 \\ \text { J 22-CX } & 487 \mathrm{C} & 1075 \mathrm{C} & 0.022 \\ \text { J 22-RS* } & 1054 \mathrm{C} & 1058 \mathrm{C} & 0.690\end{array}$

\section{EO - 1 ALI}

Bands 7 -5-5'

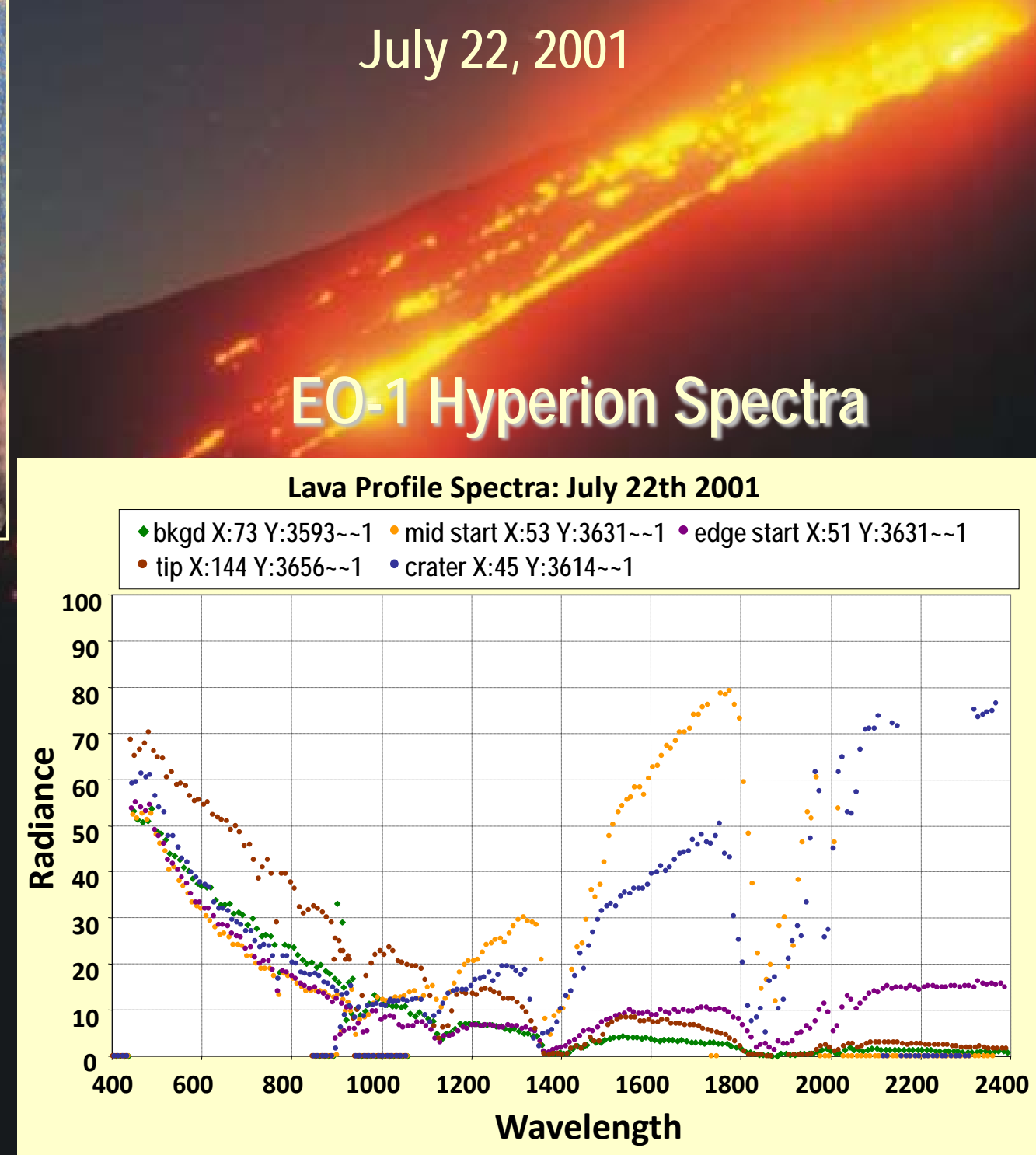


EO-1 Hyperion

(30 m)

6 dates in 2008

PRI
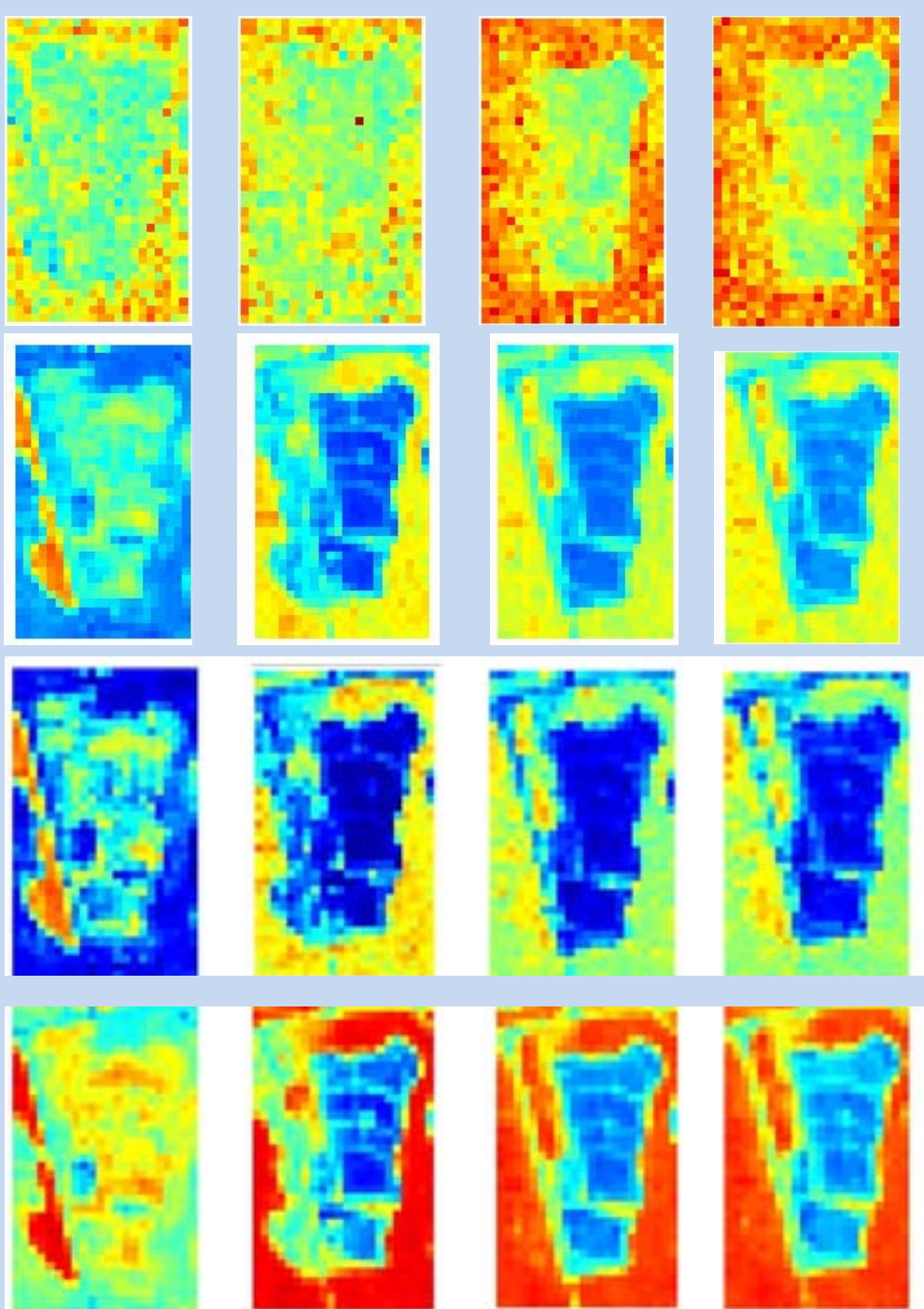

172

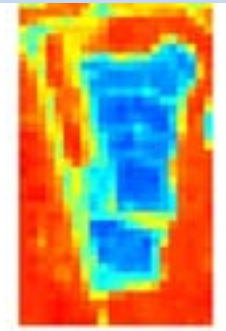

190

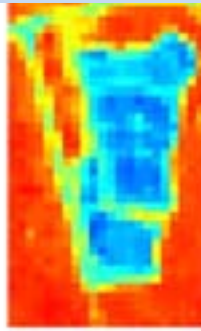

195
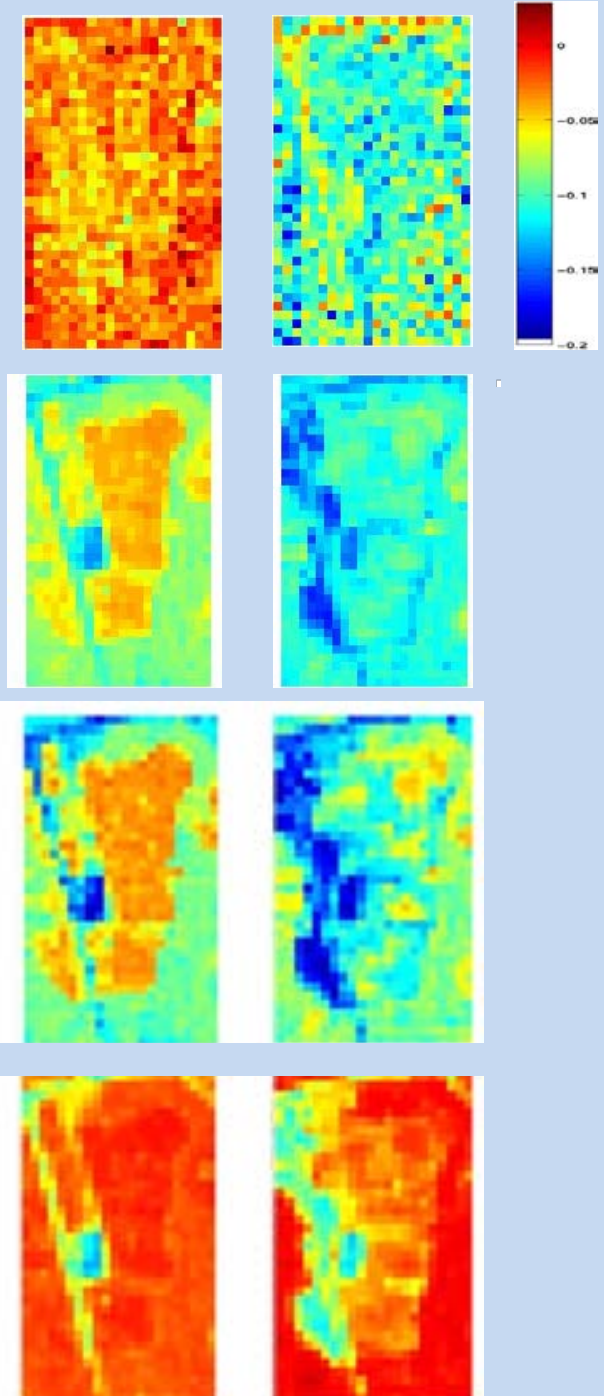

231

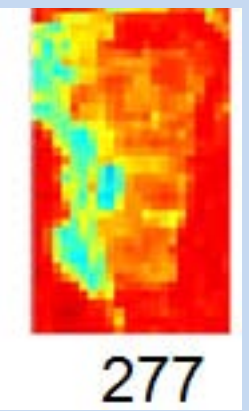

2008 


\section{EO-1 as a Pathfinder for SensorWebs}

\section{Enables Rapid Response with Remote Sensing}

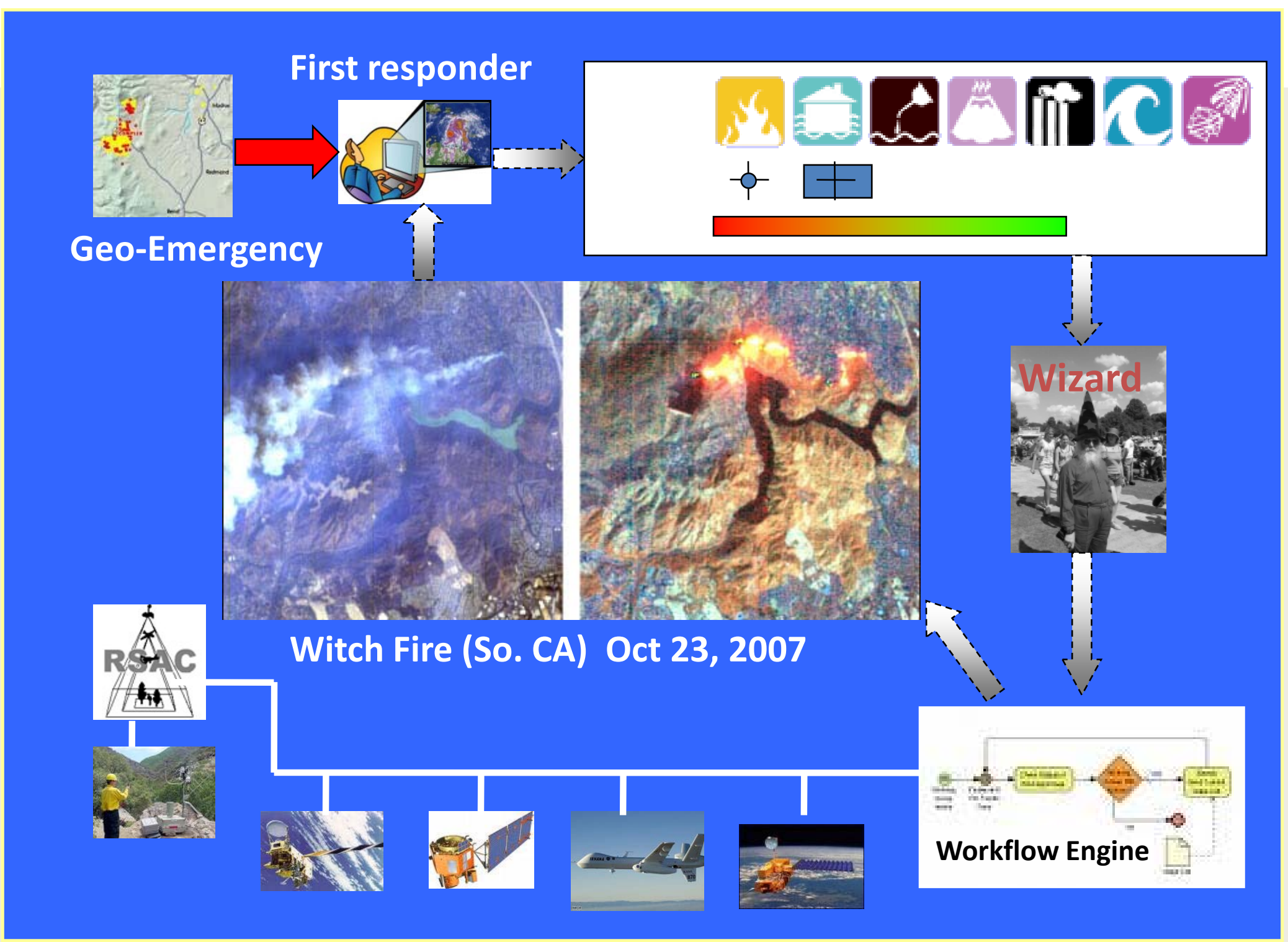




\section{SensorWeb: High Level Architecture}

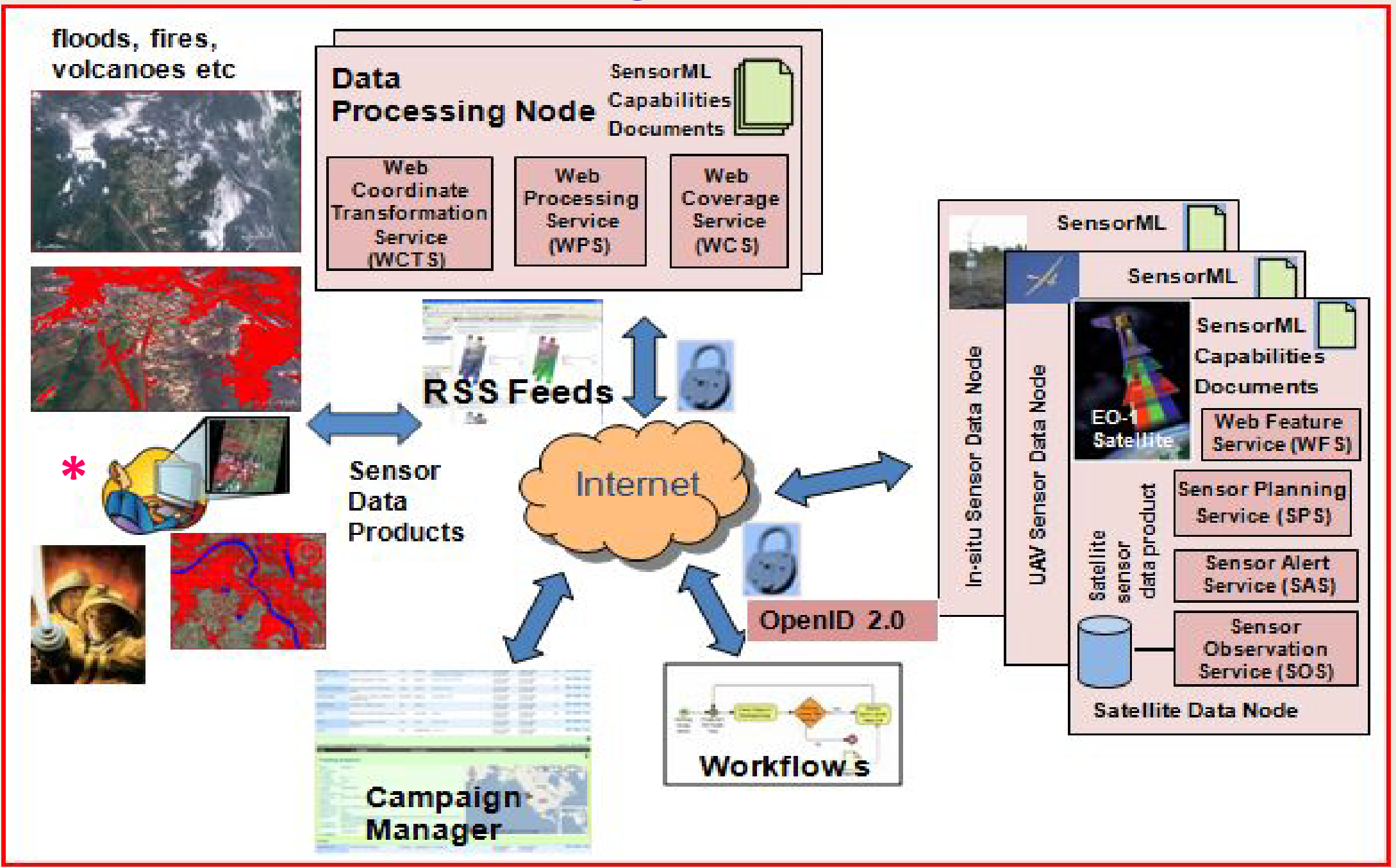

The SensorWeb architecture was developed on EO-1 as a pathfinder effort to encapsulate sensors and data processing algorithms with Open Geospatial Consortium standardized Web 2.0 Service interfaces. Thus, future missions will be able to significantly lower the cost of interoperating, automating procedures and enable rapid customization of data products. 


\section{EO-1 Provides Disaster Support}

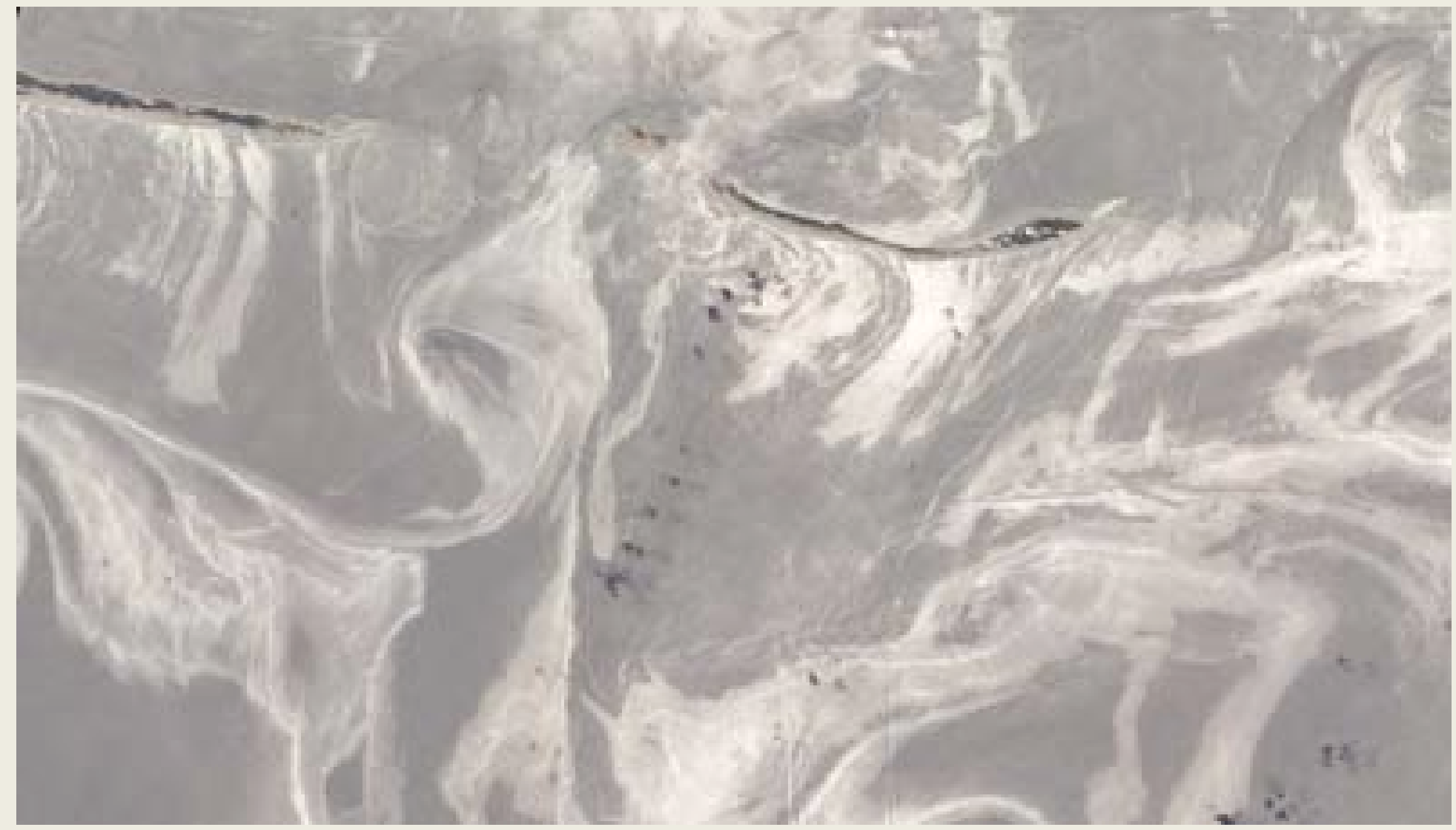

The EO-1 Advanced Land Imager (ALI) observed the BP oil spill in the Gulf of Mexico on June 26, 2010. Captured in this pan-sharpened image are streams and ribbons of oil impacting the Mississippi barrier islands of Horn Island (left) and Petit Bois (right). 
June 28, 2009

True-Color Image from ALI Manam Volcano, New Guinea

Manam Volcano, just off the coast of mainland Papua New Guinea, released a faint plume on June 28 , 2009. Bright white clouds hover over the volcano's summit. Clouds often collect over peaks, but these clouds could result from water vapor released by the volcano. Slightly darker in color, a pale blue-gray plume blows west-northwest from the summit and over the Bismarck Sea. The image below is a ground picture of the volcano.
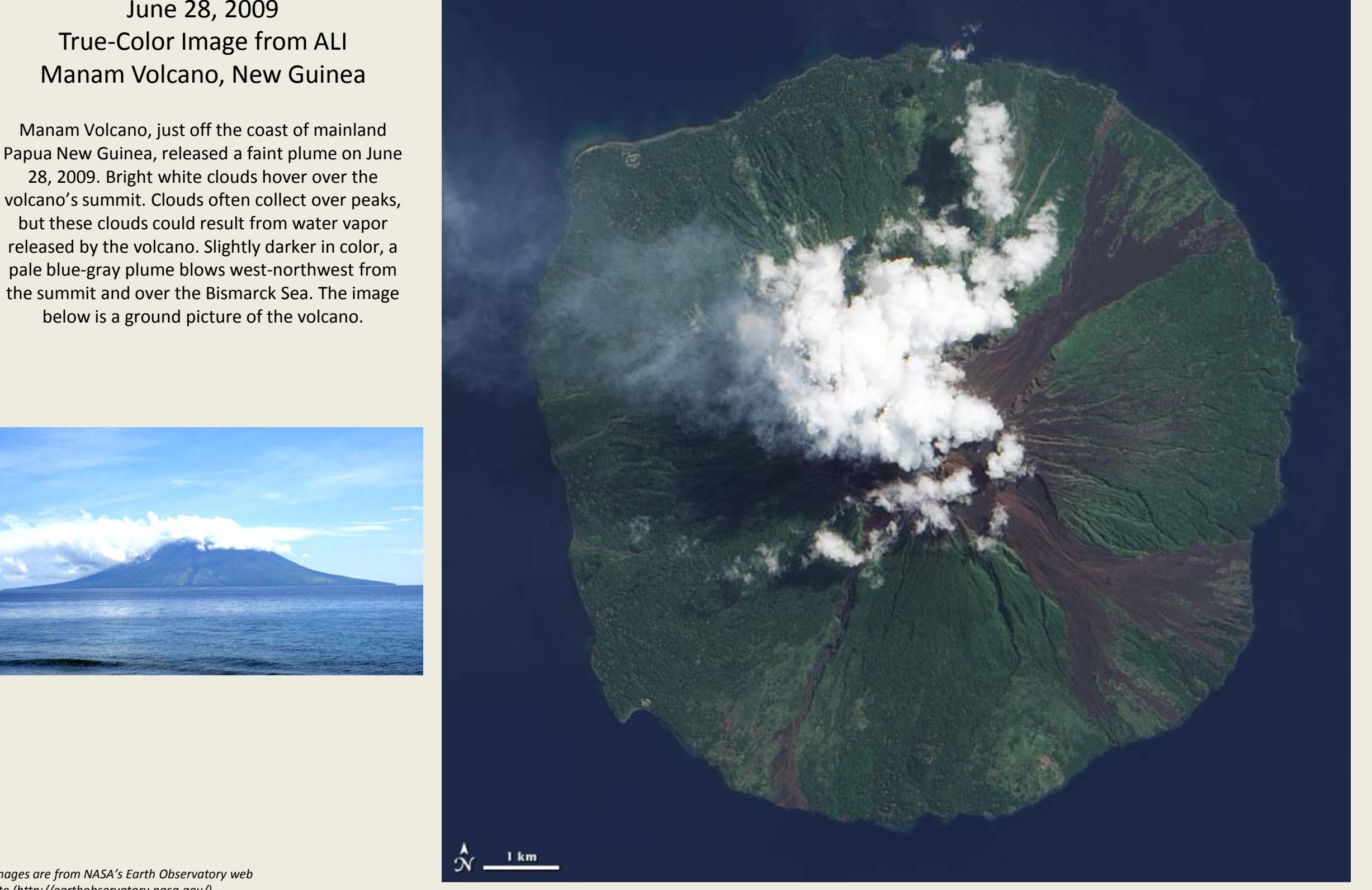


\section{October 9, 2010 True-Color Image from ALI Toxic Sludge in Hungary}

On October 4, 2010, an accident occurred at the Ajkai Timföldgyár alumina (aluminum oxide) plant in western Hungary. A corner wall of a waste-retaining pond broke, releasing a torrent of toxic red sludge down a local stream. Several nearby towns were inundated, including Kolontar and Devecser, where the sludge was 2 meters deep in places. Four people were killed immediately, likely from drowning, and several more were missing. Dozens of residents were hospitalized for chemical burns.

The alumina plant appears along the right edge of both images, and incorporates both bright blue and brick red reservoirs. The breach of the retaining wall is apparent in the close-up view. Sludge cut a channel through the northwest corner of the waste reservoir and spread onto nearby fields. The sludge forms a red-orange streak running west from the plant. The wide-area view shows the spill thinning but remaining discernible for several kilometers to the west. The New York Times reported that the stream nearest the plant empties into larger rivers. The BBC reported that authorities were pouring plaster into the Marcal River in hopes of preventing the sludge from reaching the Danube River.

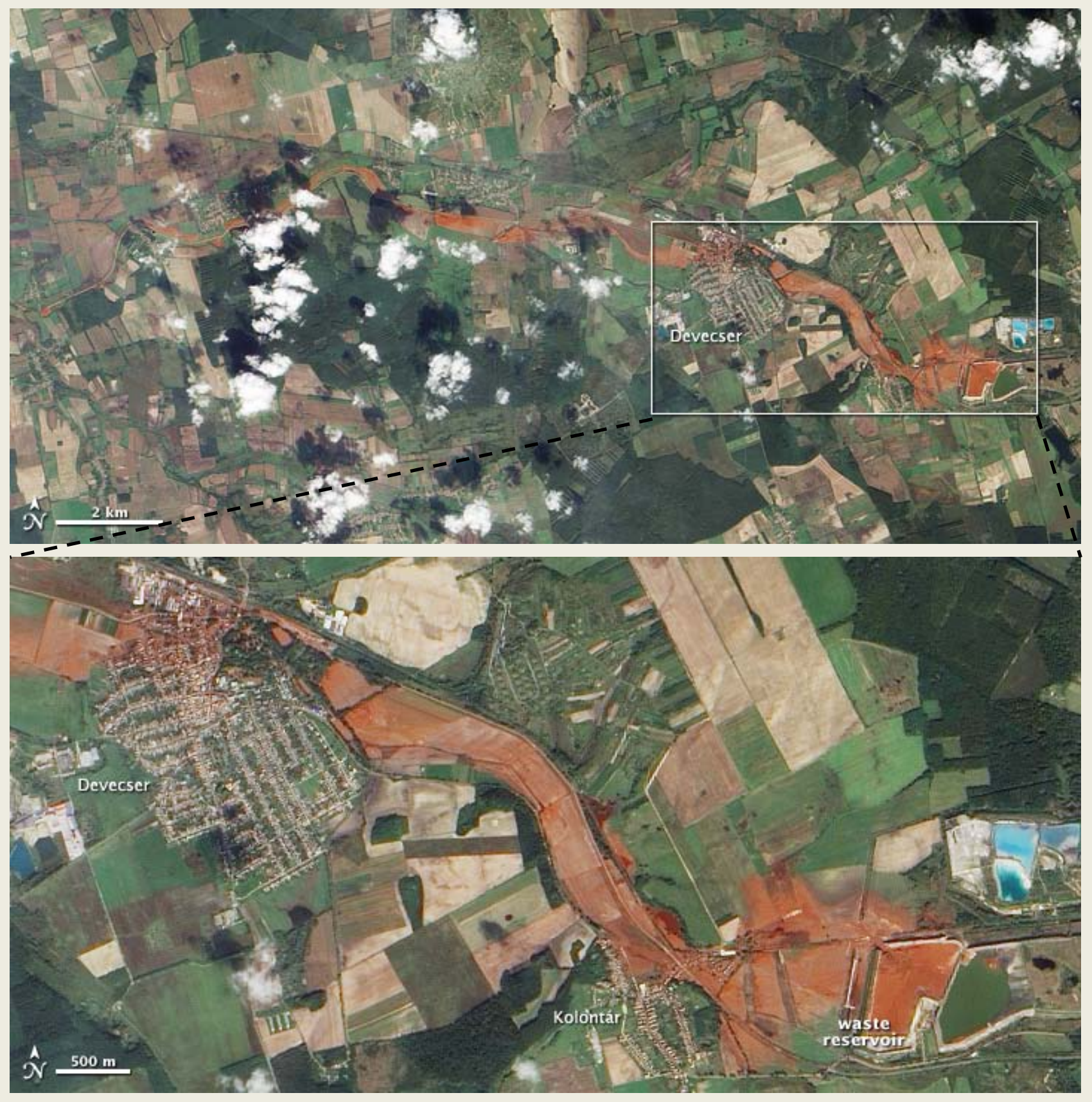




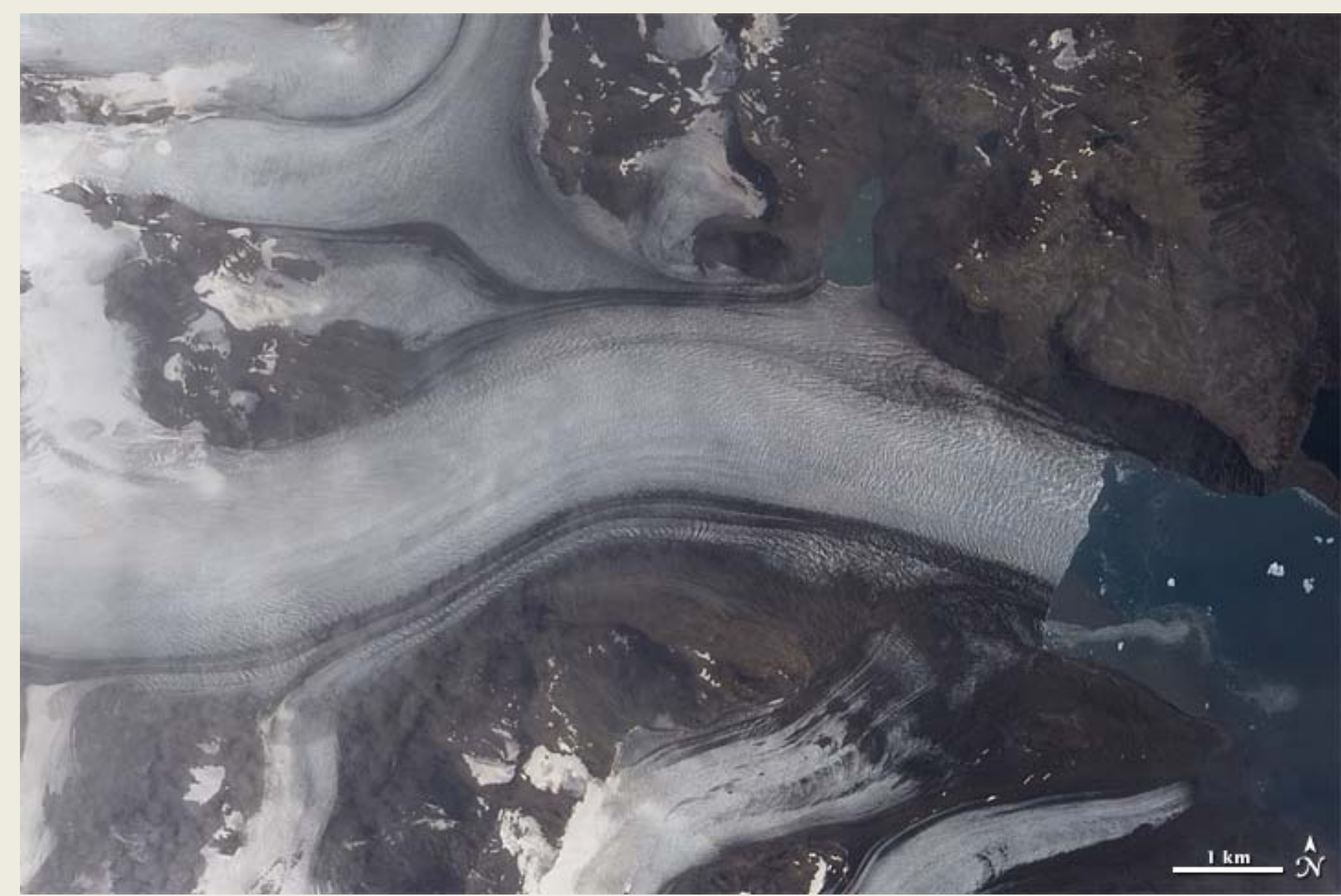

January 11, 2005

True-Color Image from ALI

Neumayer Glacier, South Georgia Island

South Georgia is an arc-shaped island that lies some 2,000 kilometers east of the southern tip of South America. Neumayer Glacier, on the island's east coast, showed very little positional change for many decades. But the glacier began losing significant mass, retreating by roughly $2 \mathrm{~km}$ from 1970 to 2002. From 2005 to 2009 (bottom), the glacier retreated an additional 1 kilometer. 


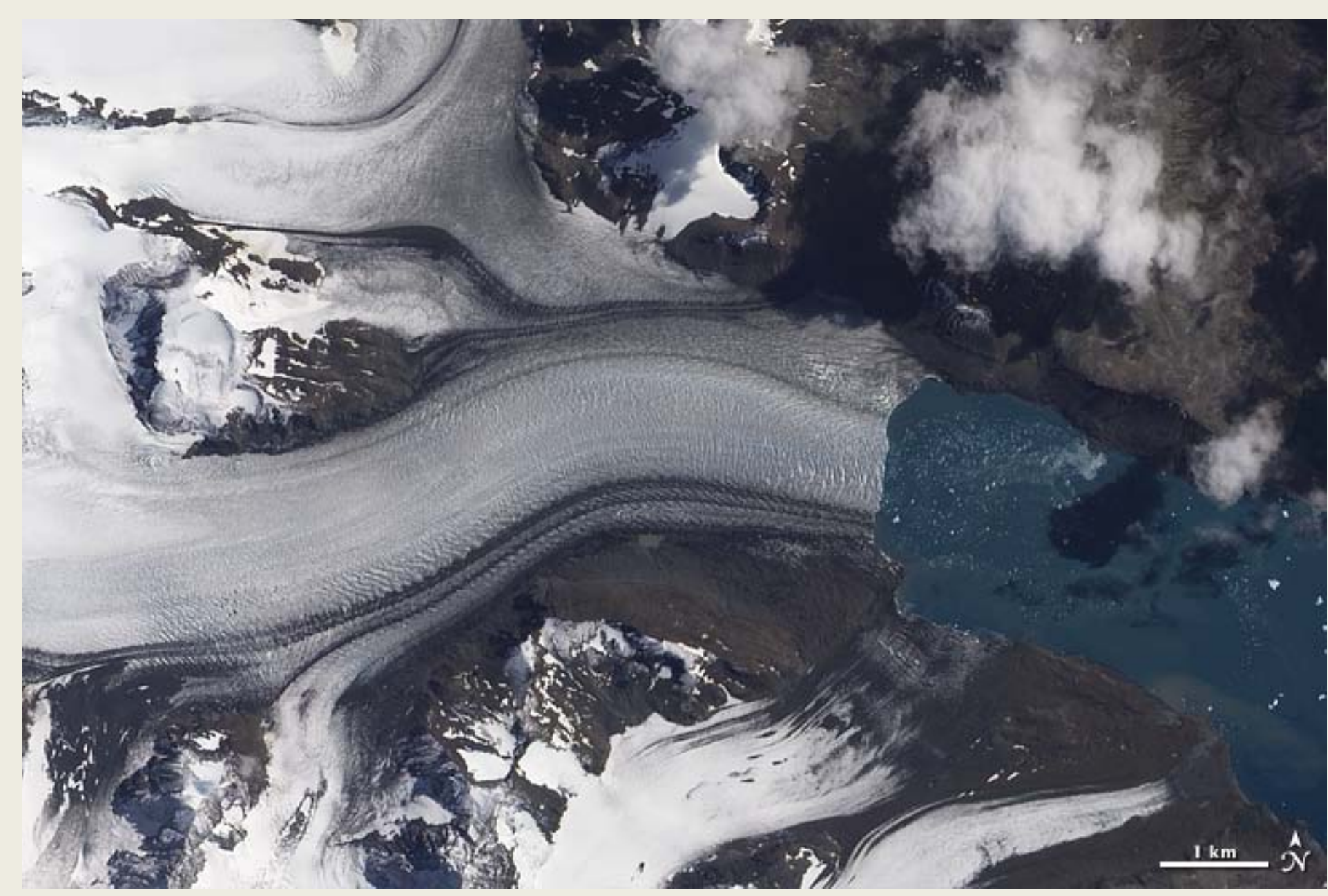

January 4, 2009

True-Color Image from ALI

Neumayer Glacier, South Georgia Island

South Georgia is an arc-shaped island that lies some 2,000 kilometers east of the southern tip of South America. Neumayer Glacier, on the island's east coast, showed very little positional change for many decades. But the glacier began losing significant mass, retreating by roughly $2 \mathrm{~km}$ from 1970 to 2002. From 2005 to 2009 (bottom), the glacier retreated an additional 1 kilometer. 


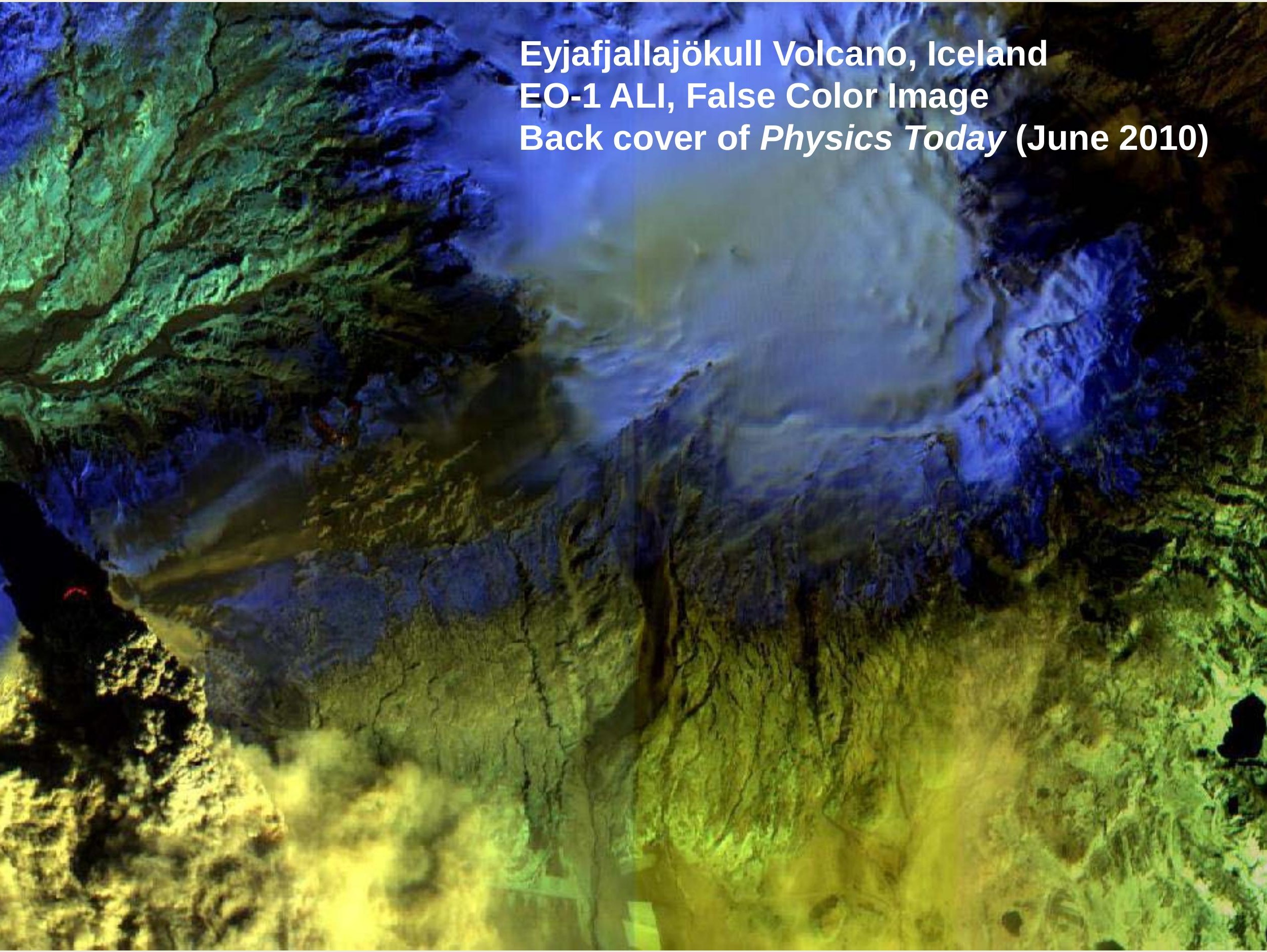




\section{Lunar Calibration Results}

Differences between Rolo model and Hyperion measurements remain stable (within 5\%) over time

Hyperion Lunar Calibration Trends for Selected Bands

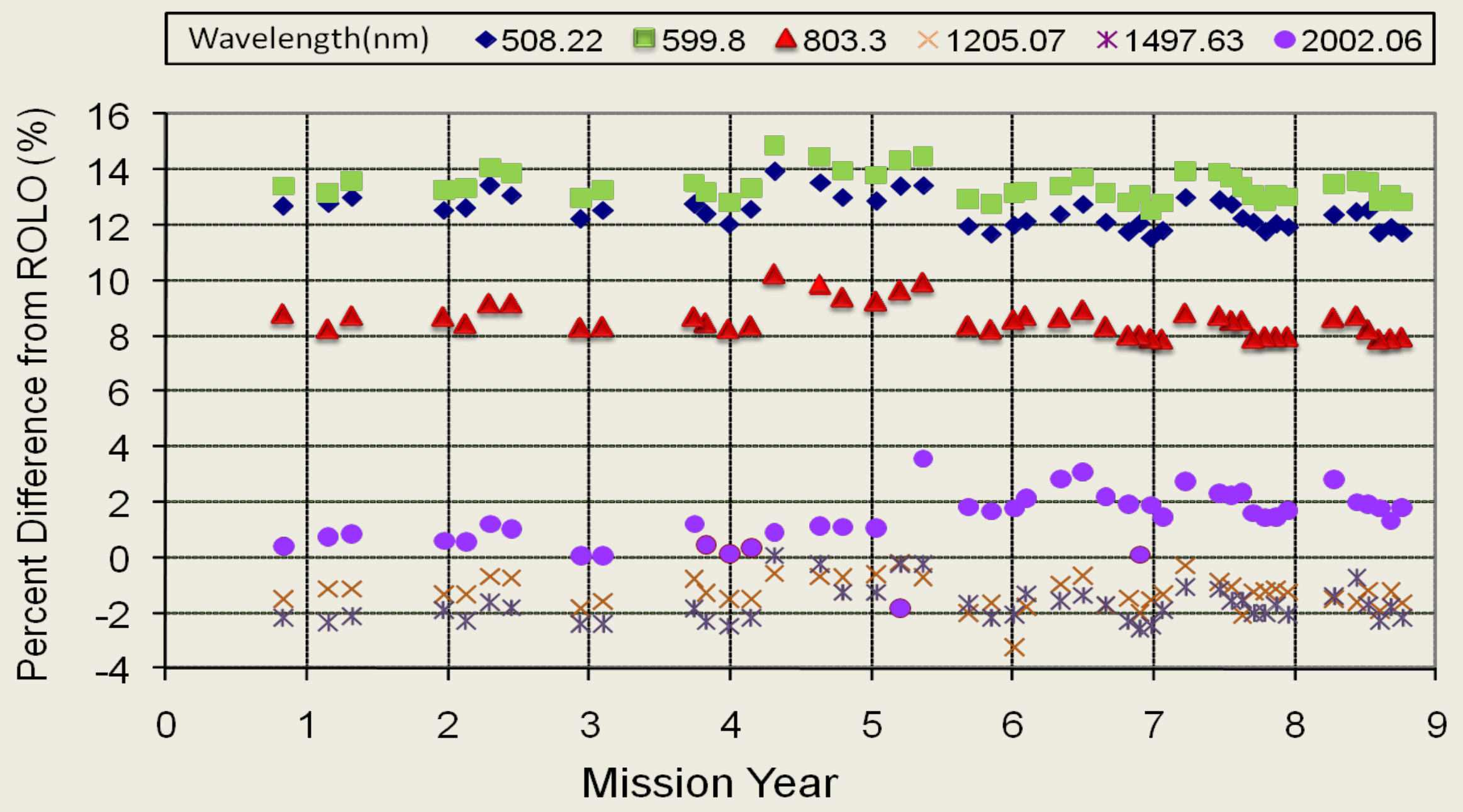




\section{Temporal Profile Selected Hyperion Bands}

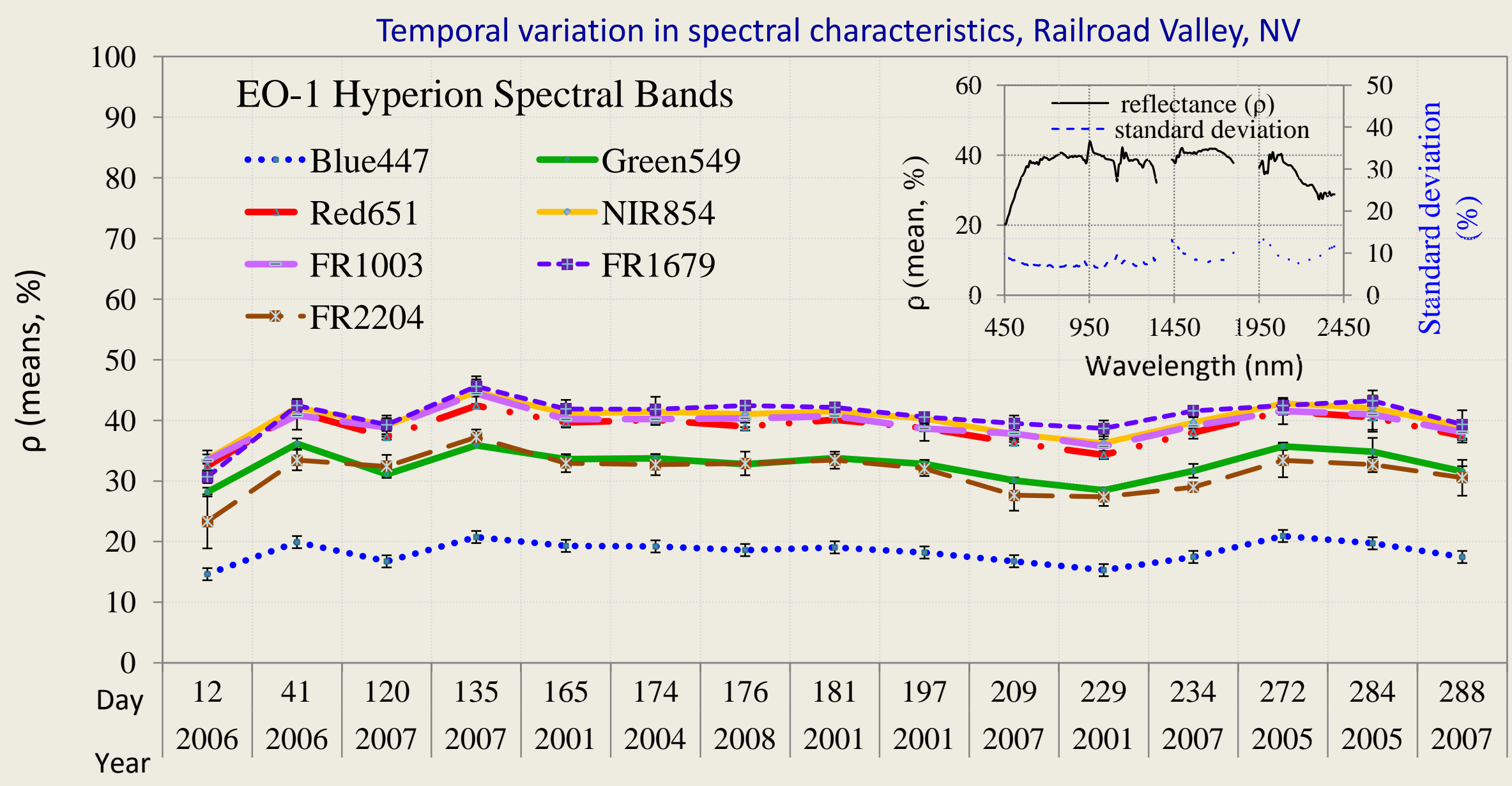

Acquisition (day and year) 


\section{Multiple Flux Sites}

Konza --1yr burn (K 1D) \& 4 year burn (K 4B) Mongu (M),

Duke-- pine (D Ip) \& hardwoods (D hw)

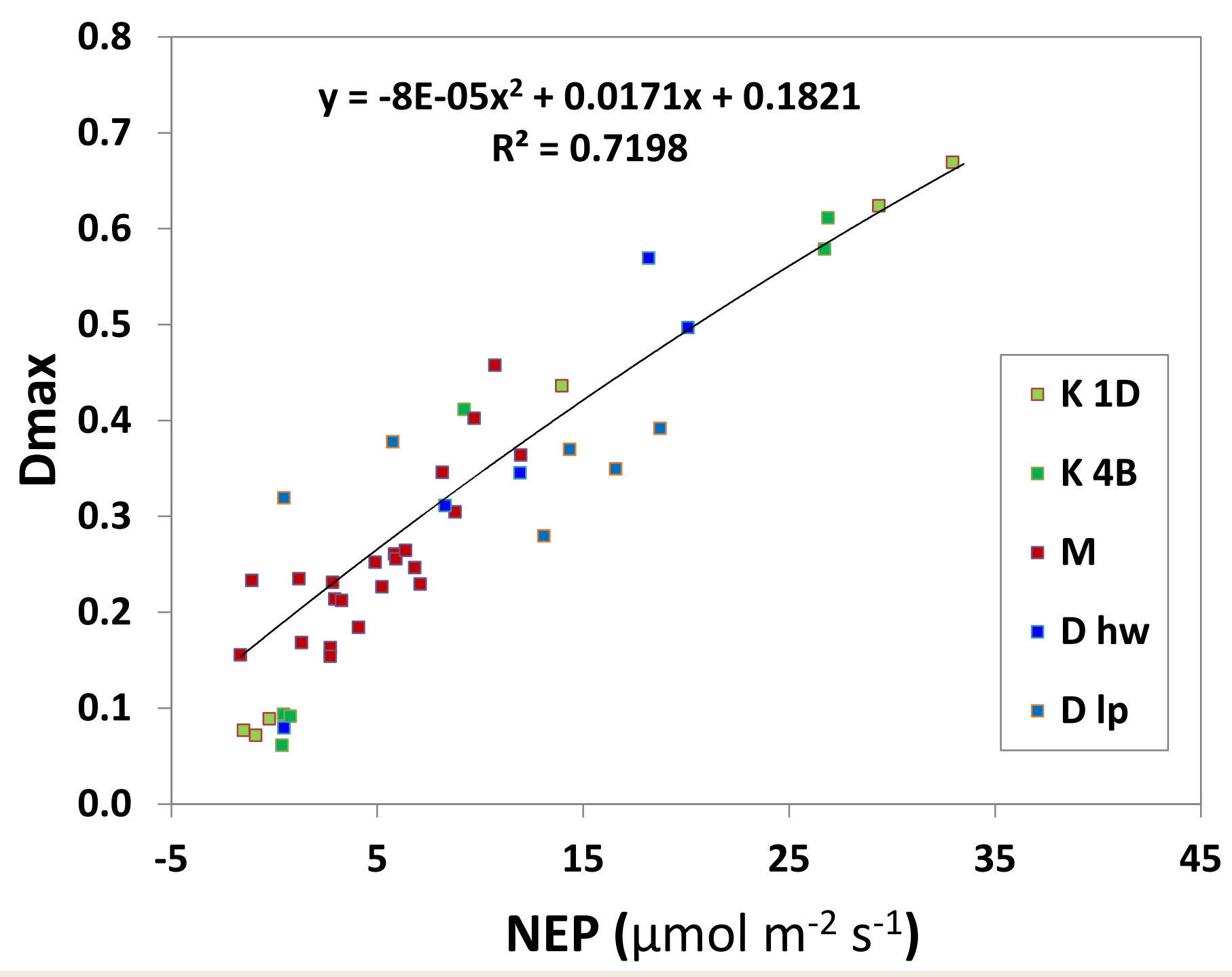




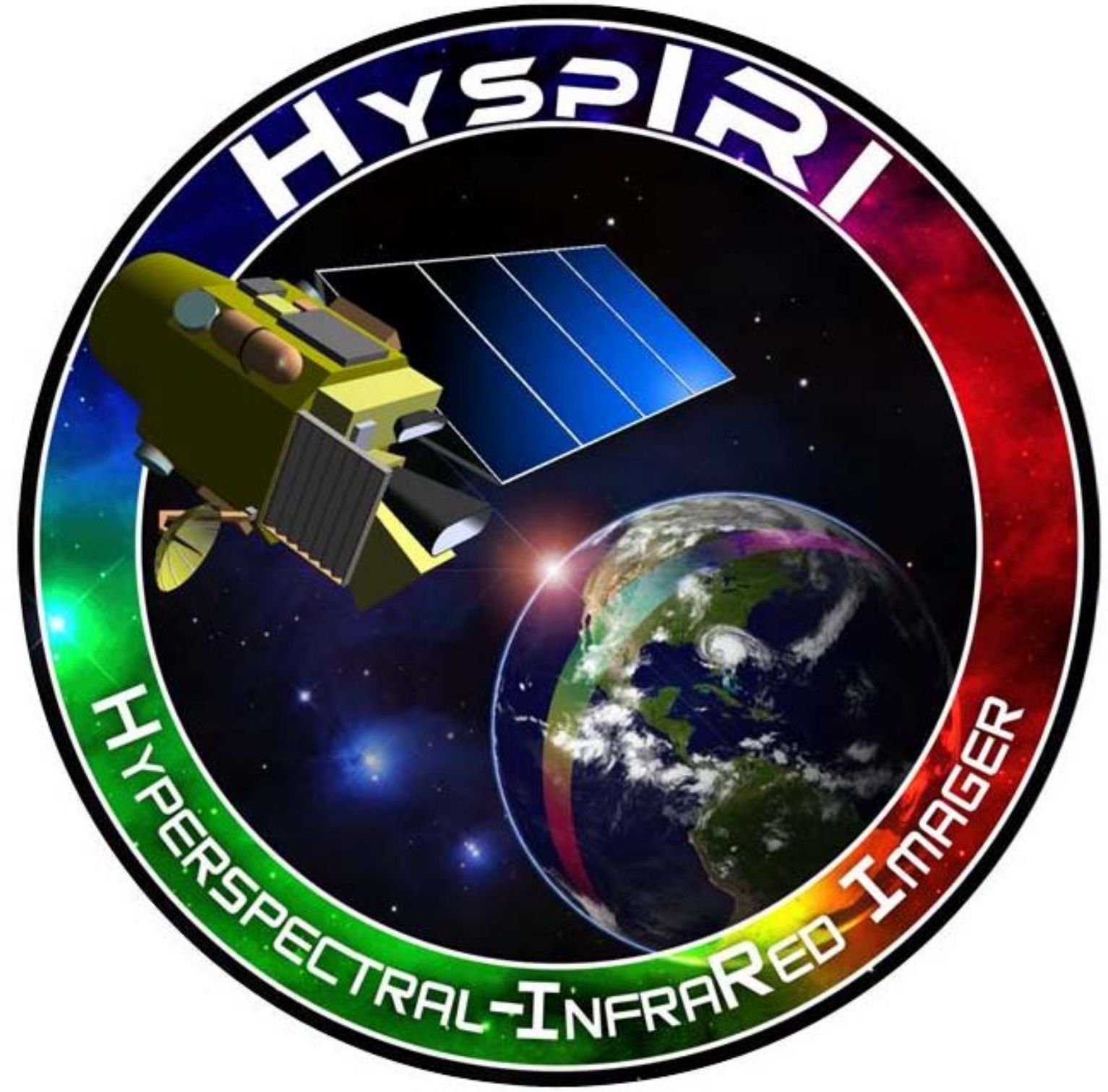




\section{NASA's strategic goal}

to advance Earth System Science to meet the challenges of climate and environmental change

How is the Earth changing and what are the consequences for life on Earth?

- How is the global Earth system changing?(Characterize)

- What are the sources of change in the Earth system and their magnitudes and trends? (Understand)

- How will the Earth system change in the future?(Predict)

- How can Earth system science improve mitigation of and adaptation to global change? (Apply) 


\section{HyspIRI Decadal Survey Climate Scien}

HyspIRI: "A hyperspectral sensor (e.g., FLORA) con with a multispectral thermal sensor (e.g., SAVII) in lo Earth orbit (LEO) is part of an integrated mission concept [described in Parts I and II] that is relevant several panels, especially the climate variability $p$

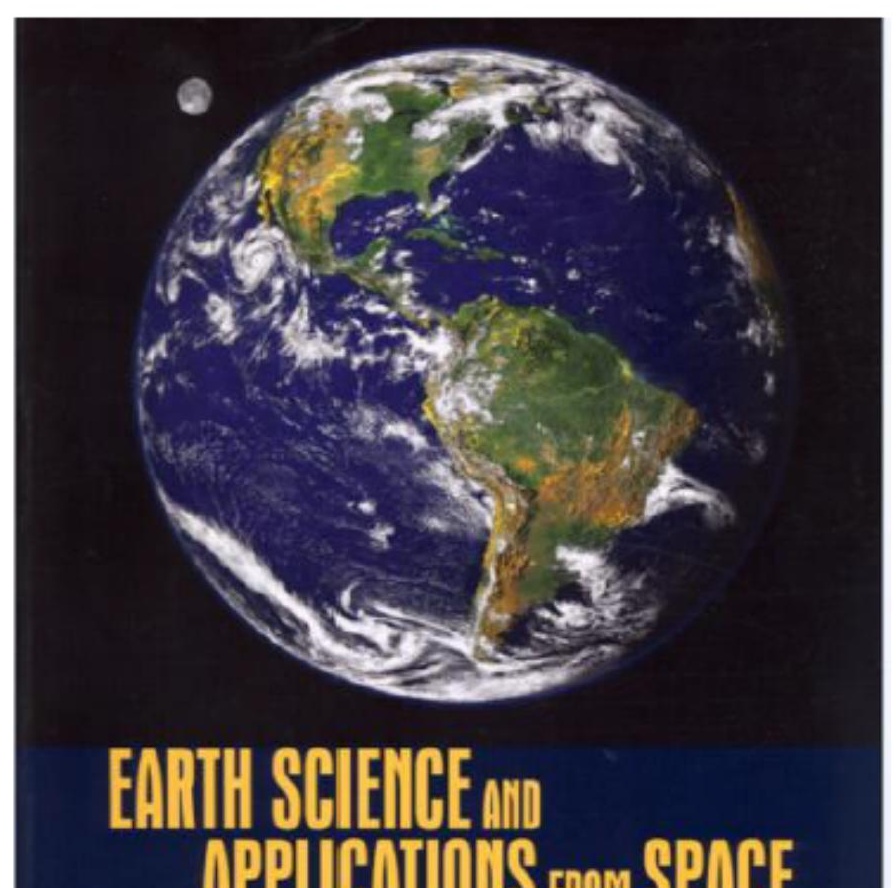




\section{Key HyspIRI Climate Objectives from the Decadal Survey and IPCC}

- Ecosystem Measurements for Climate Feedbacks

- Black Carbon/Dust Effects on Snow and Ice

- Carbon Release from Biomass Burning

- Evapotranspiration and Water Use and Availability

- Critical Volcanic Eruption Parameters 

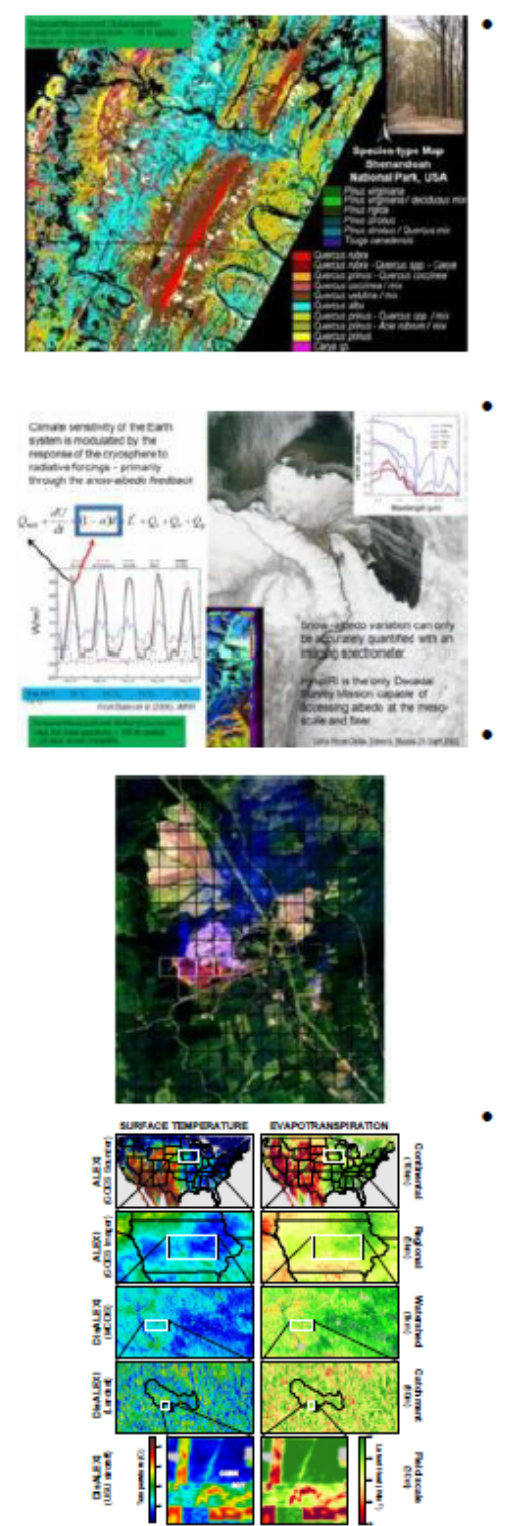

Imaging Spectrometer (VSWIR)

- Pattern and Spatial Distribution of Ecosystems and their Components

- Ecosystem Function, Physiology and Seasonal Activity

- Biogeochemical Cycles

- Changes in Disturbance Activity

- Ecosystem and Human Health

- Earth Surface and Shallow Water Substrate Composition

Multi-Spectral Thermal InfraRed (TIR)

- Volcanoes/Earthquakes

- Wildfires

- Water Use and Availability,

- Urbanization/Human Health

- Earth surface composition and change

Combined Imaging Spectrometer and Multi-Spectral Thermal Science

- Coastal habitats, and inland aquatic environments

- Wildfires

- Volcanoes

- Ecosystem Function and Diversity

- Land surface composition and change

- Human Health and Urbanization

Key HyspIRI climate objectives from the Decadal Survey and IPCC

- Ecosystem Measurement for Climate Feedback

- Black Carbon/Dust Effects on Snow and Ice

- Carbon Release from Biomass Burning

- Evapotranspiration and Water Use and Availability

- Critical Volcanic Eruption Parameters 


\section{HyspIRI Measures the Optical Spectrum}

HyspIRI VSWIR

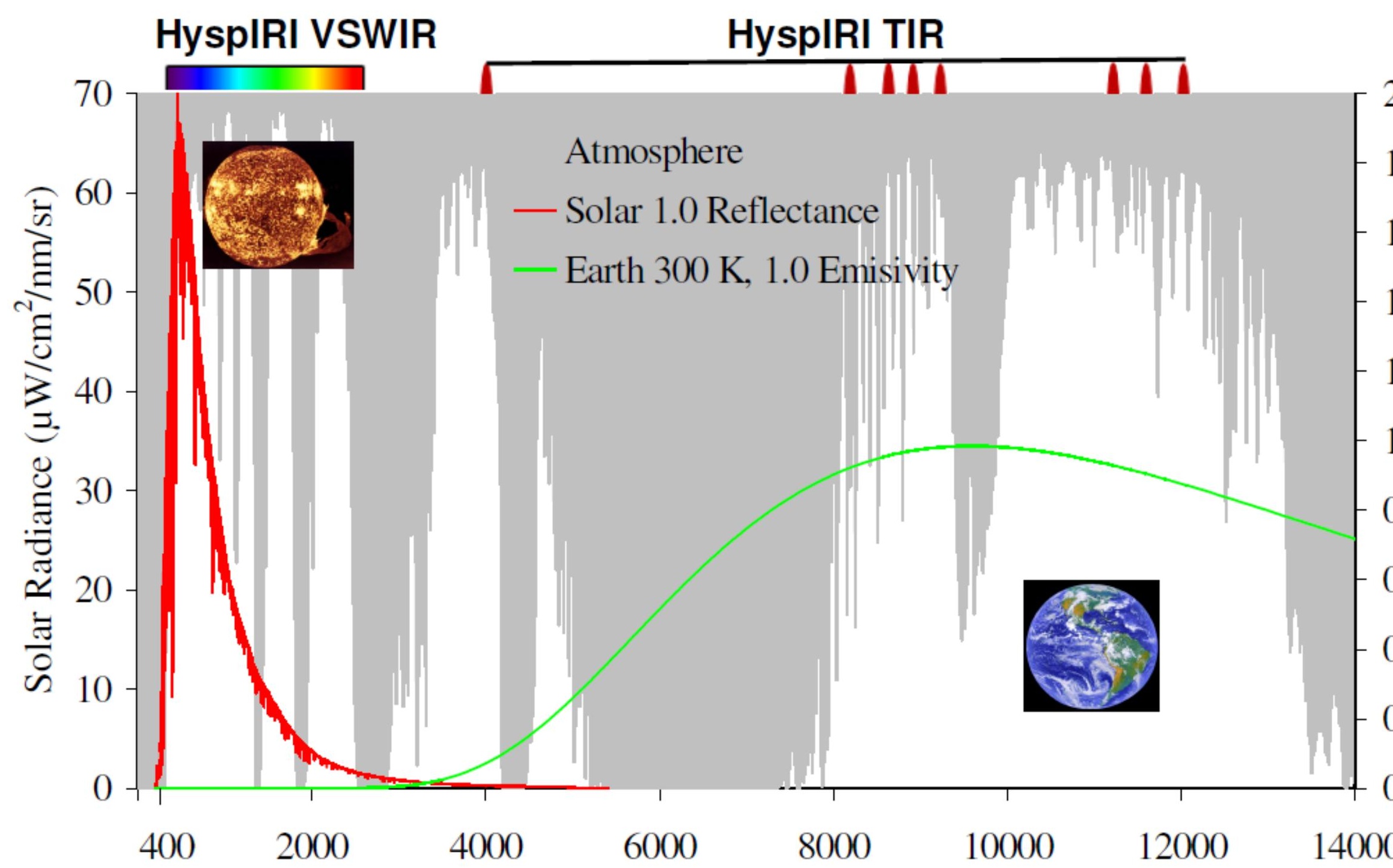

\section{HyspIRI TIR}




\section{Measuring the Terrestrial Biosphere}

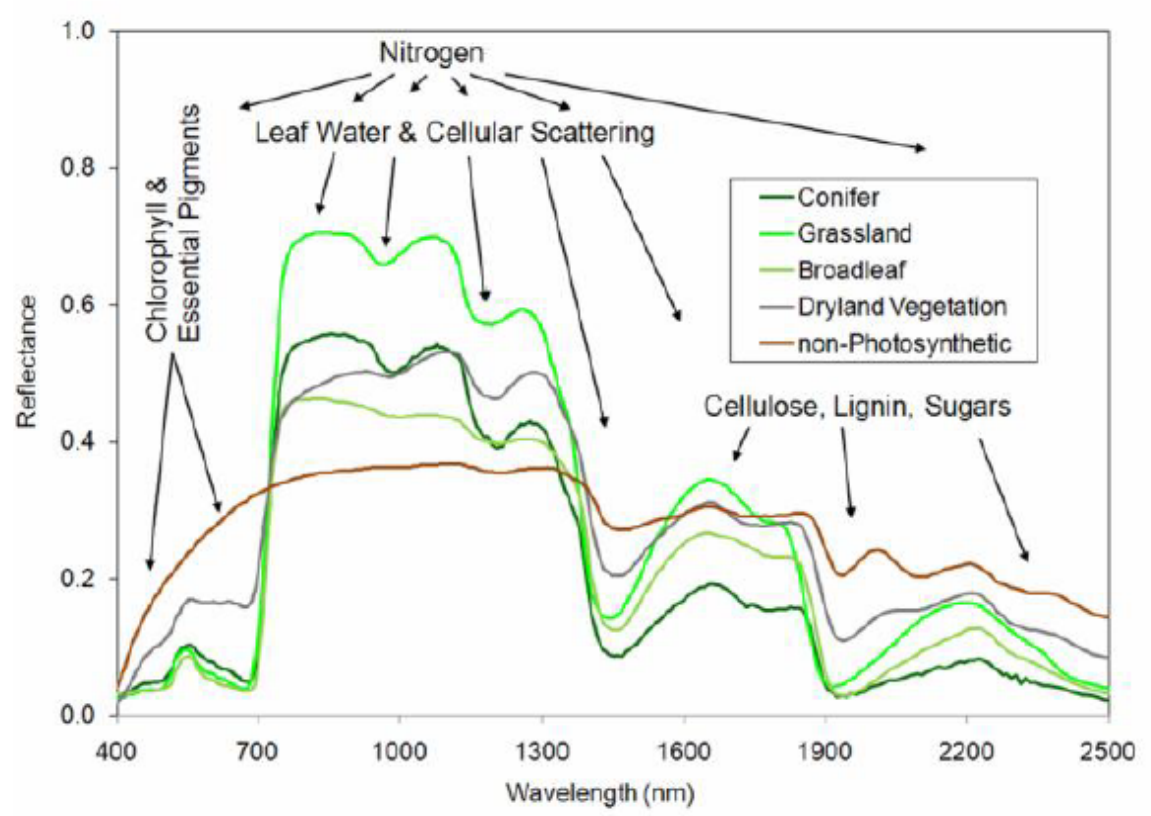

— Imaging Spectroscopy is required to measure critical variables of the terrestrial biosphere.
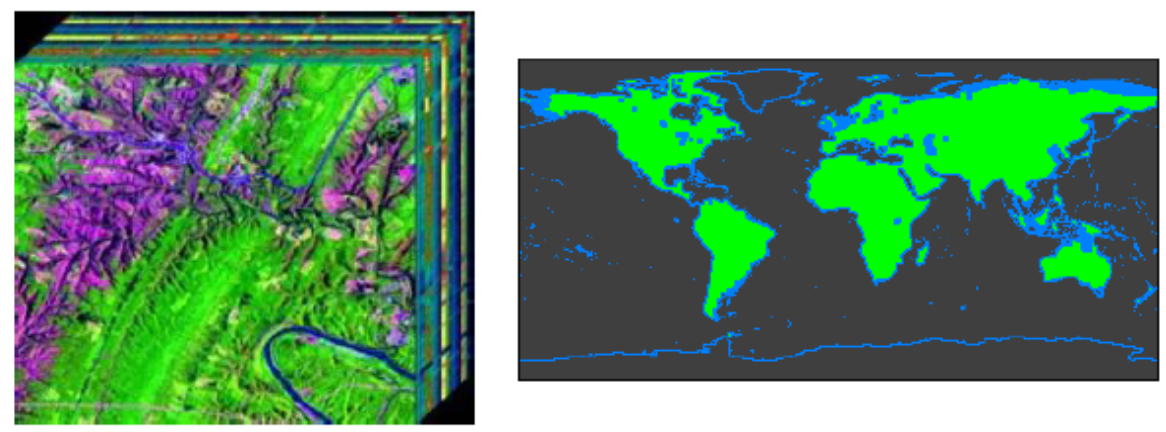

Multi-spectral imaging is insufficient

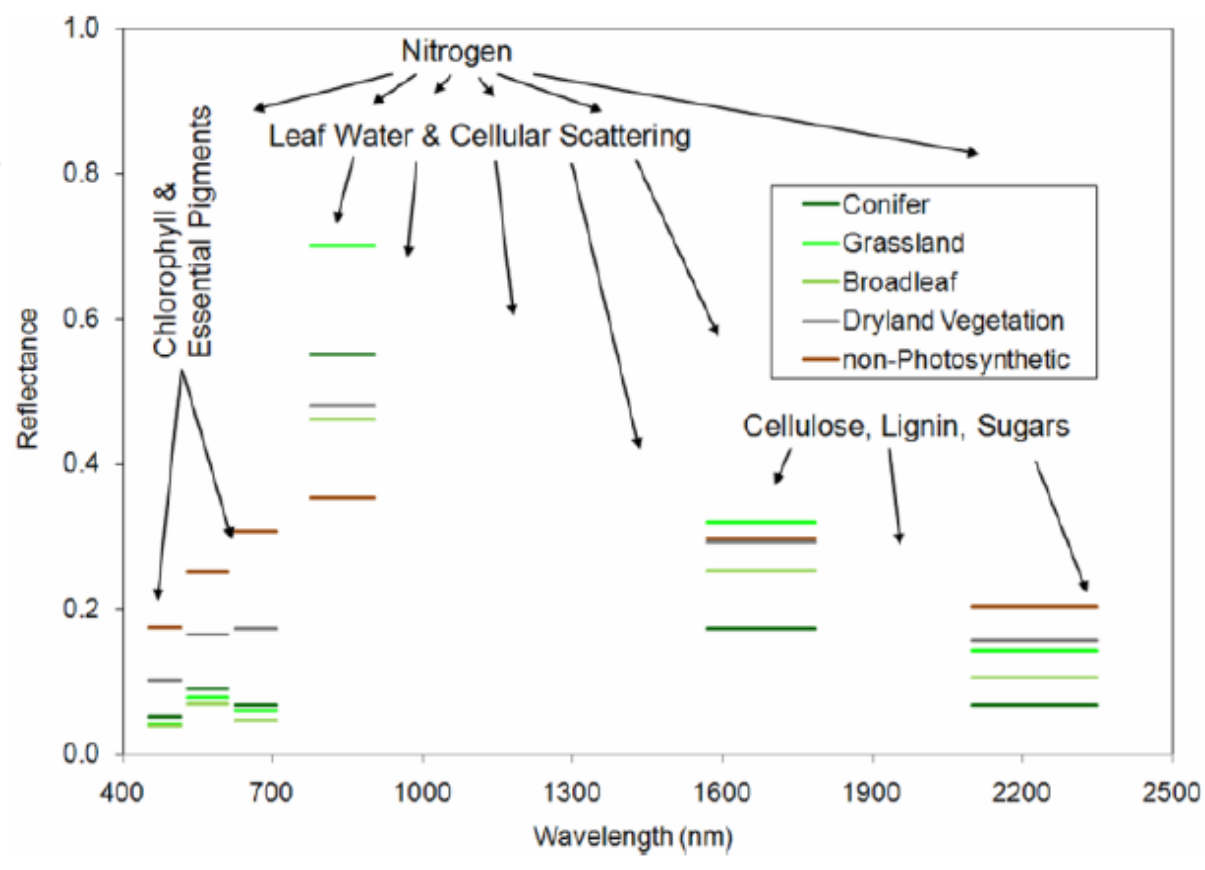


To Achieve the HyspIRI Climate Contribution,

\section{Global Coverage is Required with Revisit $<20$ Days}

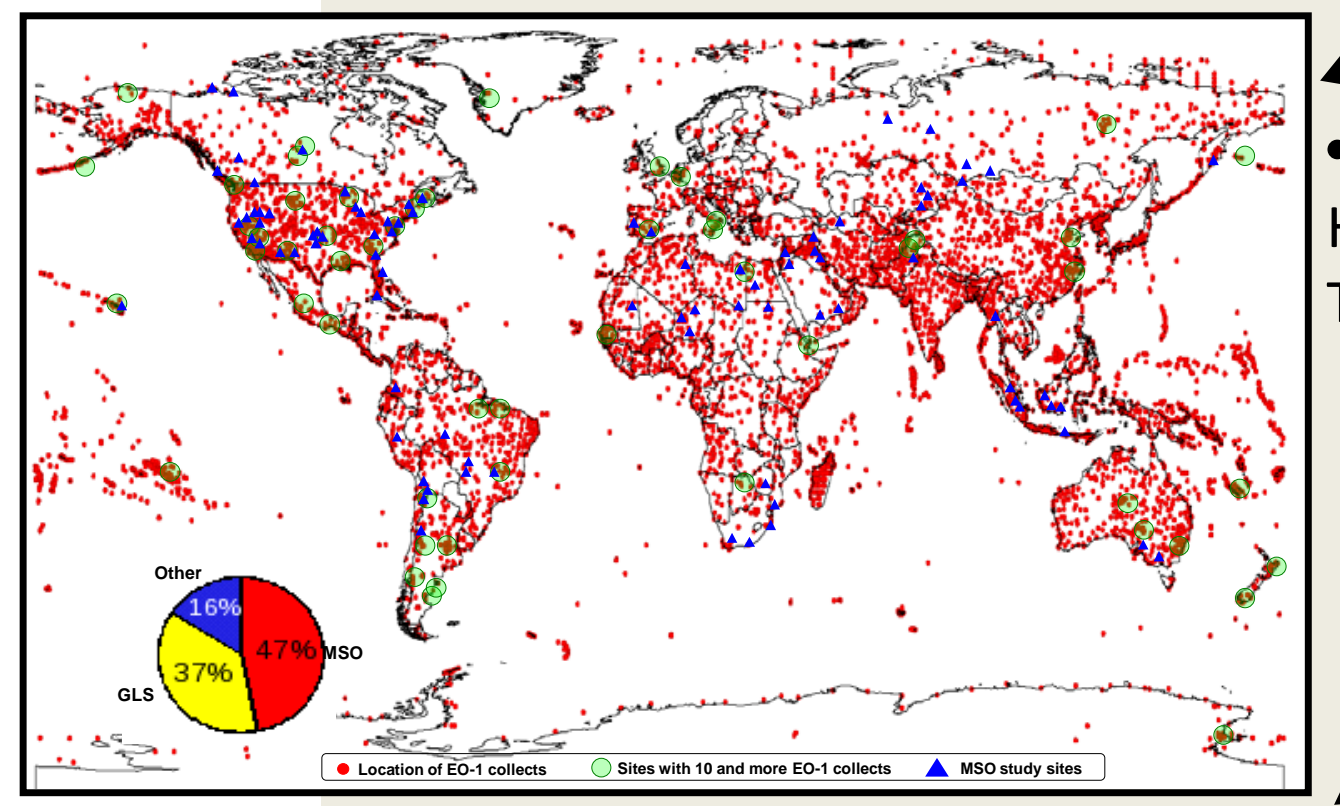

- EO-1 Hyperion acquisitions in 10 years.

Hyperion is a fully successful NASA Technology sampling Mission.

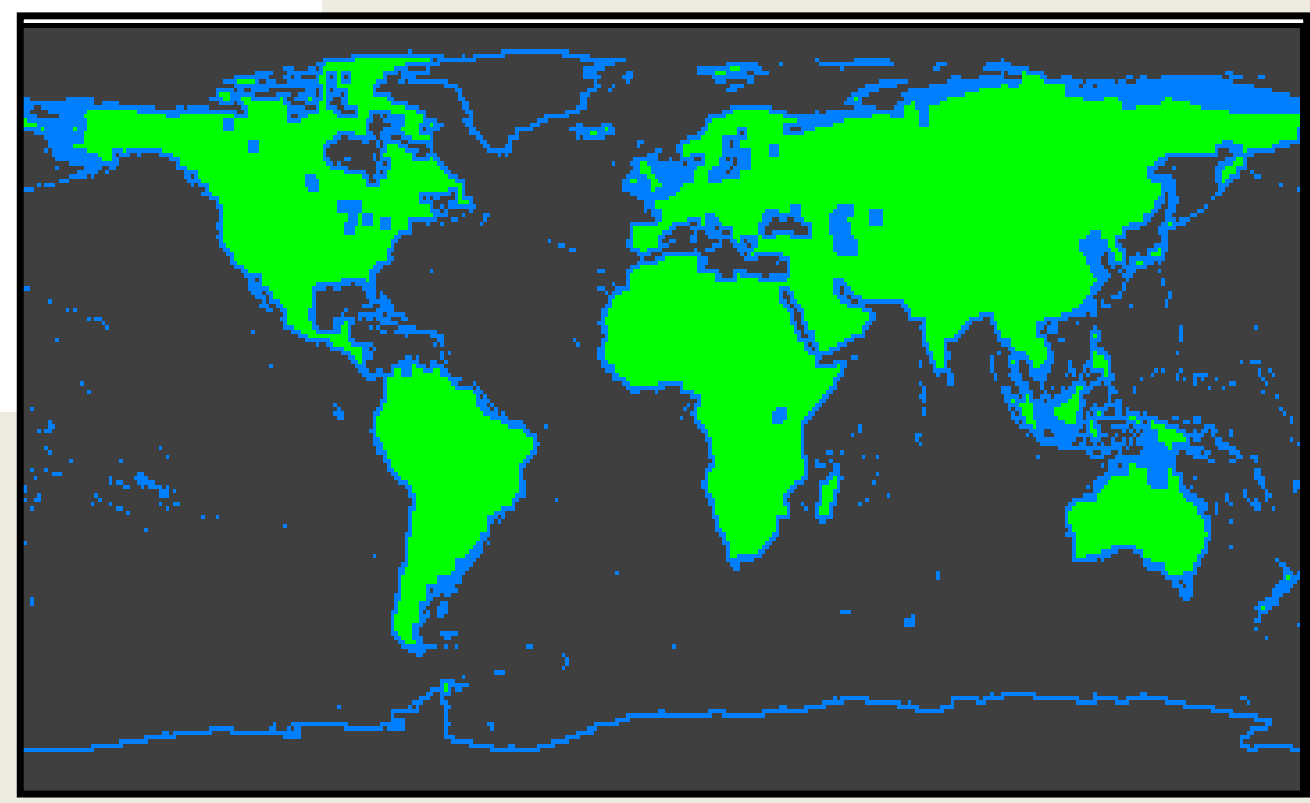

- HyspIRI VSWIR provides complete terrestrial coverage every 19 days.

- It would take Hyperion 100 years to acquire what HyspIRI measures in 1 year.

- For climate, impact, adaptation and vulnerability measurements, HyspIRI (VSWIR and TIR) has orders of magnitude more scientific coverage and quality than any planned international mission. 


\section{NASA HyspIRI NRC Decadal Survey Mission}

(1) Vegetation Functional Type (species-type)

(2) Vegetation physiological condition (health, status)

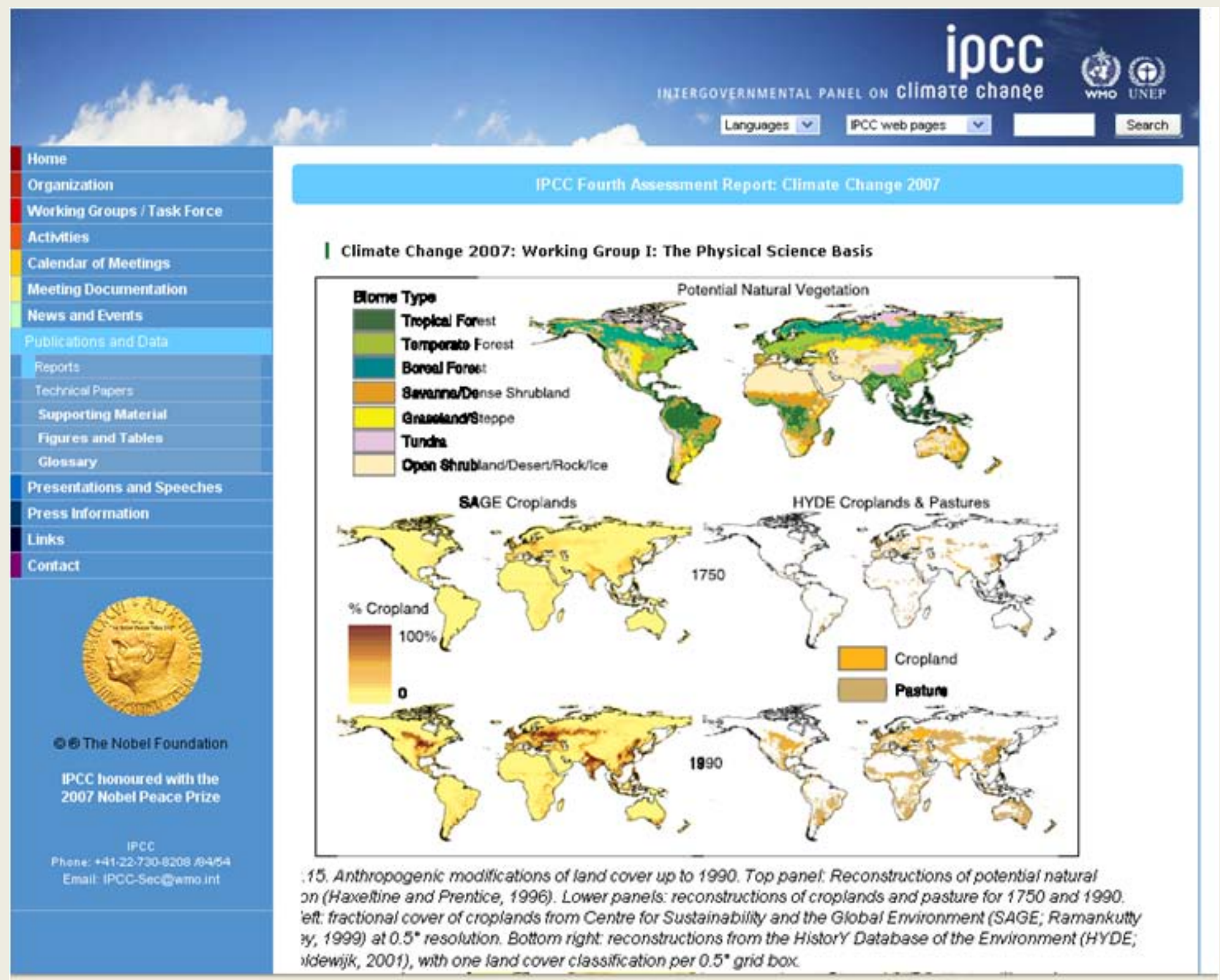




\section{NASA HyspIRI NRC Decadal Survey Mission}

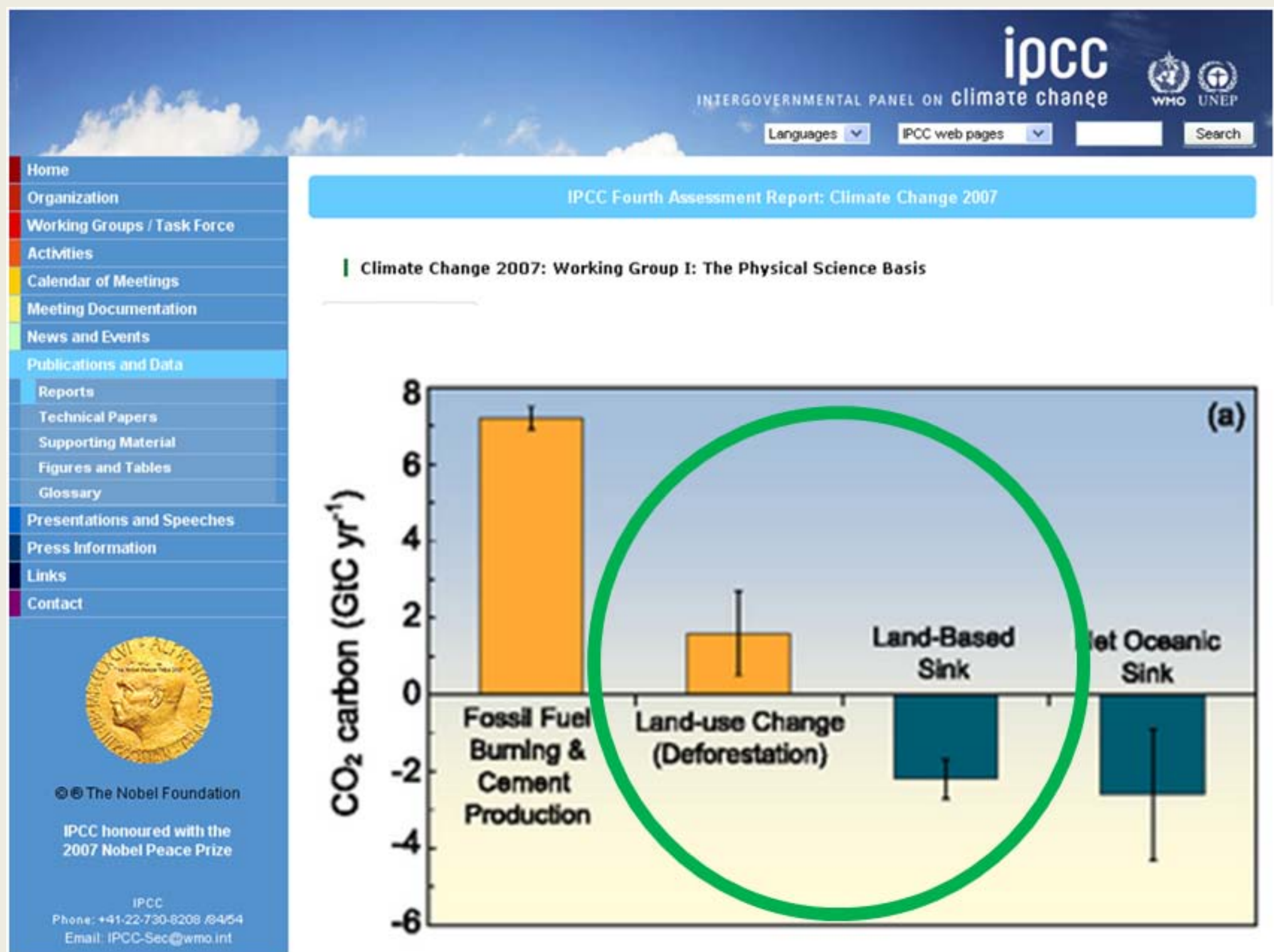




\section{HyspIRI Critical Role in Climate Carbon Cycle Scie}

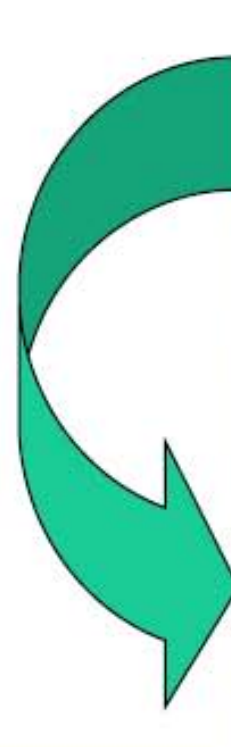

Uncertainty

Tropical forest

$N P P=P A R i$ * $f A P A R$ * LUE

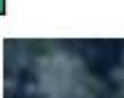

列
Uncertainty (under changing land use)

Tropical forest:

Temperate forest

Shrublands

Savannas from $+40 \%$ to $<20 \%$

from $+40 \%$ to $<20 \%$

from $+30 \%$ to $<10^{\circ}$

from $+30 \%$ to $<10 \%$ from $+50 \%$ to $<10 \%$ from $+30 \%$ to $<10 \%$ from unknown to $<1$
from $+50 \%$ to $<10 \%$
Temperate forest

Shrublands

Savannas
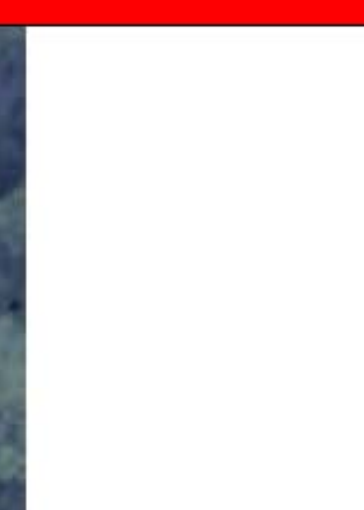

r.

Biomass = f(fractional cover, height,
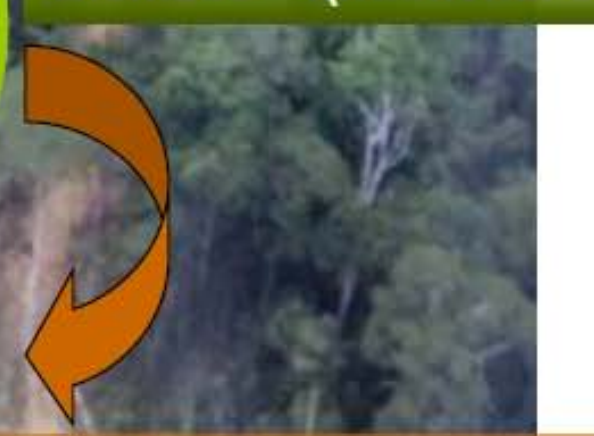

NPV Production (mortality) = fNPV cover * carbon density 


\section{Climate: Response to Disturbance}

Cerro Grande Fire Severity, Los Alamos, NM, Ray Kokaly
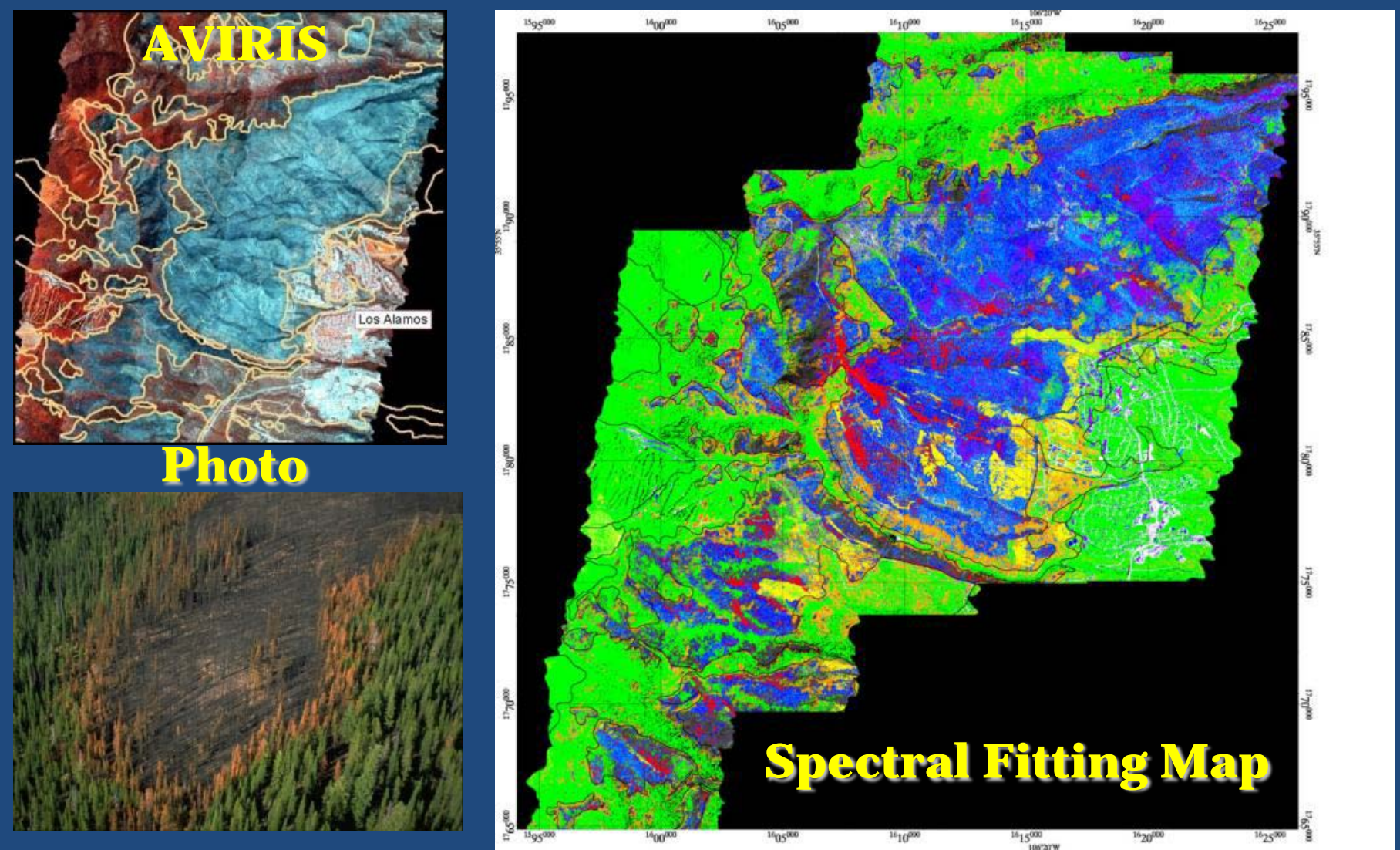

Lignin-Cellulose Lab

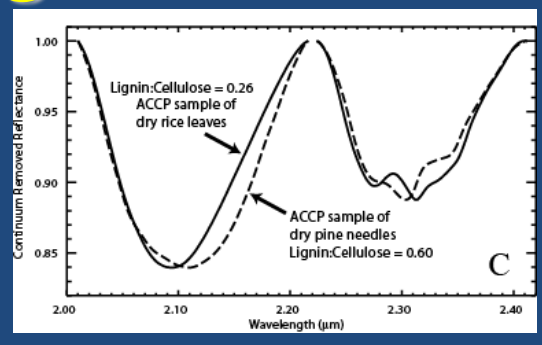

Lignin-Cellulose AVIRIS

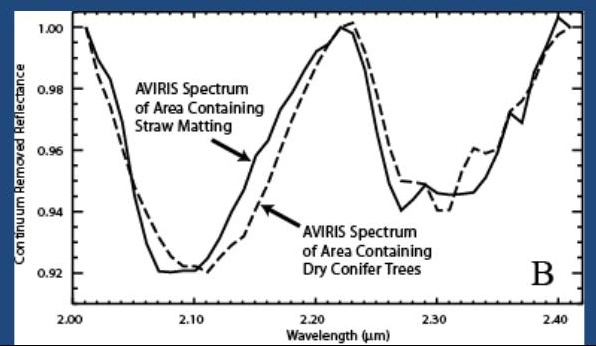

Ash//Charcoal

Mineral//Ash

Mineral-1 $\mu \mathrm{m}$

Mineral-2 $\mu \mathrm{m}$

Dry Conifer

Dry \& Green

Conifer

Straw matting

Straw matting \& Green grass

Green

Vegetation

Ray Kokaly, USGS 


\section{Spatial Resolution}

This Science Working Group has found $60 \mathrm{~m}$ in conjunction with excellent measurement position knowledge to be optimal to answer these science question globally.

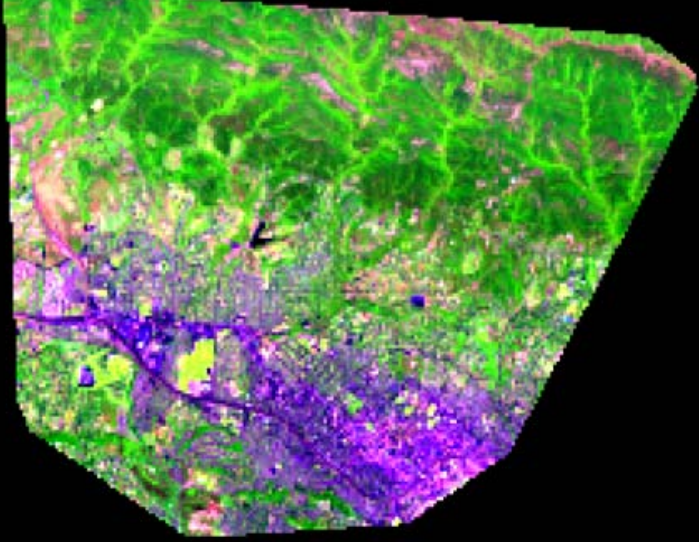

Santa Barbara, CA Front range and city
Functional type result $60 \mathrm{~m}$

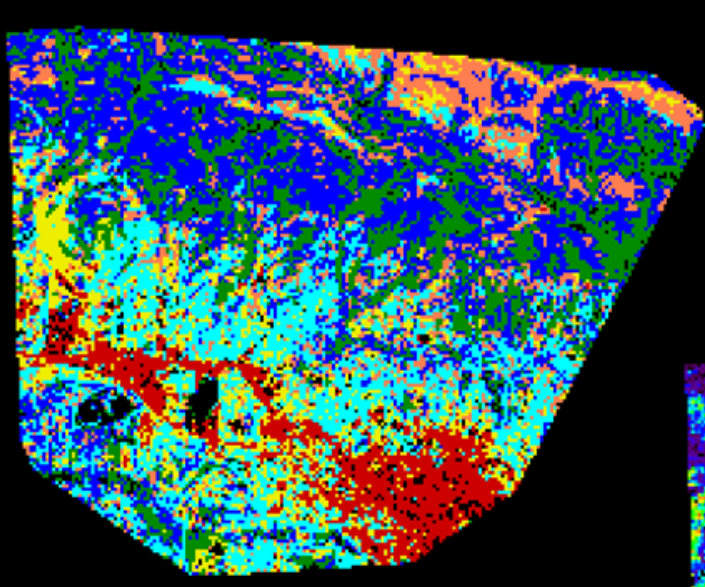

Non photosynthetic vegetation fraction
- Chamise Ceanothus

- Manzanita/Mixed

- Coast Live Oak

- Grass

- Urban

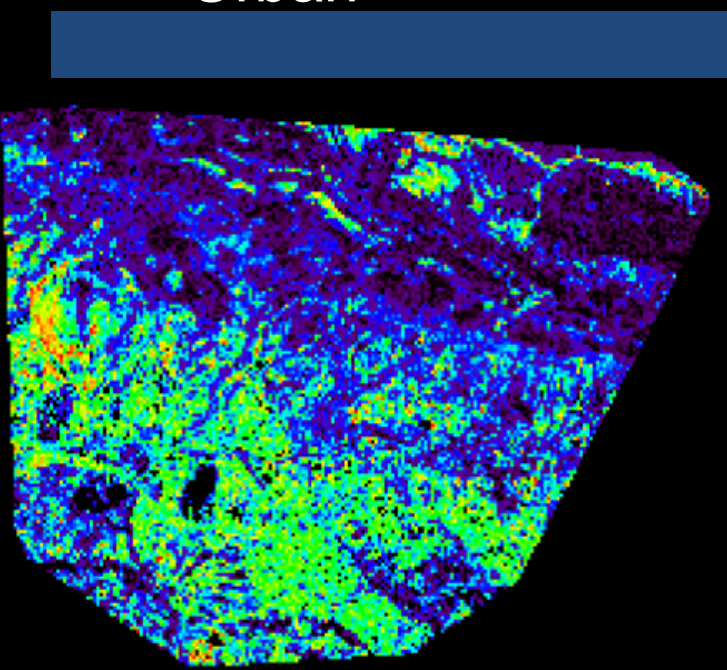

$100 \%$

$50 \%$ $0 \%$ 


\section{HyspIRI is Required to Reduce Uncertainties in the Land Carbon Fluxes}

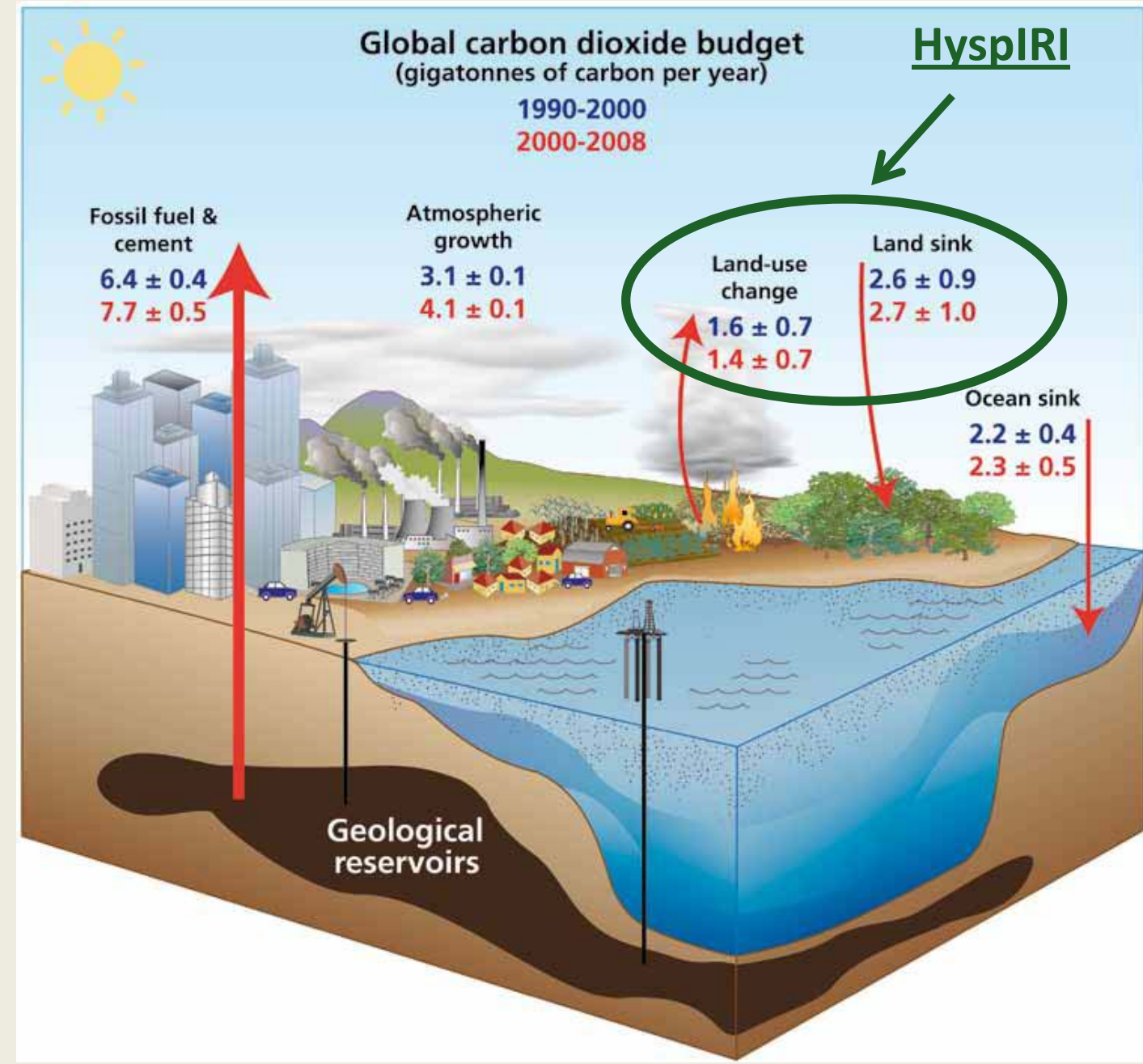
Accurate constraint of Carbon fluxes associated with land-use and terrestrial vegetation are key missing elements for closing the carbon budget.

The HyspIRI based improvement is essential for sound policy decision making and understanding climate impacts.

Addresses critical climate carbon feedback uncertainty (IPCC WG-2)

Global CO2 budget for 1990-2000(blue) and 2000-2008 (red) (GtC per year). Emissions from fossil-fuel and landuse change are based on economic and deforestation statistics. Atmospheric CO2 growth is measured directly. The land and ocean CO2 sinks are estimated using observations for 1990-2000 (Denman et al. IPCC 2007). For 2000-2008, the ocean CO2 sink is estimated using an average of several models, while the land CO2 sink is estimated from the balance of the other terms. 


\begin{tabular}{|c|c|c|c|}
\hline Major Model Inputs & CENTURY & CASA & SiB3 \\
\hline Vegetation Type & Prescribed & General Land Cover & General Land Cover \\
\hline Plant Functional Types & Prescribed & -- & Prescribed \\
\hline Fractional Carbon Cover & -- & --- & -- \\
\hline Vegetation Greenness & - & NDVI & NDVI \\
\hline Fractional PAR Absorption & -- & NDVI & NDVI \\
\hline Leaf Area Index (0-4 LAI units) & Prescribed & NDVI & NDVI \\
\hline Leaf Area Index (4-10 LAl units) & - & -- & - \\
\hline Canopy Gap Frequency and Size & -- & -- & -- \\
\hline Light-use Efficiency (leaf water, N) & -- & -- & -- \\
\hline Live vs. Senescent Biomass & -- & - & -- \\
\hline Woody vs. Leaf Biomass & Prescribed & Prescribed & Prescribed \\
\hline Canopy Allometry & Prescribed & Prescribed & Prescribed \\
\hline
\end{tabular}




\section{Albedo and Black Carbon/Dust Effects in Snow/lce}

Example: What is causing the downwasting and retreat of Himalayan glaciers?

For snow and ice in the Himalaya, increasing temperatures and increasing dust and soot combine in unknown proportions to accelerate melt through their changes in albedo. HyspIRI is the only sensor that allows us to attribute changes in albedo into effects from temperature and dust/black carbon and at a fine enough spatial resolution that heterogeneous terrain can be resolved. Multiband sensors such as NPOESS VIIRS have neither capacity.

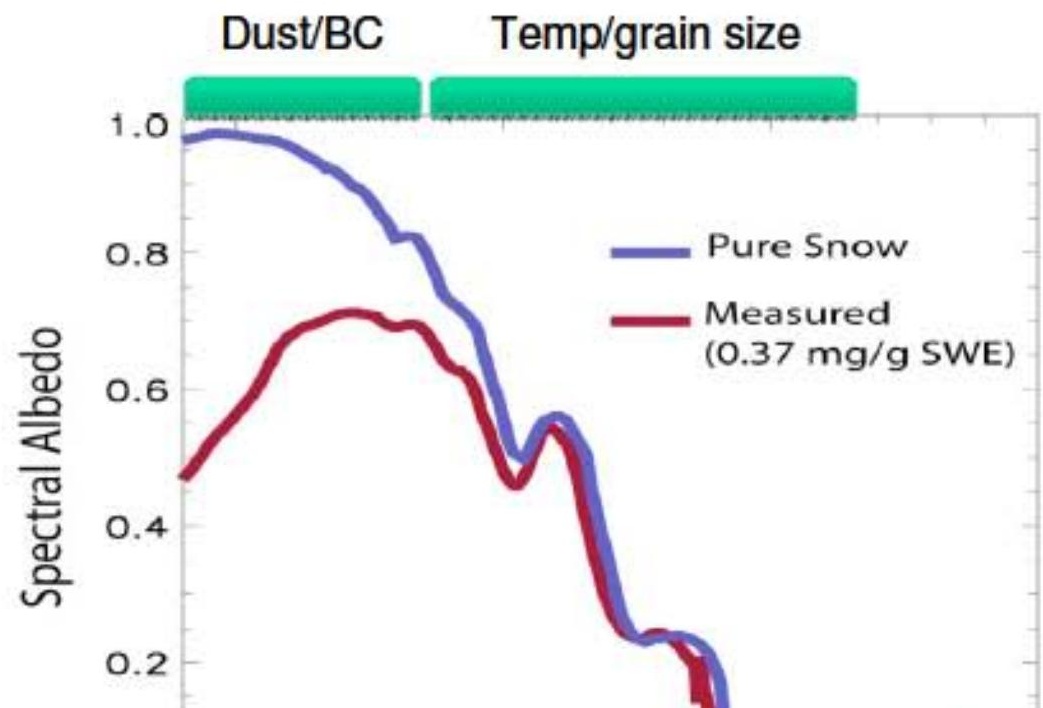

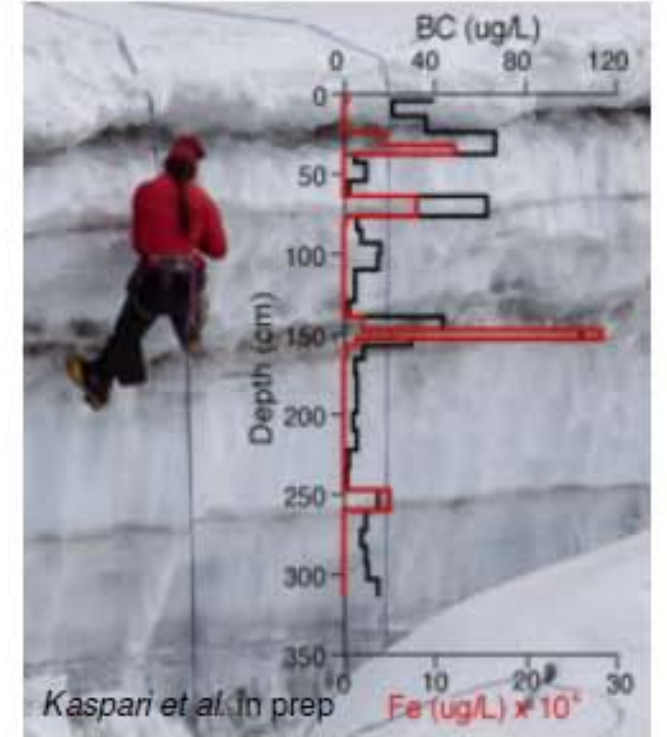
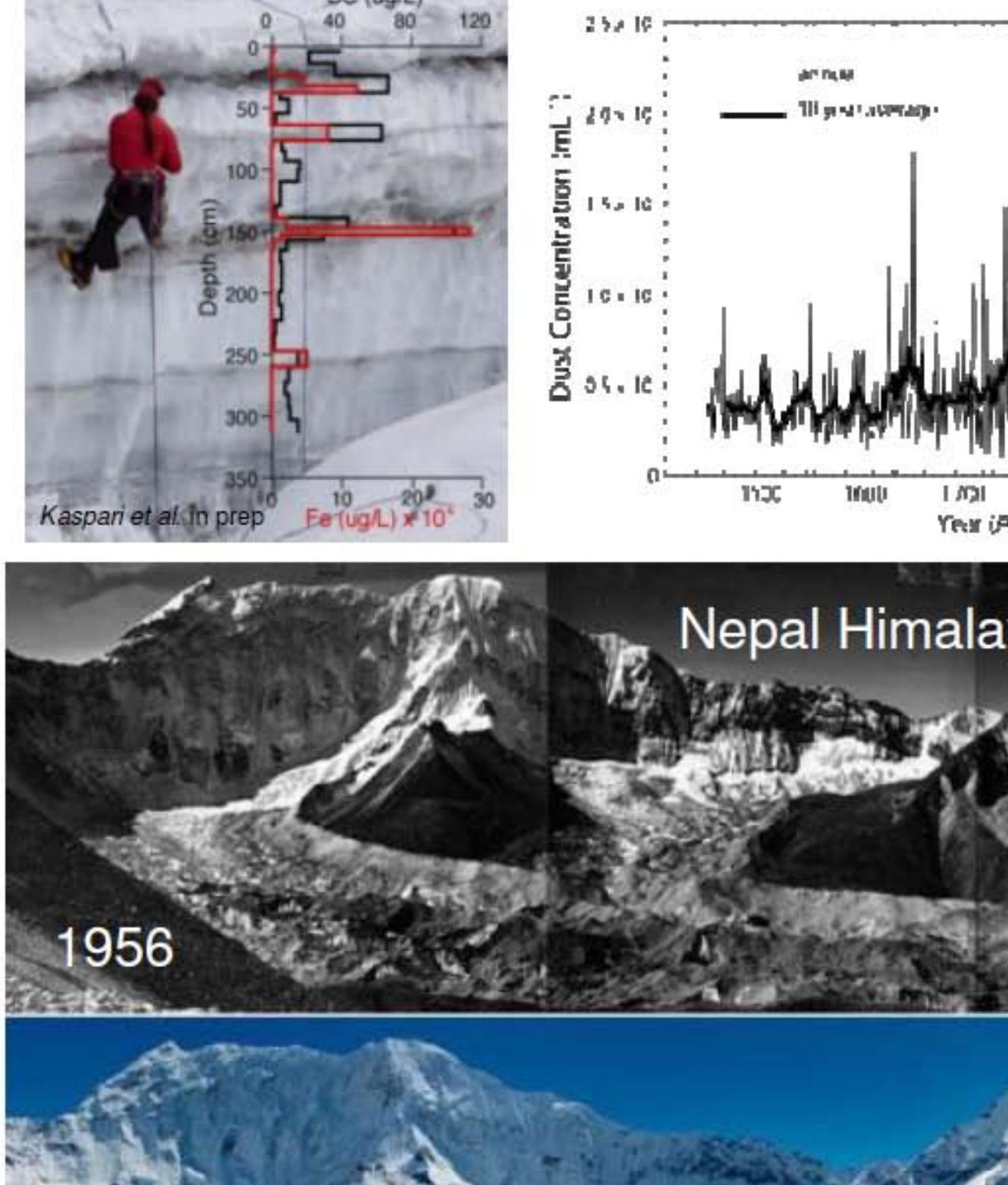


\section{High Spatial and Temporal Resolution Requ to Accurately Measure Evapo-transpiration}
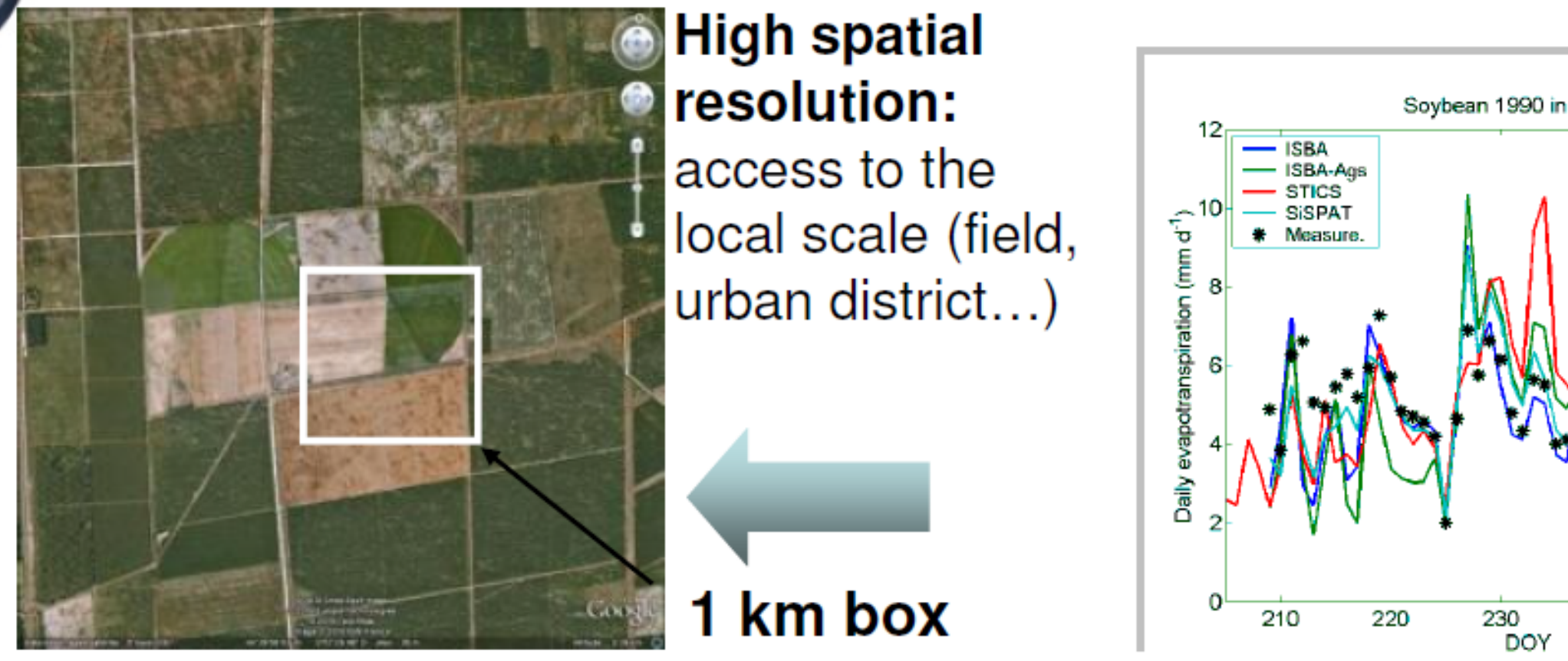

$1 \mathrm{~km}$ data does not capture field scale variation

ET is very dynamic col
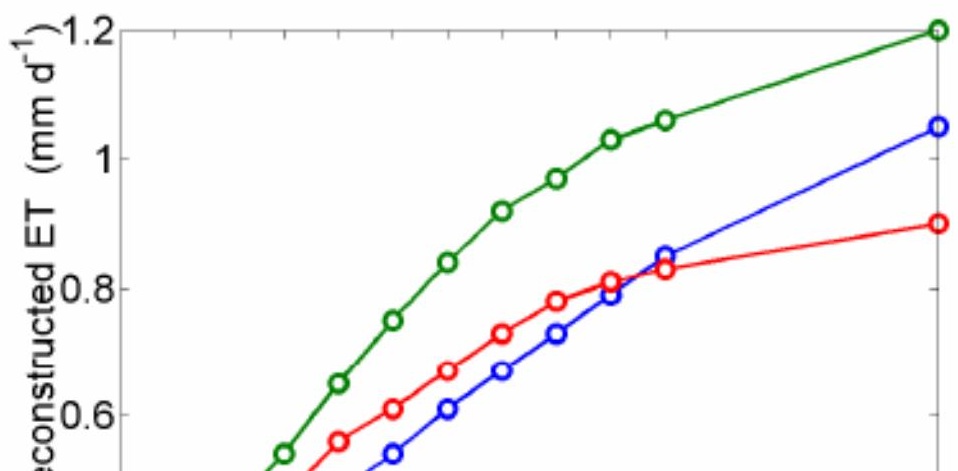

High revisit: rapid response to surface

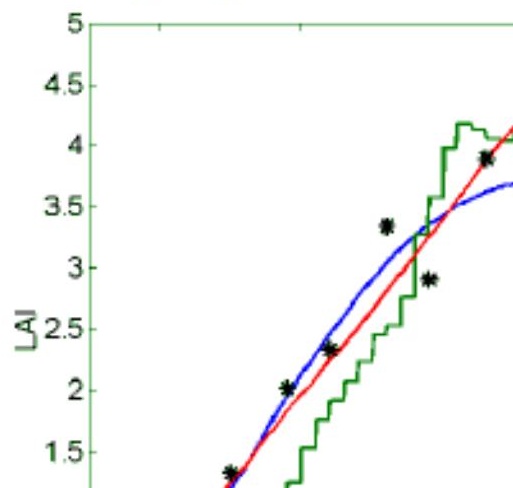




\section{Critical Volcanic Eruption Parameters}

\section{ASTER Observations of the Eyjafjallajökull Eru 19 April 2010 - 12:51 UTC}

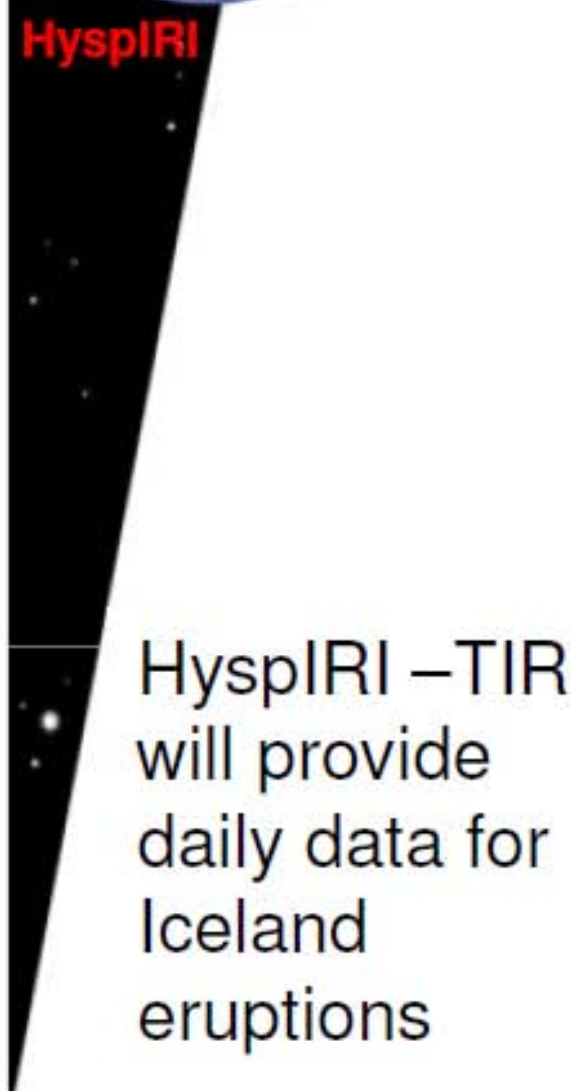

Total Views in 5-days

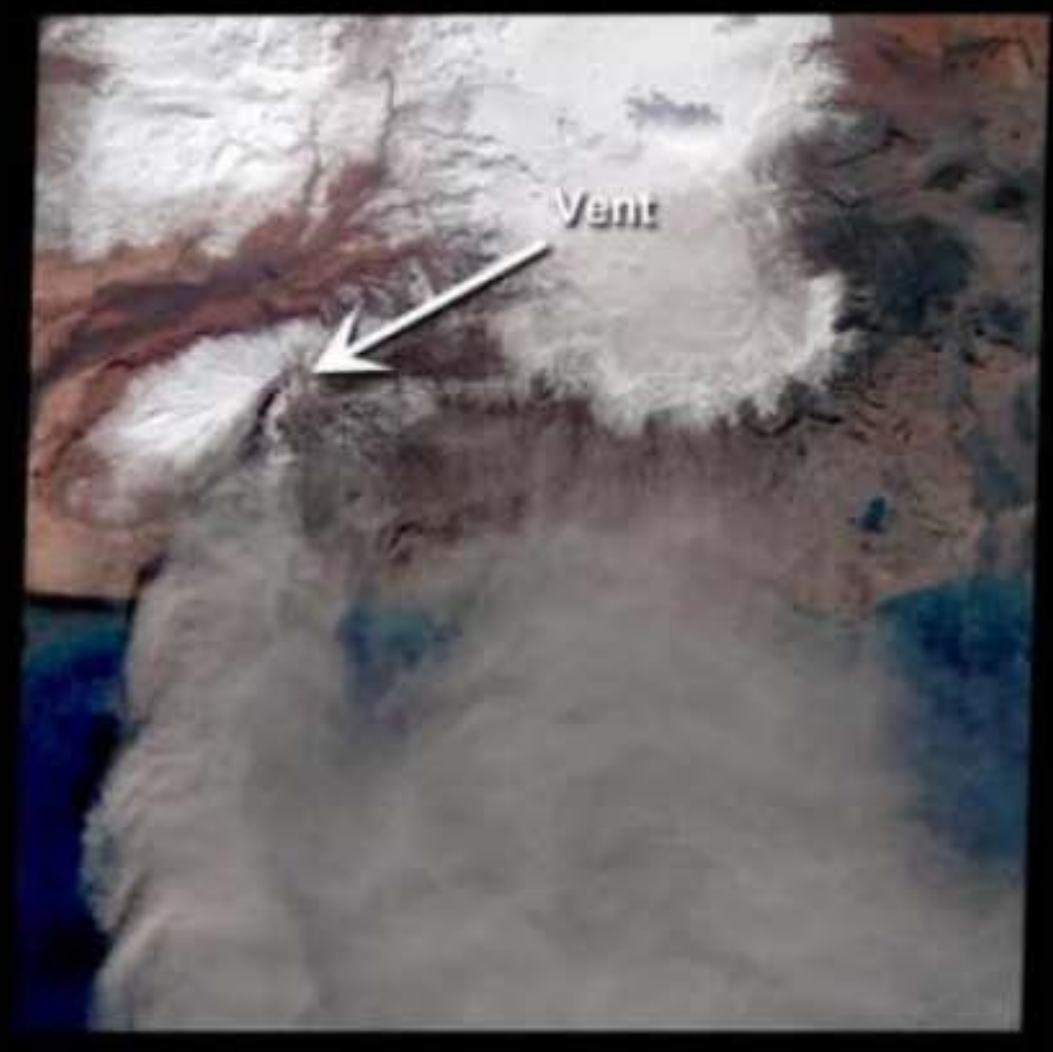

Visible - Near Infrared

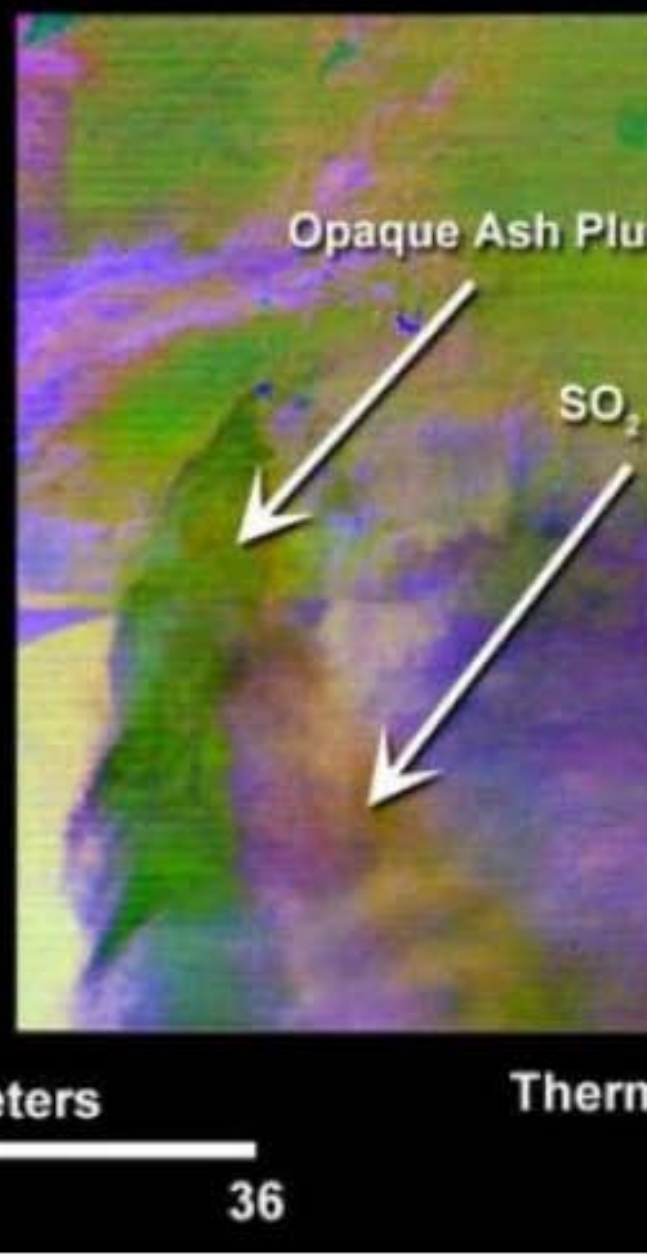

$2-3 \quad 3-4 \quad 4-5 \quad 5-6 \quad 6+$

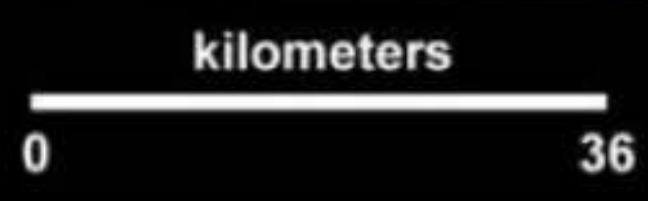




\section{Critical Volcanic Eruption Parameters}

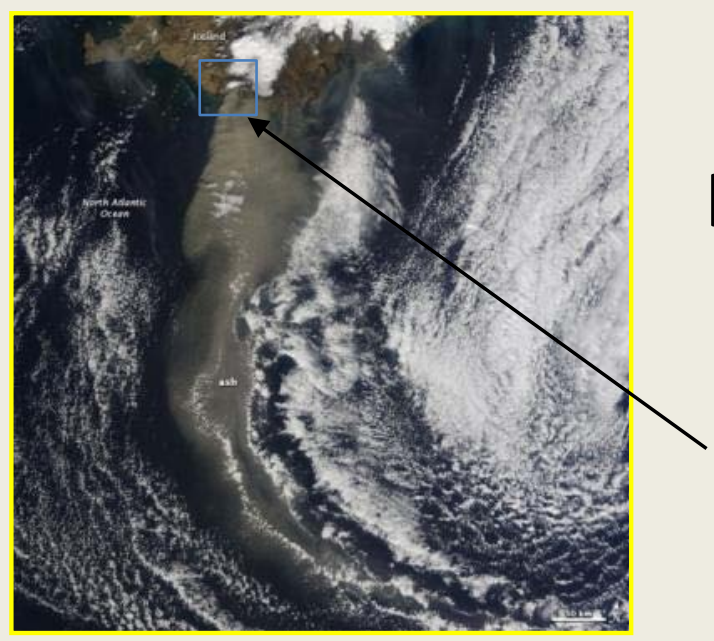

\section{Eyjafjallajökull Iceland Volcano Eruption}

April 192010

MODIS image of ash plume.

(c)

HyspIRI Response vs. $\mathrm{SO}_{2}$ Transmission

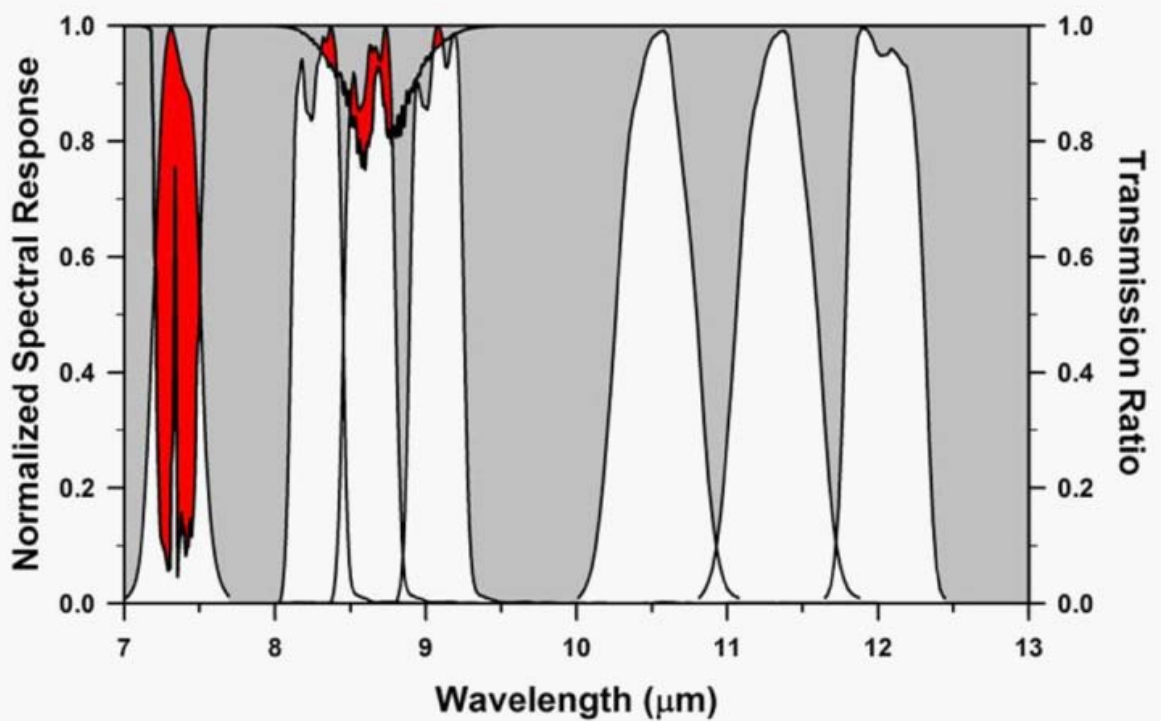

Need HyspIRI-TIR bands to separate ash from gas

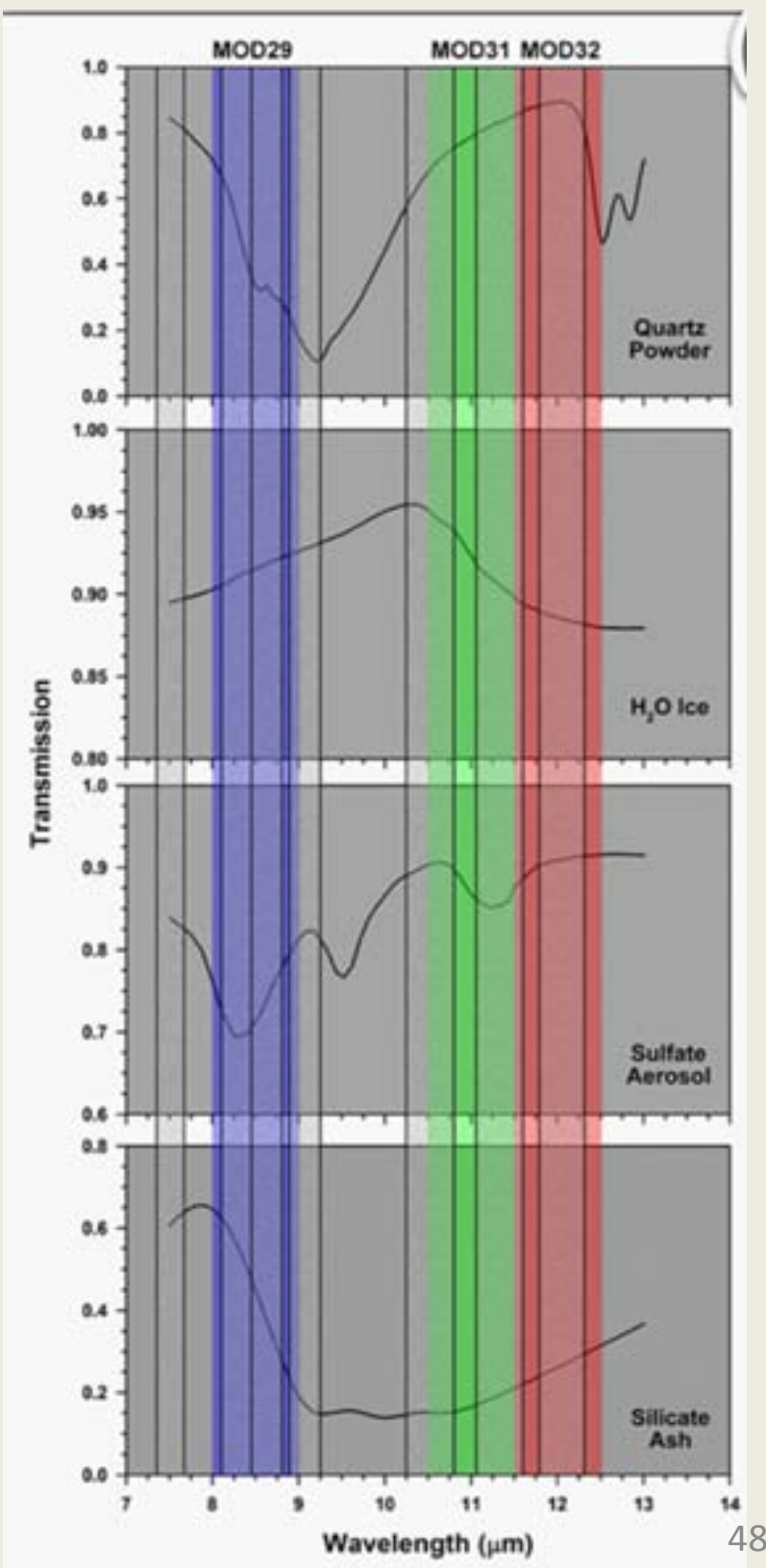




\section{Climate and Applications}

ASTER Observations of the Eyjafjallajökull Eruption 1S A;r: : $: 0$ - 12:51 UTC

HyspIRI -TIR will provide daily data for Iceland eruptions

Total Views in 5-days

$2-3 \quad 3-4 \quad 4-5 \quad 5-6 \quad 6+$

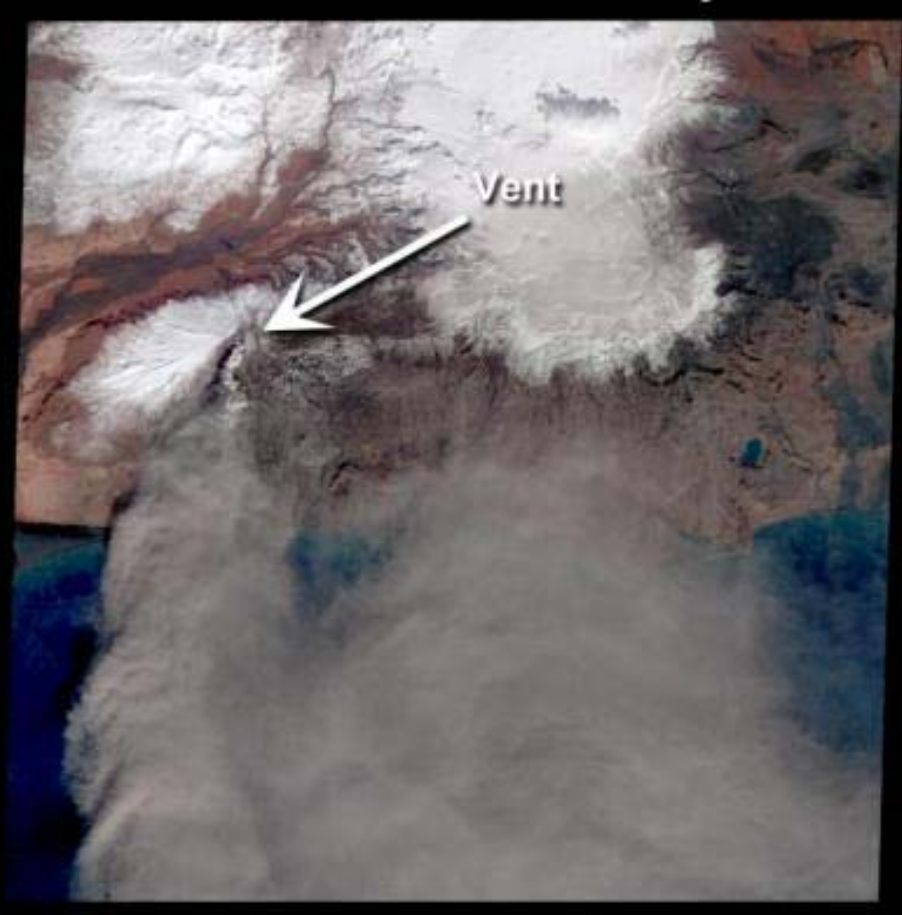

Visible - Near Infrared

\section{Opaque Ash Plume}

$\mathrm{SO}_{2}$ Plume
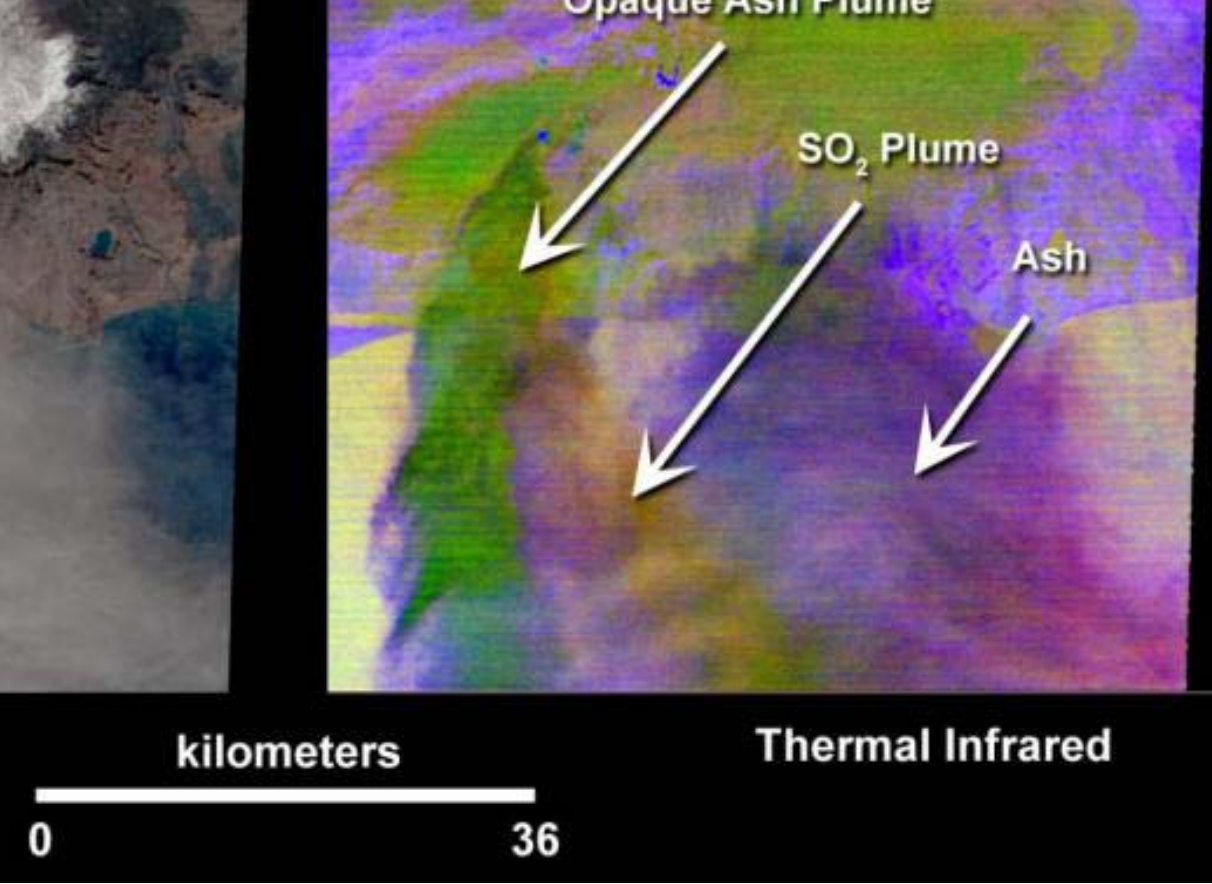


\section{HyspIRI-TIR Provides Orders of Magnitt Improvement in Detection}

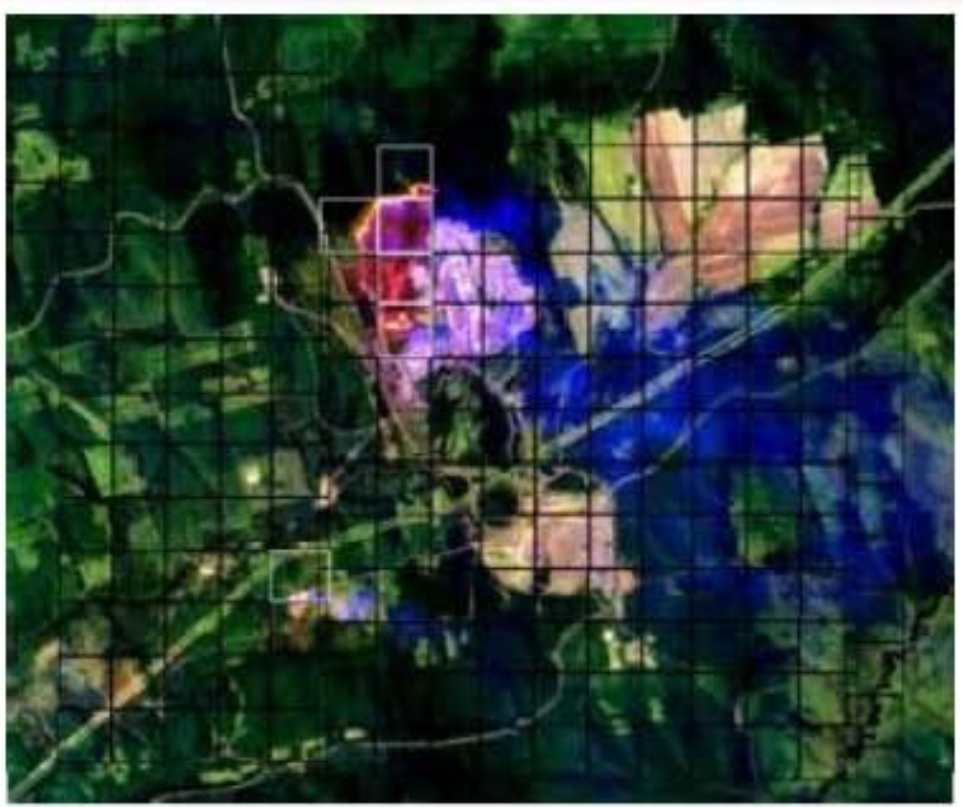

$\bullet$

HysplR

HyspIRI detects agricultural fires which are a major carbon contributor and cannot be reliably detected
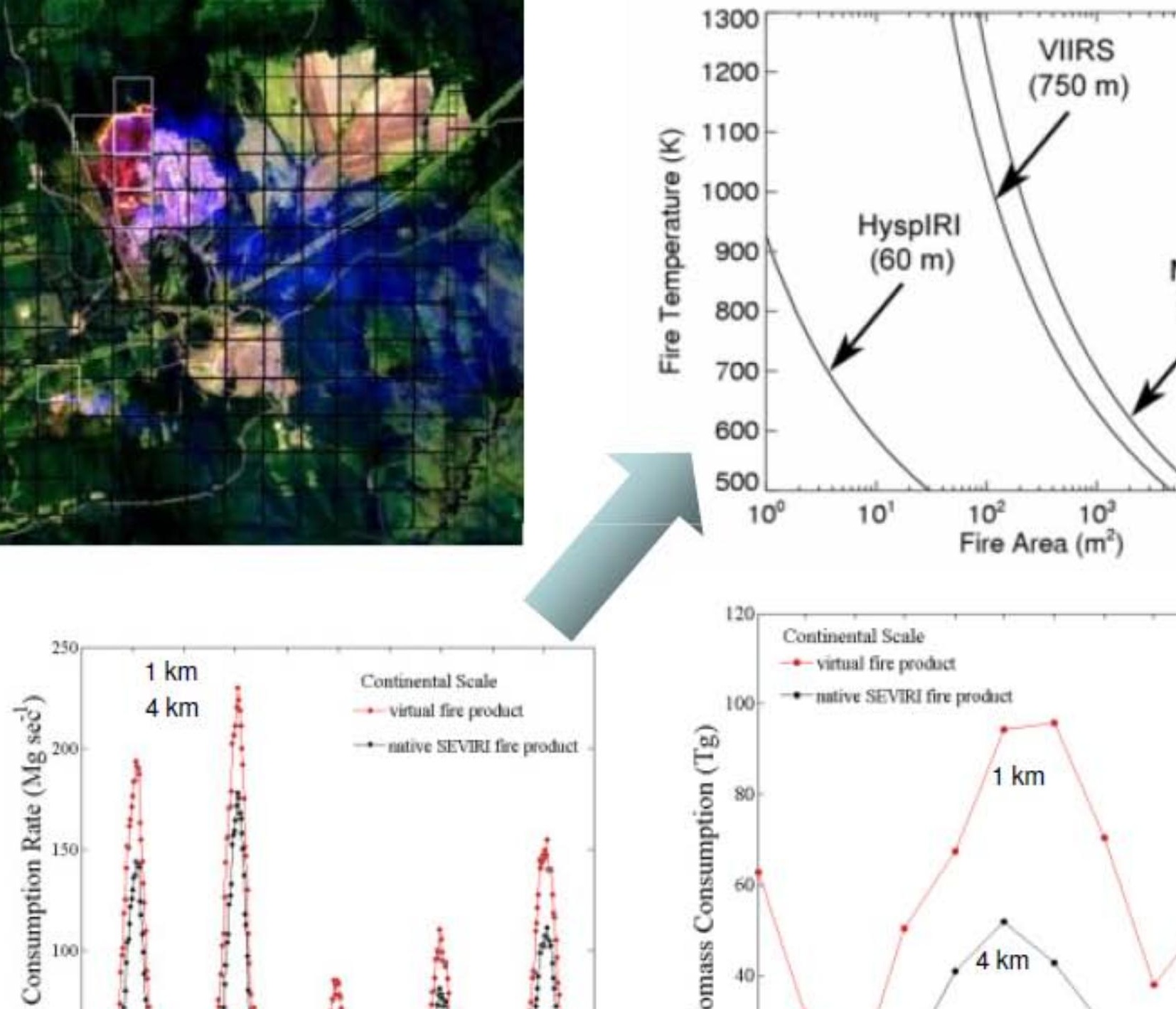


\section{Fire Radiative Energy}

FRE-based Estimated OCBC : 2003
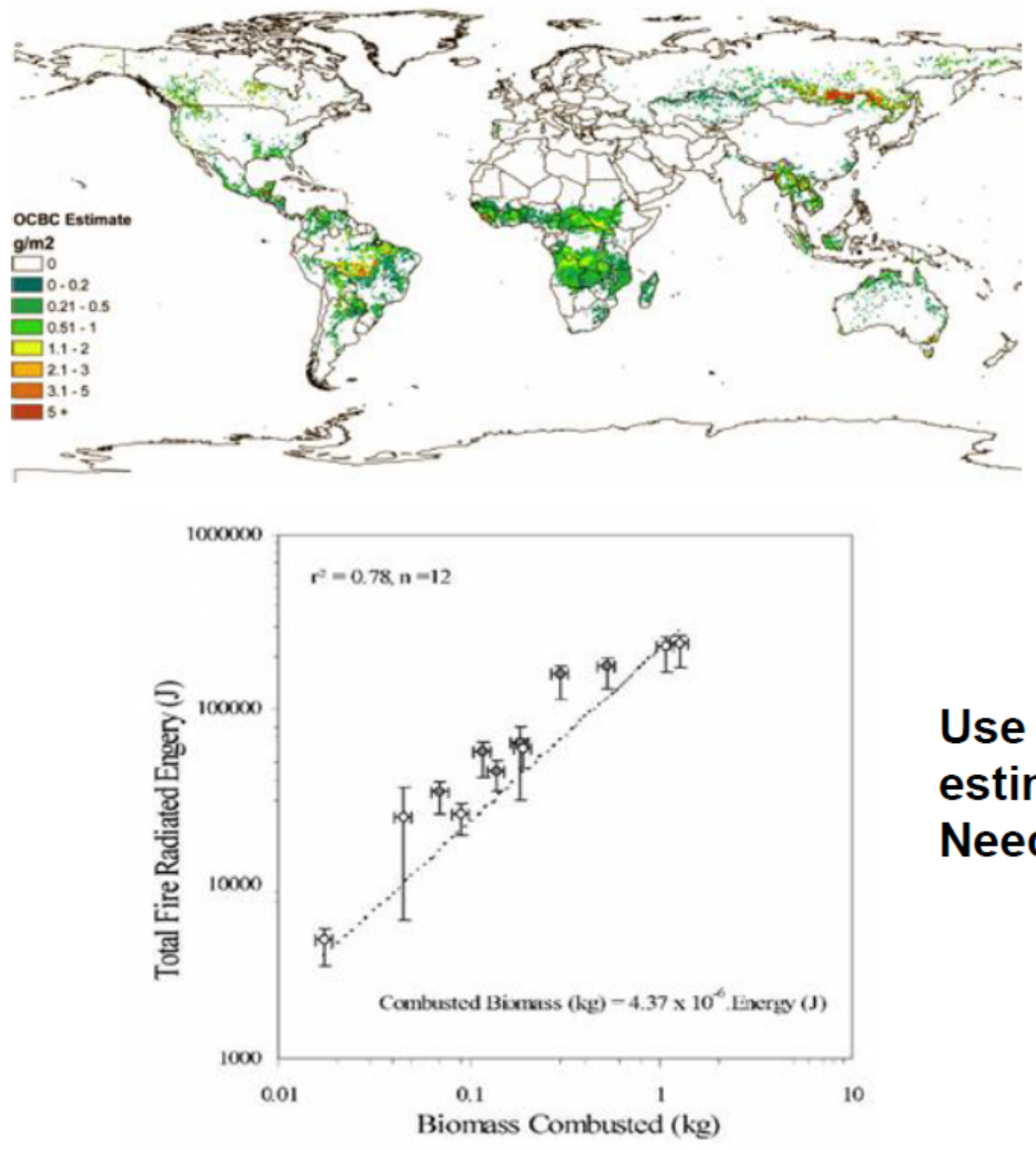

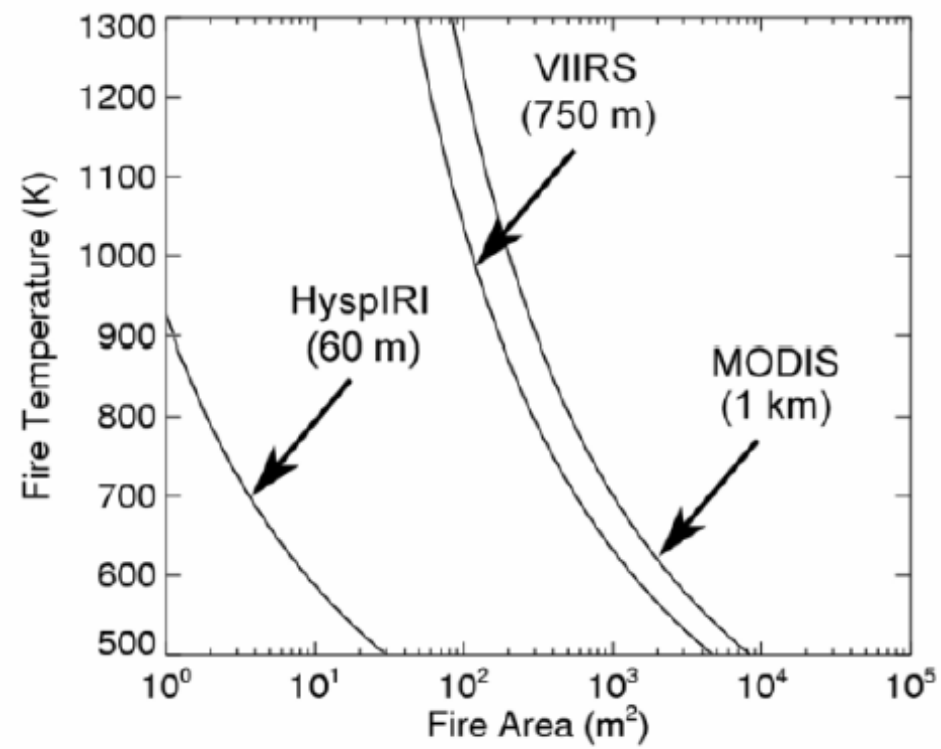

$90 \%$ probability of detection; boreal forest; nadir view

Use Fire Radiative Energy to estimate combusted biomass: Need 3-5 um data

Ellicott et al 2009

Wooster et al 2002 and 2003 


\section{Global Fire Emission Estimates}

Biomass burning and fossil fuel emissions release $\sim 10^{15} \mathrm{~g}$ of (C) to the atmosphere each year. Biomass burning constitutes 25\% of all global C emissions.

Region

Central and northern

South America

Southern South

America

Northern Africa

Southern Africa

Southeast Asia

Boreal (north of $38^{\circ} \mathrm{N}$ )

Other

Global
Fire emissions 1997-2009 average $\left(10^{15} \mathrm{~g} \mathrm{C} \mathrm{yr}^{-1}\right)$

0.04

0.27

0.48

0.27

0.04

0.18

0.73

2.01
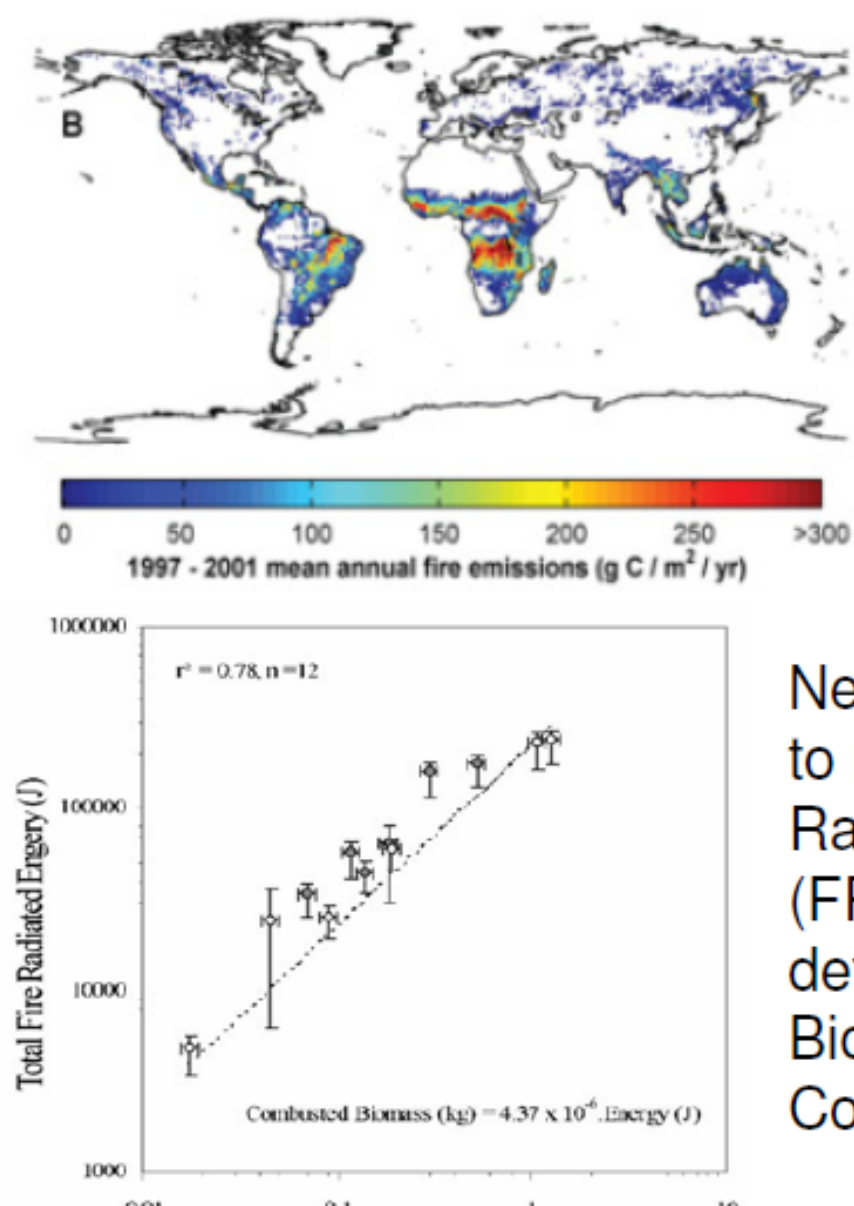

Need $4 \mathrm{u}$ to measu Radiative (FRP) to deterimin Biomass Combust 


\section{Challenges}

High Data volume

Low Latency Data

Atmospheric Correction for L2 Products

Data Processing Chain

Data archive/distribution

Calibration/Validation

Combined VSWIR and TIR

Global Collections

Regional Collections 
SensorWeb Design for User-Defined L2 Products Prototype for HyspIRI Using EO-1

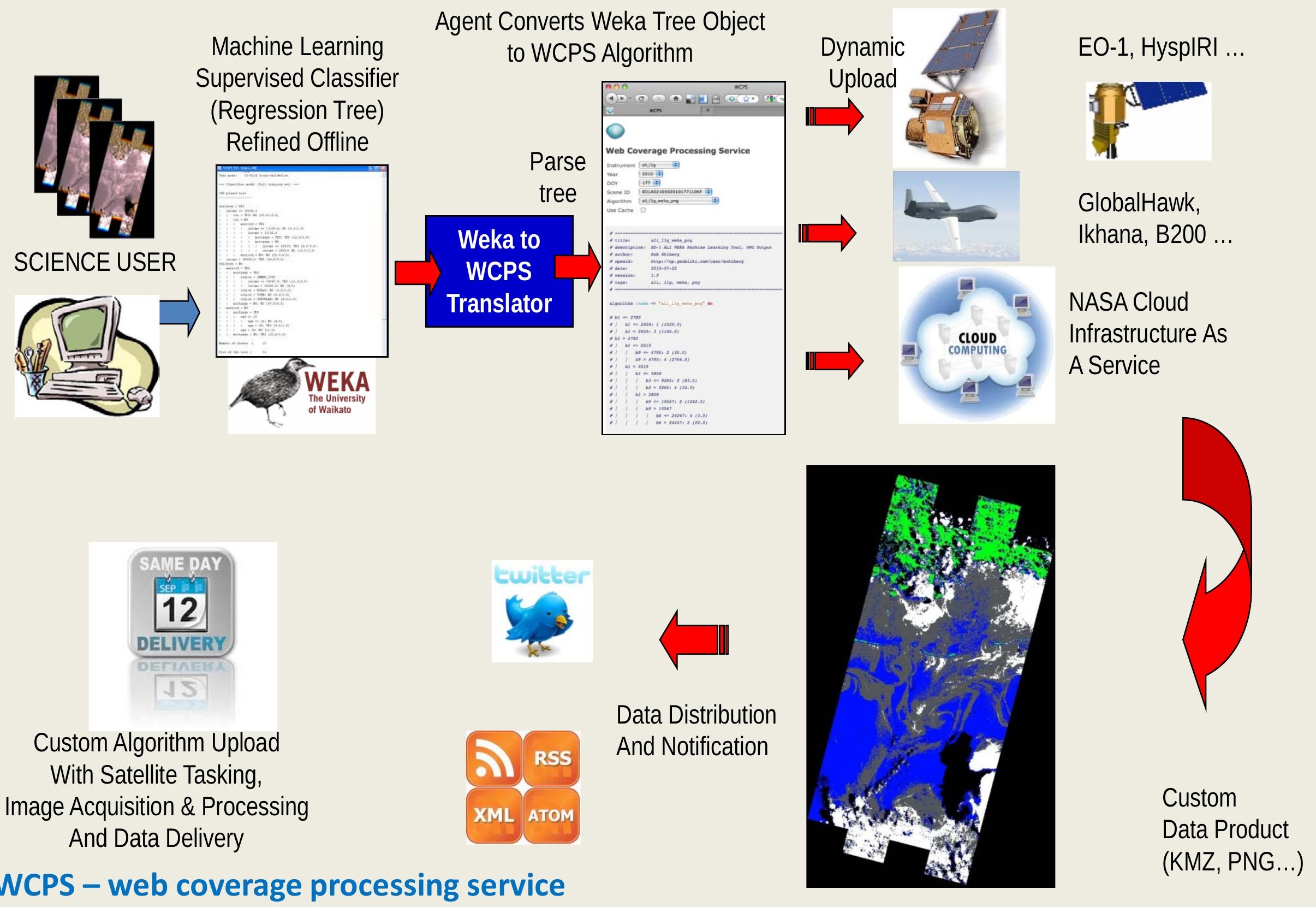




\section{Fire SensorWeb Experiments with U.S. Forest Service}

From 2003 to 2009, SensorWeb team conducted a variety of experiments to identify how best to inject SensorWeb technology into assisting Forest Service to manage large wildfires and assist decision makers. This involved interoperating satellite sensors and an Unmanned Aerial System sensors to produce useful data products to assist U.S Forest Service emergency managers.

Detect: National Fire Interagency Center (NIFC) large fire map and MODIS daily hot pixel maps acted as triggers Respond: Trigger EO-1 and Unmanned Aerial System (UAS) images automatically to take a detailed look

Product Generation: Active fire maps, burn scar maps Delivery: Experimented with various web based delivery such as mash up displays and RSS feeds

"An exciting aspect of the SensorWeb capability is the ability to automatically image, process and deliver higher resolution satellite imagery products online with little effort."

Everett Hinkley

National Remote Sensing Program Manager
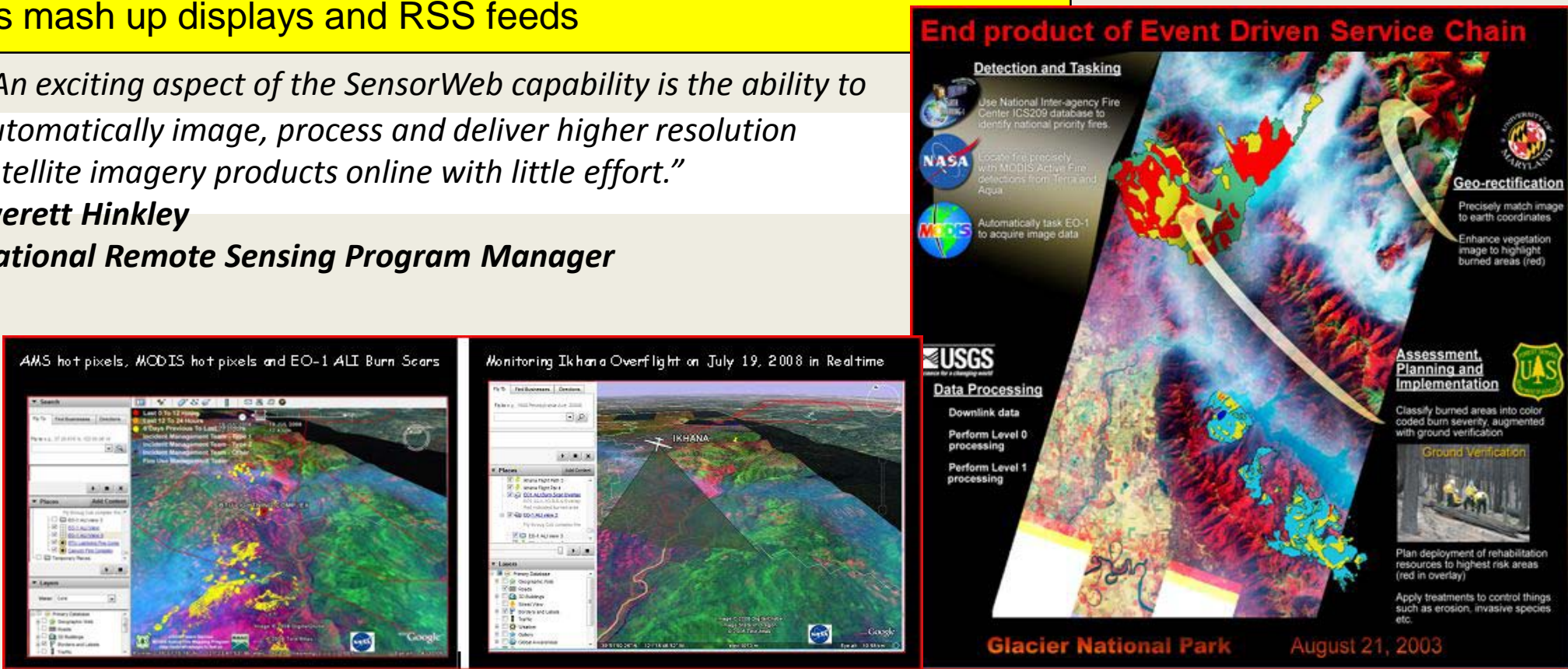

Burned Area Reflectance Classification (BARC) map -

used by Forestry Service to efficiently rehabilitate burned areas

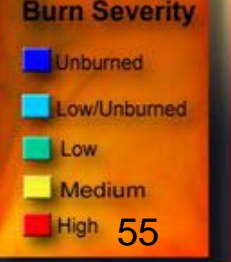




\section{Step 3 Improvement for EO-1 - Overview}

Hyperion and ALI

Level 0

Processed data from GSFC, building 3 server
External users, especially international (e.g. disaster(workers)
NASA Investigators

Technologists
Starlight 100

\section{Gigabit Ethernet}

10 Gbps

\section{Exchange}

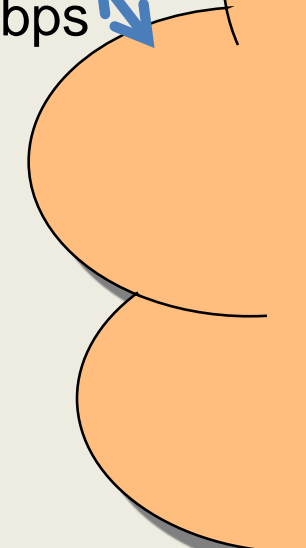

Eucalyptus-based Elastic Cloud SW $300+$ core processors

$40 \times 2$ Tbytes of storage

10 Gbps connection to GSFC

- being upgraded to 80 Gbps (Part of OCC) At Univ of Illinois at Chicago

Supplied by Open Cloud Consortium Open Science Data Cloud Virtual Machines \& htto server to VM's

\section{Atmospheric Correction for ALI \& Hyperion}

Web Coverage Processing Service (WCPS) to enable users to customize Level 2 products 


\section{Transformation to On-Demand Product Cloud Part 1 EO-1 Data Product Pipeline}

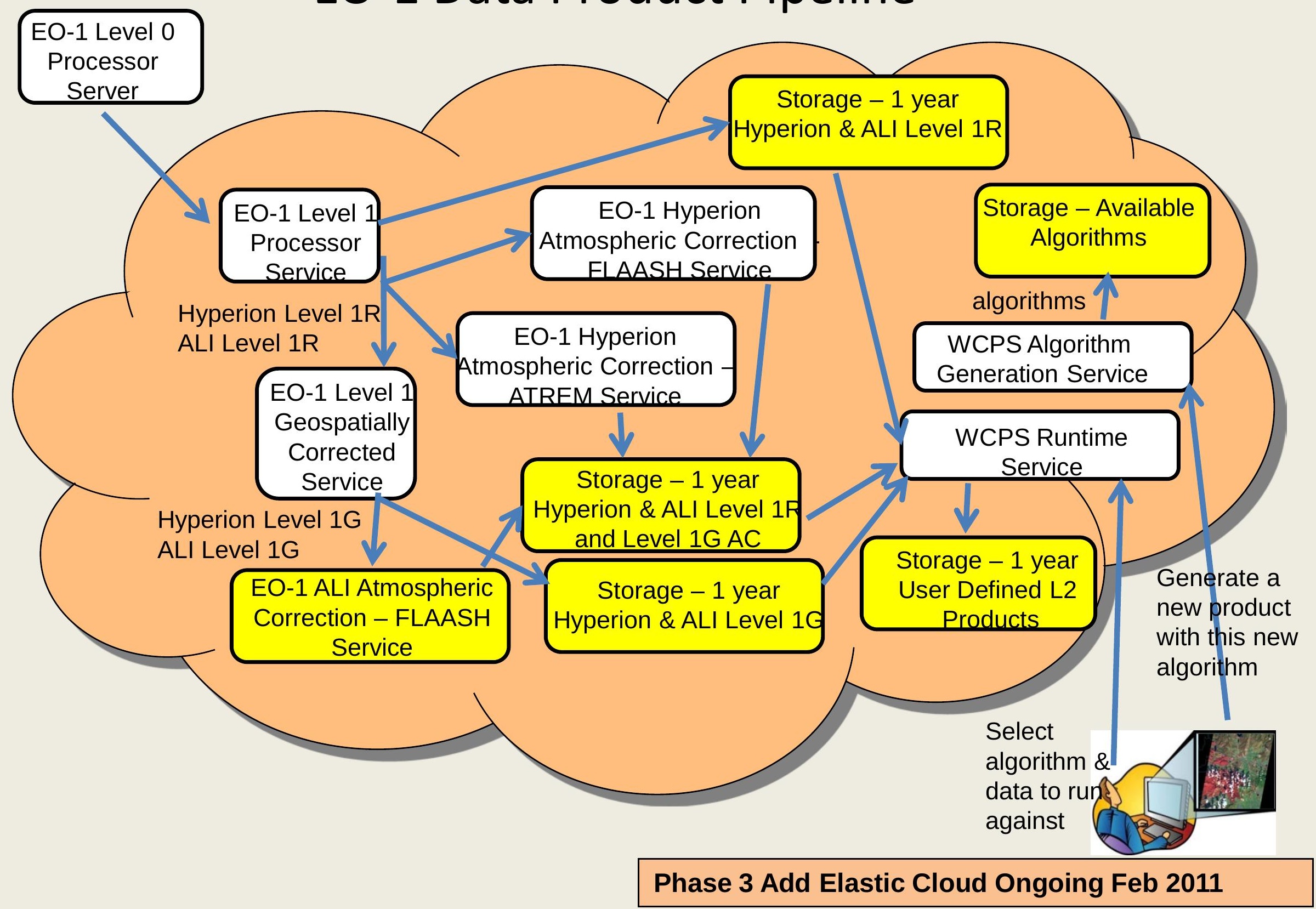




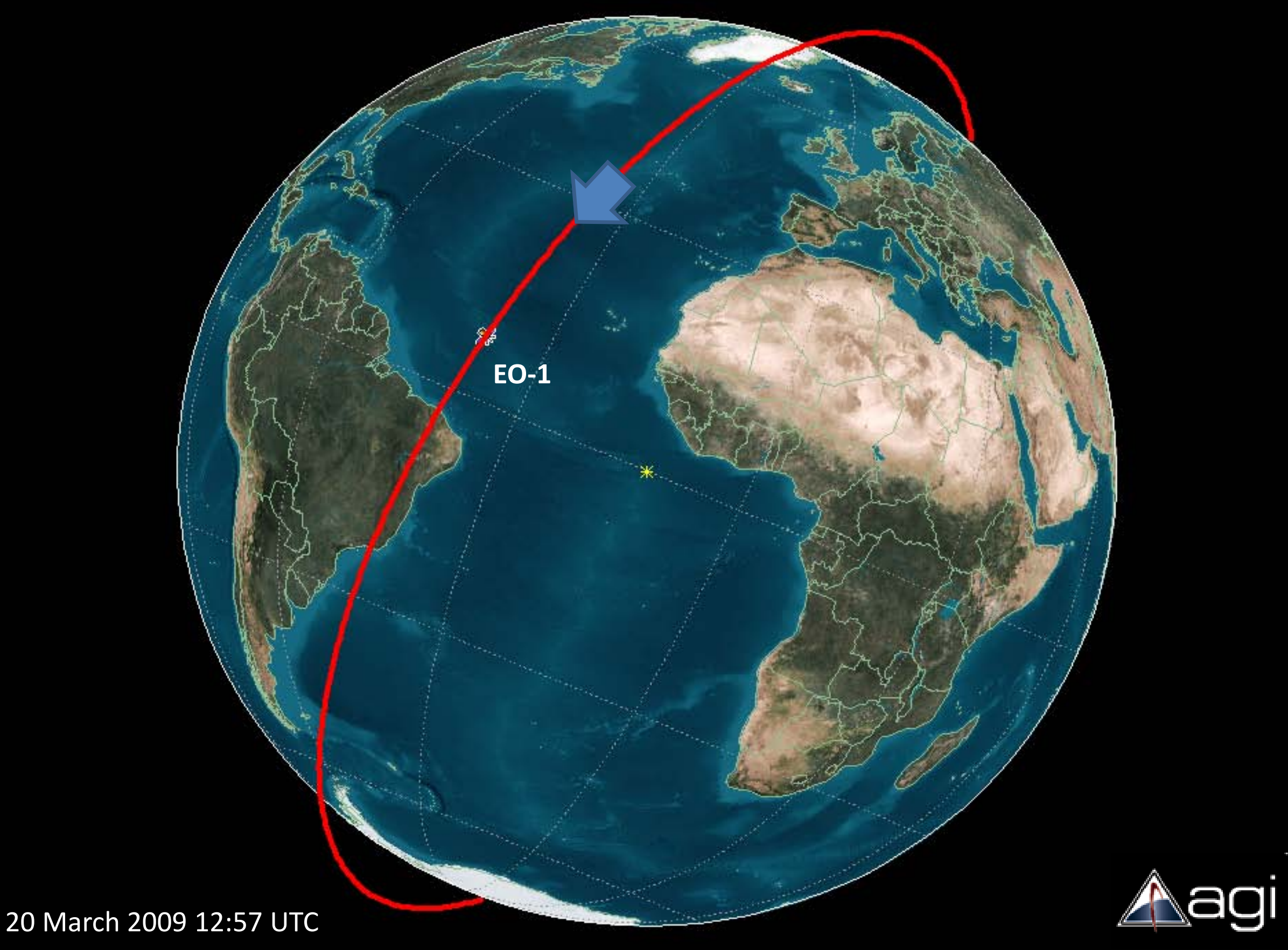

